\title{
Avaliação de métodos de desenvolvimento de aplicações web
}

Sandro Lopes Bianchini 



\title{
Avaliação de métodos de desenvolvimento de aplicações web
}

\author{
Sandro Lopes Bianchini
}

Orientador: Prof. Dr. José Carlos Maldonado

Dissertação apresentada ao Instituto de Ciências Matemáticas e de Computação - ICMC/USP, como parte dos requisitos para obtenção do título de Mestre em Ciências de Computação e Matemática Computacional.

USP - São Carlos

Fevereiro/2008 

À minha mãe, que me deu a vida, e à Marília que fez com que essa vida valesse ser vivida. 



\section{Agradecimentos}

Agradeço primeiramente a Deus pela oportunidade de viver. Aos meus avós Elvira e Ary, por todo o amor a mim dedicado, onde quer que estejam. À minha amada mãe e à Marília, minha companheira de vida.

Ao meu orientador Prof. Dr. José Carlos Maldonado, pela orientação e por um dia ter acreditado em mim. E, é claro, aos meus amigos (minha família), pessoas especiais que compartilharam comigo alegrias, tristezas e momentos que jamais esquecerei (e espero que hajam muitos outros) e me ajudaram tanto direta quanto indiretamente na condução deste trabalho: Erika (pela paciência e atenção, sempre e nessa fase final) e Bira, Van (não esperava encontrar uma irmã nessa altura do campeonato), Falcão (um tremendo de um f...), Valter, Ana e Chefe (pela parceria de sempre), Ellen (Mammy), Melzinha (só não é mais meiga do que a bondade no seu coração :) ) Marcão (sempre pronto para assassinar um cereal! E, é claro pra dar aquela força), Alê (pelas noites no labes escrevendo artigos), Chan, Gabriela e Pelúcio, Paula e Otávio, DoEndo, Aretha, Auri, Ades, Ré, Andrézitos (URMF), Mônika (minha eterna representante de classe :) ), Marcella, Camila, Rogério, Flávia, Maris, Dinho, Ivan, Gustavo, Alfraino, Tininha e Cris, Vasco, Edson Jr, Lu e Richard, Simone e Marcelão, Rocha, Ícaro, Profa. Rosely, Thaíse, Débora Maria, Andréa (Dinda), Tati, Mari (filhinha...se um dia minha filha tiver a metade do seu juízo...) e Jão, Calvo, Pedra, Gambi, Marllos, Magrelo, Resina, Cró, Vânia, Fred, Pintor, Carlão, Tiago, Viviane, Magaly e Claudião, Felipinho (menino do andré), Murilo, Percy, Camilo, Roberto, Dornelas, Seu Arly, Sandrão, Stanley, Damiance, Kicho, Tonton, Marina e Xassa, Lilica, Elisa, Menotti, Sandra, Rosana, Graça, Simone e Paulo. Antes que eu receba alguma represália, agradeço também ao meu sogro, Sr. Rodolpho, Teko, Gu e Pã.

E, também agradeço à seguintes pessoas, de quem jamais esqueço, não importa o quão distante estamos fisicamente, no momento: Diga (grande Digão), Batata (sempre mala), Zazá (Steve, Infoway, Jojo, Cramulhãozinho...), Kiô (Ironheart), Mari (prima do coração), Lu, Joãzinho e Fernando, Vanessa e Longo, Chakal, Igor (da terrinha, Guiné Bissau), Joe (velho Joe, 10 anos...), Lee, Pigu, Olívia, Melissa (Athena). Para àqueles que esqueci, peço perdão pela falha mnemônica.

A todos vocês, que com muito carinho e prazer posso chamá-los de amigos, deixo um pequeno trecho de um livro do Paulo Coelho: "Um guerreiro da luz nunca esquece a gratidão. Durante a luta, foi ajudado pelos anjos; as forças celestiais colocaram cada coisa em seu lugar, e permitiram que ele pudesse dar o melhor de si. Os companheiros comentam - Ele tem sorte! - E o guerreiro consegue muito mais do que a sua capacidade permite. Por isso, quando o sol se põe, ajoelha-se e agradece O Manto Protetor a sua 
volta. Sua gratidão não se limita ao mundo espiritual; ele jamais esquece os amigos, porque o sangue deles se misturou ao seu no campo de batalha. Um guerreiro não precisa que ninguém the recorde a ajuda dos outros; ele se lembra sozinho, e divide a recompensa com eles."

Agradeço também aos funcionários do ICMC, em especial a secretaria da pós-graduação pela atenção e apoio.

À FAPESP pelo apoio financeiro. 
Courage is not simply one of the virtues, but the form of every virtue at the testing point.

(C. S. Lewis) 


de uma abordagem sistemática e disciplinada é essencial, dado o crescente aumento do uso e da complexidade de tais aplicações. Nesse cenário, a Engenharia de Aplicações Web, ou simplesmente Engenharia Web, torna-se uma atividade mandatória. A Engenharia Web não é uma transcrição exata da Engenharia de Software, pois considera características inerentes às aplicações Web como, por exemplo, multiplicidade do perfil de usuários e uso de multimídia. A Engenharia Web é apoiada por ferramentas, técnicas e métodos. A escolha desses elementos para um domínio de aplicação pode tornar-se uma tarefa difícil para desenvolvedores e demais interessados e é fundamental para o desenvolvimento efetivo de aplicações Web. Neste trabalho, é apresentado uma proposta de avaliação de métodos de desenvolvimento de aplicações Web. Essa proposta partiu de um conjunto de métodos selecionados por meio de trabalhos comparativos anteriores disponíveis na literatura e do levantamento de suas principais características, após estudo de caso que consistiu em modelar uma mesma aplicação (um portal Web) com os diferentes métodos selecionados. A cada característica associaram-se pesos, refletindo sua relevância a domínios especifícos, e valores refletindo seu grau de apoio a um método. Como resultado, obteve-se um arcabouço - conjunto de guidelines - para avaliar e/ou especificar métodos de desenvolvimento de aplicações Web. Esse arcabouço foi aplicado ao conjunto de métodos selecionados do estudo de caso e foram obtidas evidências da efetividade do arcabouço proposto.

Palavras-chave: Engenharia Web, métodos de desenvolvimento, avaliação de métodos 


increasing use and complexity of such applications. In this scenario, the Web Applications Engineering, or simply Web Engineering, becomes a mandatory activity. The Web Engineering is not an accurate transcription of the Software Engineering. Besides incorporating its rules and lines of direction, the Web Engineering also considers inherent characteristics of Web applications such as user profiles multiplicity and multimedia resources. For the Web applications development process, the Web Engineering is supported by tools, techniques and methods. Among them, choosing appropriate elements for a given application domain may represent a challenge for interested developers. This work aims at supporting such choices through a proposal of an evaluation of current development methods for Web Applications. The proposed framework started from a set of well-known development methods found in the literature from which the main characteristics were identified by a case study consisted in modelling the same Web application by different methods. For each characteristic, weights have being associated, reflecting its relevance for specific domains, and values reflecting its degree of support to a method. As result, a framework is estabilished - set of guidelines to evaluate and/or to specify methods of development of Web applications. This framework was applied to the set of selected methods of the case study and evidences have been provided effectiveness of the proposed framework.

Keywords: Web Engineering, Development Methods, Development Methodologies 

1 Introdução 1

1.1 Contexto . . . . . . . . . . . . . . . . . . . . . . 1

1.2 Motivação e Relevância . . . . . . . . . . . . . . . . . . . . 2

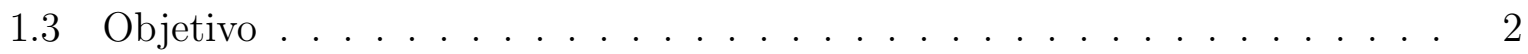

1.4 Organização do Documento . . . . . . . . . . . . . . . . 3

2 Engenharia Web 5

2.1 Considerações Iniciais . . . . . . . . . . . . . . . . . . . . . . . 5

2.2 Aplicações Web . . . . . . . . . . . . . . . . . . . 6

2.2.1 Classificação . . . . . . . . . . . . . . . . . . . 6

2.2 .2 Arquitetura . . . . . . . . . . . . . . . . . . . 8

2.2 .3 Características . . . . . . . . . . . . . . . . 9

2.3 Engenharia Web . . . . . . . . . . . . . . . . . . . 11

2.4 Processo de Desenvolvimento . . . . . . . . . . . . . . . . . . . . . . 12

2.5 Métodos de Desenvolvimento de aplicações Web . . . . . . . . . . . . 15

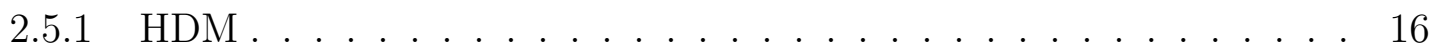

$2.5 .2 \mathrm{RMM} \ldots \ldots \ldots \ldots \ldots \ldots \ldots \ldots$

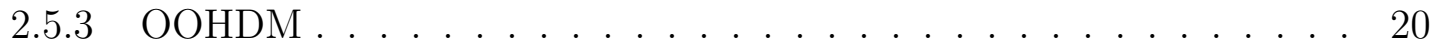

2.5 .4 UWE . . . . . . . . . . . . . . . . . . 20

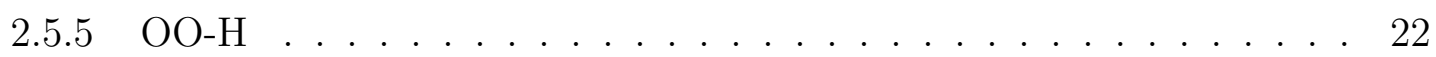

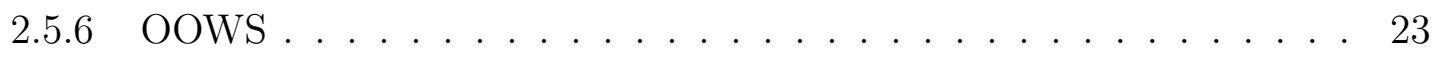

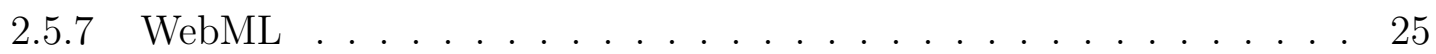

2.5 .8 HMBS/M . . . . . . . . . . . . . . . . 27

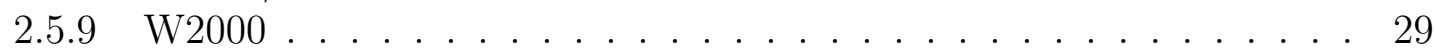

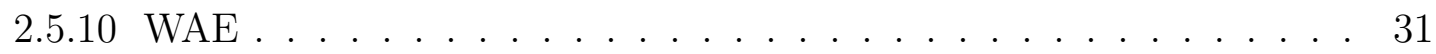

2.5 .11 SWM . . . . . . . . . . . . . . . . . 32

2.5.12 $\mathrm{ECO} \ldots \ldots \ldots \ldots \ldots \ldots$

2.6 Análise, comparação e avaliação de métodos de desenvolvimento Web com base na literatura . . . . . . . . . . . . . . . . . . . . 34 2.6.1 Comparação entre atributos gerais . . . . . . . . . . . . . 34 
2.6.2 Comparação entre etapas de desenvolvimento . . . . . . . . . . . . 35

2.6.3 Comparação entre aspectos de informação e funcional . . . . . . . . . 35

2.6.4 Avaliação de métodos para aplicações hipermídia . . . . . . . . . . . 38

2.6.5 Arcabouço para linguagens visuais de modelagem . . . . . . . . . . 39

2.7 Considerações Finais . . . . . . . . . . . . . . . . . . . . . 40

3 Arcabouço para a avaliação de métodos $\quad 43$

3.1 Considerações Iniciais . . . . . . . . . . . . . . . . . . . . . . . . . 43

3.2 Etapas de elaboração do arcabouço de avaliação . . . . . . . . . . . . . . . 44

3.2.1 Estudos comparativos . . . . . . . . . . . . . . . . . 44

3.2.1.1 Comparação entre atributos gerais . . . . . . . . . . . 44

3.2.1.2 Comparação entre etapas de desenvolvimento . . . . . . . 48

3.2.1.3 Comparação entre entre aspectos de informação e funcionais 48

3.2 .2 Estudo prático . . . . . . . . . . . . . . . . . 50

3.2 .2 WAE . . . . . . . . . . . . . . . 52

3.2.2.2 WebML . . . . . . . . . . . . . . . 52

$3.2 .2 .3 \mathrm{~W} 2000 \ldots \ldots \ldots \ldots \ldots \ldots$

$3.2 .2 .4 \quad \mathrm{OO}-\mathrm{H} \ldots \ldots \ldots \ldots \ldots$

3.2.3 Arcabouço de avaliação: Características e sistema de pesos e valores 54

3.3 Exemplo de uso do arcabouço . . . . . . . . . . . . . . . . . . . 58

3.3 .1 Comparação de valores . . . . . . . . . . . . . . . . 64

3.4 Considerações Finais . . . . . . . . . . . . . . . . . . 65

$\begin{array}{lll}4 \text { Conclusão } & 67\end{array}$

$\begin{array}{ll}\text { Referências } & 69\end{array}$

$\begin{array}{ll}\text { A Requisitos do Portal } & 77\end{array}$

A.1 Requisitos funcionais . . . . . . . . . . . . . . . . . . 77

A.2 Análise de requisitos . . . . . . . . . . . . . . . . . . . . . . 81

$\begin{array}{ll}\text { B Modelos de navegação } & 91\end{array}$ 
2.1 Tecnologias para o desenvolvimento de aplicações Web

2.2 Modelo de processo de desenvolvimento de aplicações Web proposto por Pressman (2005) . . . . . . . . . . . . . . . . . . . 13

2.3 Modelo de desenvolvimento de aplicações Web proposto por Murugesan e Ginige (2005) . . . . . . . . . . . . . . . . . . . 14

2.4 Etapas do Método RMM . . . . . . . . . . . . . . . . . . . . . 18

2.5 Processo do método UWE . . . . . . . . . . . . . . . . . . . . 22

2.6 Uma visão geral do método OO-H . . . . . . . . . . . . . . . . . . . 24

2.7 Abordagem do método OOWS . . . . . . . . . . . . . . . . . . . . 24

2.8 Fases do Método HMBS/M . . . . . . . . . . . . . . . . . . . . . 28

2.9 Estrutura do método W2000 . . . . . . . . . . . . . . . . . 30

2.10 Representação em ícone de estereótipo criado no método WAE. . . . . . . 32

2.11 Atividades do método ECO . . . . . . . . . . . . . . . . . . . 34

2.12 Estrutura do arcabouço para avaliação de linguagens de modelagem visuais com as oito áreas que o compõem. . . . . . . . . . . . . . . . . . 39

3.1 Comparação entre Métodos de Desenvolvimento: Aspectos de Informação e Funcional . . . . . . . . . . . . . . . . . . . . . . . . 49

3.2 Fragmento do modelo de navegação da WebML. . . . . . . . . . . . . . . . 53

3.3 Exemplo de gráfico para visualização dos valores atribuídos para as caraterísticas de um método, com suas marcas destacadas e indicadas. . . . . . 56

3.4 Gráfico de valores para o método WAE. . . . . . . . . . . . . . . . . 62

3.5 Gráfico de valores para o método WebML. . . . . . . . . . . . . . . . 62

3.6 Gráfico de valores para o método W2000 . . . . . . . . . . . . . 63

3.7 Gráfico de valores para o método OO-H . . . . . . . . . . . . . 64

3.8 Comparação entre os valores atribuídos para as características. . . . . . . . 65

A.1 Caso de uso funcional - Administrador e visitante . . . . . . . . . . . . . 81

A.2 Caso de uso funcional - Especialista e usuário cadastrado . . . . . . . . . . 82

A.3 Diagrama de atividades do administrador do Portal . . . . . . . . . . . . . 83

A.4 Diagrama de atividades do especialista I. . . . . . . . . . . . . . . . 84

A.5 Diagrama de atividade do especialista II. . . . . . . . . . . . . . . . 85

A.6 Diagrama de atividade do especialista III. . . . . . . . . . . . . . . . . . 86

A.7 Diagrama de atividade do especialista IV . . . . . . . . . . . . . . . . 87 
A.8 Diagrama de evolução de estados para requisição de cadastro. . . . . . . . 88

A.9 Diagrama de evolução de estados para submissão de conteúdo. . . . . . . . 89

A.10 Diagrama de classes do Portal de Conhecimento. . . . . . . . . . . . . . 90

B.1 Diagrama do modelo UX, do método WAE. . . . . . . . . . . . . . . . . 91

B.2 Diagrama do modelo navegacional do método WebML. . . . . . . . . . . . 92

B.3 Diagrama do modelo navegacional do método OO-H, um NAD (Navigational Access Diagram). . . . . . . . . . . . . . . . . . . . . . . . . . 93

B.4 Diagrama de informação da hyperbase, do W2000 . . . . . . . . . . . . . 93 


\section{Lista de Tabelas}

2.1 Relação de Inclusão Entre Classificações de Aplicações Baseadas na Web 7

2.2 Sumário das Fases do Método OOHDM . . . . . . . . . . . . . . . . . . . 21

3.1 Comparação entre Métodos de Desenvolvimento: Atributos Gerais . . . . . 44

3.2 Comparação entre Métodos de Desenvolvimento: Etapas de Processo . . . 48

3.3 Valores das característica de notação para o método WAE. . . . . . . . . . 61

3.4 Valores da características de engenharia para o método WAE . . . . . . . . 61

3.5 Valores das característica de notação para o método WebML. . . . . . . . . 61

3.6 Valores da características de engenharia para o método WebML . . . . . . 62

3.7 Valores das característica de notação para o método W2000. . . . . . . . . 63

3.8 Valores da características de engenharia para o método W2000 . . . . . . . 63

3.9 Valores das característica de notação para o método OO-H. . . . . . . . . . 63

3.10 Valores da características de engenharia para o método $\mathrm{OO}-\mathrm{H} \quad \ldots . . .63$ 



\subsection{Contexto}

O crescimento da Internet causou um impacto significante nos negócios, comércio, indústria, bancos, finanças, educação e setores de entretenimento e na vida particular das pessoas (Murugesan et al., 1999). Um fato que ilustra esse impacto é o tempo de apenas quatro anos que levou para atingir 50 milhões de pessoas, sendo que o telefone, o rádio e televisão levaram 75, 35 e 15 anos, respectivamente, para atingir o mesmo número de pessoas (Ginige, 2000). A conseqüência desse impacto é a criação de um novo mundo, um mundo virtual, onde é possível realizar tarefas desde compras de ações até reservas de vôos, entre outras atividades. Entre os serviços disponíveis na Internet, o serviço conhecido por World Wide Web, ou apenas Web, facilitou a criação dessas atividades nesse mundo virtual.

Originalmente, a Web foi criada por Tim Berners-Lee como um projeto para o $\mathrm{CERN}^{1}$, para compartilhar informações em grupos de pesquisa (W3C, 2005). Seu crescente uso fez surgir uma nova geração de sistemas de informação, que combinam navegação por meio de um espaço heterogêneo utilizando operações de consulta que incidem diretamente na informação apresentada. Do ponto de vista do projeto de aplicações Web, introduziu-se a hipermídia aos sistemas de informação (Schwabe e Rossi, 1998).

A história do desenvolvimento de aplicações na Web é relativamente curta. No princípio, havia apenas sistemas hipermídia (sistemas compostos por documentos conectados

\footnotetext{
${ }^{1}$ Organização Européia para Investigação Nuclear.
} 
entre si por elos pré-definidos) com pouca ênfase no planejamento ou projeto e poucos foram propriamente testados. Atualmente, existem sistemas na Web que são aplicações de grande porte, que envolvem interação sofisticada de usuários a bases de dados e, ainda, algumas dessas aplicações podem ser consideradas de missão crítica (Griffiths et al., 2002).

Diante dessas novas aplicações encontradas na Web, a utilização de uma abordagem sistemática e disciplinada, ou seja, a utilização de Engenharia de Software, no desenvolvimento dessas aplicações tornou-se necessária. Atividades e esforços nessa direção agregaram-se sob o termo Engenharia de Aplicações Web ou simplesmente Engenharia Web.

\subsection{Motivação e Relevância}

À medida que a dependência no uso das aplicações Web cresceu, o desempenho, confiabilidade e qualidade exigidas para essas aplicações também cresceu. Com isso, a expectativa e demanda depositadas em tais aplicações aumentaram de modo significante, resultando em um número maior de projetos envolvendo-as.

O conhecimento envolvido sobre como desenvolver aplicações Web intensificou-se nos últimos anos por meio da utilização de Engenharia de Software para a construção dessas aplicações (Ginige, 2002). Surgiram diferentes notações, métodos e ferramentas que oferecem diferentes visões para o processo de desenvolvimento de aplicações Web, tais como, a WebML (Ceri et al., 2000a), o OOHDM (Schwabe et al., 1996), as extensões para a linguagem UML (Conallen, 2002), OOWS (Fons et al., 2003), entre outras. Com diferentes métodos e técnicas para o desenvolvimento de aplicações Web, a escolha de um método pode tornar-se uma tarefa difícil, levando-se em consideração propósitos comerciais, educacionais ou informativos.

\subsection{Objetivo}

Diante do cenário apresentado nas seções anteriores, este trabalho tem como objetivo propor um arcabouço para a avaliação de métodos de desenvolvimento de aplicações Web, ou apenas "arcabouço de avaliação". Por meio desse arcabouço de avaliação, desenvolvedores e demais interessados poderão escolher métodos que melhor atendam os requisitos de modelagem e projeto de suas aplicações Web.

Para atingir esse objetivo, foram estudados métodos de desenvolvimento encontrados na literatura (HDM (Garzotto et al., 1993), RMM (Isakowitz et al., 1995), OODHM (Rossi, 1996), UWE (Koch, 2000), OO-H (Gómez et al., 2001), WebML(Ceri et al., 2000b), HMBS/M (Carvalho, 1998; Carvalho et al., 1999), W2000 (Baresi et al., 2001a), WAE (Conallen, 2002), SWM (Griffiths et al., 2002), ECO (Figueiredo, 2005), OOWS (Fons 
et al., 2003)), e deles foram selecionadas as principais características existentes em cada. Além do estudo dos métodos, foram estudadas análises comparativas entre eles (Domingues, 2005; Gu et al., 2002; Koch, 2000; Lee et al., 1998) e propostas de avaliação de linguagens visuais de modelagem (Bobkowska, 2005) e de avaliação de métodos de desenvolvimento de aplicações hipermídia (Christodoulou et al., 1998). Após o levantamento das características e estudo das análises comparativas e avaliações mencionadas, para definir o arcabouço de avaliação proposto, foi realizado um estudo de caso, que consistiu na modelagem de uma mesma aplicação, utilizando-se diferentes métodos. Com esse estudo, foi possível conhecer as características de cada método e adquirir conhecimento para organizá-las. Cada característica relacionada foi então dividida em característica de notação ou característica de modelos de engenharia. A aplicação utilizada para a modelagem foi um portal Web, aplicação desenvolvida no escopo do trabalho de Costa (2005), denominada Portal de Conhecimento de Ferramentas, Estratégias, Técnicas e Critérios de Teste de Aplicações Web. Essa aplicação foi selecionada por reunir traços de aplicações hipermídia e lógica similar a aplicações convencionais, como, por exemplo, acesso a banco de dados.

Além da classificação supracitada, para a construção do arcabouço de avaliação, pesos foram atribuídos a cada característica, refletindo a relevância de cada uma dentro de um domínio de aplicação Web. No caso deste trabalho, os pesos foram atribuídos dentro do domínio de portais Web. E, além dos pesos, valores são dados a cada característica, refletindo seu grau de apoio a um método. Com os pesos e valores devidamente computados, um valor total é obtido para cada método. Quanto maior esse valor, melhor é o método para o desenvolvimento de aplicações no domínio escolhido.

\subsection{Organização do Documento}

Neste capítulo foram apresentados o contexto no qual este trabalho se insere, a motivação e a metodologia utilizada para realizá-lo. O restante deste documento está assim organizado: no Capítulo 2 são apresentadas a definição, as características e a classificação das aplicações Web e também apresentada uma visão da Engenharia Web, seus conceitos, definições e processos, além de apresentar métodos de desenvolvimento de aplicações para Web, objeto de estudo deste trabalho, e trabalhos relacionados; no Capítulo 3 é apresentado o arcabouço de avaliação baseado na observação de características de métodos encontrados na literatura e um exemplo da utilização do arcabouço de avaliação para um domínio específico de aplicação Web. No Capítulo 4 são apresentadas a conclusão deste trabalho e as perspectivas de trabalhos futuros. E, por fim, nos Apêndices A e B são apresentados a análise de requisitos e os modelos elaborados para cada método, respectivamente. 



\section{Engenharia Web}

\subsection{Considerações Iniciais}

A Web integrou-se à nossa vida e trabalho em poucos anos. Partindo de seu objetivo inicial, de facilitar a criação e o compartilhamento de informação entre poucos cientistas, usando simples sites Web estáticos que consistiam em textos interligados por elos (hyperlinks), a Web teve seu escopo ampliado e novas propostas de uso surgiram. Empreendimentos, turismo, bancos, instituições educacionais e até governos usam aplicações baseadas na Web para aprimorar ou estender suas operações. Muito sistemas de informação legados têm sido progressivamente migrados para a Web (Murugesan e Ginige, 2005).

Com o passar dos anos, as aplicações Web evoluíram e trouxeram consigo diferentes disciplinas como multimídia, ciência da informação e tecnologia de informação e comunicação. Além disso, o aumento do uso dessas aplicações fez com que fossem desenvolvidas de maneira ad-hoc em sua maioria, sem um mínimo rigor, abordagem sistemática ou controle e garantia de qualidade (Ginige, 2002; Murugesan e Deshpande, 2000; Pressman, 2005). O aumento da complexidade e sofisticação das aplicações Web, bem como suas características e particularidades, trouxeram a necessidade de uma nova abordagem para seu desenvolvimento, a Engenharia de aplicações Web ou apenas Engenharia Web.

Na Seção 2.2.1 são apresentadas as possíveis classificações de aplicações Web encontradas na literatura. Na Seção 2.2.2 são apresentadas arquiteturas utilizadas para essas aplicações, e na Seção 2.2.3 são relacionadas características intrínsecas às aplicações Web. 
A partir da Seção 2.3 é apresentado formalmente o conceito de Engenharia Web, seguido na Seção 2.4 por propostas de processos de desenvolvimento de aplicações Web e na Seção 2.5 pelos diferentes métodos utilizados para o desenvolvimento dessas aplicações, objetos de estudo deste trabalho. Na Seção 2.6 é mostrada uma comparação entre métodos de aplicações Web, por meio de diferentes parâmetros e na Seção 2.6.4 são descritos trabalhos relacionados à avaliação de métodos de desenvolvimento e à Engenharia Web.

\subsection{Aplicações Web}

\subsubsection{Classificação}

Na comunidade científica, atualmente não existe um consenso sobre alguma classificação padrão para as aplicações Web. Existem classificações abrangentes e simples, como a de Pressman (2005), até classificações mais detalhadas, como a de Powell et al. (1998).

Na classificação proposta por Pressman (2005), uma aplicação Web compreende todo o tipo de aplicação existente para a Web, desde um simples site Web até um portal de comércio eletrônico com intenso processamento de informações. A partir dessa definição abrangente, outros pesquisadores propuseram novas divisões, baseadas na funcionalidade das aplicações ou em seus detalhes técnicos. Por exemplo, Conallen (2002) classificou aplicações pelo fato de serem geradas de maneira dinâmica ou não. Para as aplicações geradas de maneira dinâmica, Araújo (2001) adicionou uma nova classificação, para aquelas que são centradas em banco de dados. De modo similar, Powell et al. (1998) classificou também as aplicações estáticas em dois tipos, caso possuam formulário de entrada de dados, e ainda dividiu as aplicações centradas em banco de dados que possuem a capacidade de exibirem informação específica, de acordo com o usuário. De um modo geral, na classificação de Powell et al. (1998), pode-se observar um acréscimo de características a cada nova divisão para as aplicações Web, descrita a seguir:

- Site estático: é o tipo mais simples de uma aplicação baseada na Web, correspondente a uma coleção de páginas estáticas. A partir de uma página é possível acessar as outras por meio de elos. Como exemplo dessas aplicações temos os documentos, ou informações editadas e publicadas em formato HTML;

- Site estático com formulários de entrada: esse tipo de site provê um nível de interação básico implementado por meio de formulários de entrada. Isso permite uma maior interação por parte dos usuários. Exemplos desse tipo são questionários, livros de visita, comentários e sugestões, entre outros; 
- Site com acesso a dados dinâmicos: o usuário, por meio de consultas, pode ter acesso a bases de dados. As respostas das consultas são geradas dinamicamente e geralmente apresentadas no formato de documentos HTML, DHTML ou XML;

- Site criado dinamicamente: geralmente são criados nos casos em que o site deve fornecer conteúdo personalizado, dependendo da interação do usuário;

- Aplicação Web: este tipo de aplicação baseada na Web herda atributos dos tipos relacionados anteriormente e acrescenta lógica de negócios, para promover interação do usuário com dados armazenados em bases de dados. Desse modo, fornecem a mesma funcionalidade de uma aplicação de software tradicional.

Procurando resumir as características encontradas, Domingues (2005), a partir das características fornecidas pelos autores supracitados, elaborou uma tabela com tais dados(Tabela 2.1).

Tabela 2.1: Relação de Inclusão Entre Classificações de Aplicações Baseadas na Web (Domingues, 2005)

\begin{tabular}{|c|c|c|c|c|c|}
\hline Classificação & \multicolumn{5}{|c|}{ Categorias } \\
\hline $\begin{array}{c}\text { Powell et al. } \\
\text { (1998) }\end{array}$ & $\begin{array}{c}\text { sites Web } \\
\text { estáticos }\end{array}$ & $\begin{array}{c}\text { sites Web } \\
\text { estáticos } \\
\text { com for- } \\
\text { mulários } \\
\text { de entrada } \\
\text { de dados }\end{array}$ & $\begin{array}{c}\text { sites Web } \\
\text { com acesso } \\
\text { a dados } \\
\text { dinâmico }\end{array}$ & $\begin{array}{l}\text { sites Web } \\
\text { criados } \\
\text { dinamica- } \\
\text { mente }\end{array}$ & $\begin{array}{c}\text { aplicações } \\
\text { Web }\end{array}$ \\
\hline Araújo (2001) & \multicolumn{2}{|c|}{$\begin{array}{l}\text { páginas de } \\
\text { informações }\end{array}$} & \multicolumn{2}{|c|}{$\begin{array}{c}\text { aplicações Web } \\
\text { centradas em banco } \\
\text { de dados }\end{array}$} & $\begin{array}{c}\text { aplicações } \\
\text { Web que } \\
\text { apóiam a } \\
\text { realização } \\
\text { de } \\
\text { transação } \\
\text { de } \\
\text { negócios }\end{array}$ \\
\hline Conallen (2002) & site & Web & & plicações W & \\
\hline Pressman (2005) & \multicolumn{5}{|c|}{ aplicações Web } \\
\hline
\end{tabular}

Entre as classificações apresentadas, desenvolvedores e profissionais de tecnologia de informação não consideram como parte de seu domínio de estudo aplicações que apenas exibem informações (Deshpande e Hansen, 2001), no caso os sites estáticos, sites Web estáticos com formulários de entrada de dados (Powell et al., 1998), páginas de informações (Araújo, 2001) e sites Web (Conallen, 2002). Desse modo, as aplicações Web consideradas para estudo são aquelas que apresentam uma lógica para a transação de negócios 
(Araújo, 2001; Powell et al., 1998)). Ampliando-se essa caracterização, tem-se a definição de Finkelstein et al. (2002), na qual uma aplicação Web é uma aplicação que é executada no ambiente Web, envolve aspectos hipermídia, como hipertextos e multimídia, em combinação com a lógica de aplicações convencionais. No contexto deste trabalho será considerada essa definição para aplicação Web.

Além da classificação apresentada, nota-se a existência de outro tipo de aplicação dentro do ambiente Web: os Web Services. Eles são componentes de software distribuídos pela Internet e que utilizam tecnologias abertas como XML (W3C, 2006), SOAP (W3C, 2007), WDSL (W3C, 2001) que apóiam o desenvolvimento rápido e de baixo custo de aplicações (Papazoglou e Georgakopoulos, 2003). Esses serviços podem ser implementados, oferecidos e utilizados por diferentes empresas, provendo uma infra-estrutura para colaboração e integração entre aplicações. Desse modo, estão relacionados ao paradigma de computação orientada a serviços, que utilizam os Web Services como elementos essenciais para a construção de aplicações, envolvendo camadas de serviços, funcionalidades e regras descritas na chamada arquitetura orientada a serviços (SOA).

Geralmente, para um usuário que utiliza uma aplicação Web, os Web Services são transparentes, uma vez que são componentes utilizados internamente pelas aplicações e não possuem uma interface gráfica (Pamplona, 2004). Para um desenvolvedor, são como componentes de software, mas ao invés de serem utilizados localmente, os são de maneira distribuída, por meio do ambiente Web.

Os métodos estudados neste trabalho (Seção 2.5) não fazem referências a computação orientadas a serviços ou SOA. Portanto, Web Services não foram considerados como objetos de estudo. No entanto, em trabalhos futuros, características relacionadas a aplicações orientadas a serviços deverão ser definidas e avaliadas.

\subsubsection{Arquitetura}

Para o desenvolvimento bem-sucedido de aplicações Web, o conhecimento de sua arquitetura é um requisito fundamental. De um modo geral, as aplicações Web possuem três componentes básicos: um servidor Web, uma conexão de rede e um cliente. O servidor Web é um software executado em um computador remoto que responde a solicitações de outro software chamado cliente, via uma conexão de rede previamente estabelecida. Esses componentes podem ser estruturados em uma arquitetura composta por três camadas. Essas camadas separam as funções de interface com o usuário (apresentação), as funções de acesso ao banco de dados e às funções de lógica de negócio existentes em uma aplicação Web. Por meio de um servidor Web pode-se ter acesso às funções de lógica de negócio e de acesso aos dados, enquanto que o cliente possui funções de interface com o usuário 
(Conallen, 2002). Na Figura 2.1, pode-se observar as três camadas mencionadas e as tecnologias relacionadas.

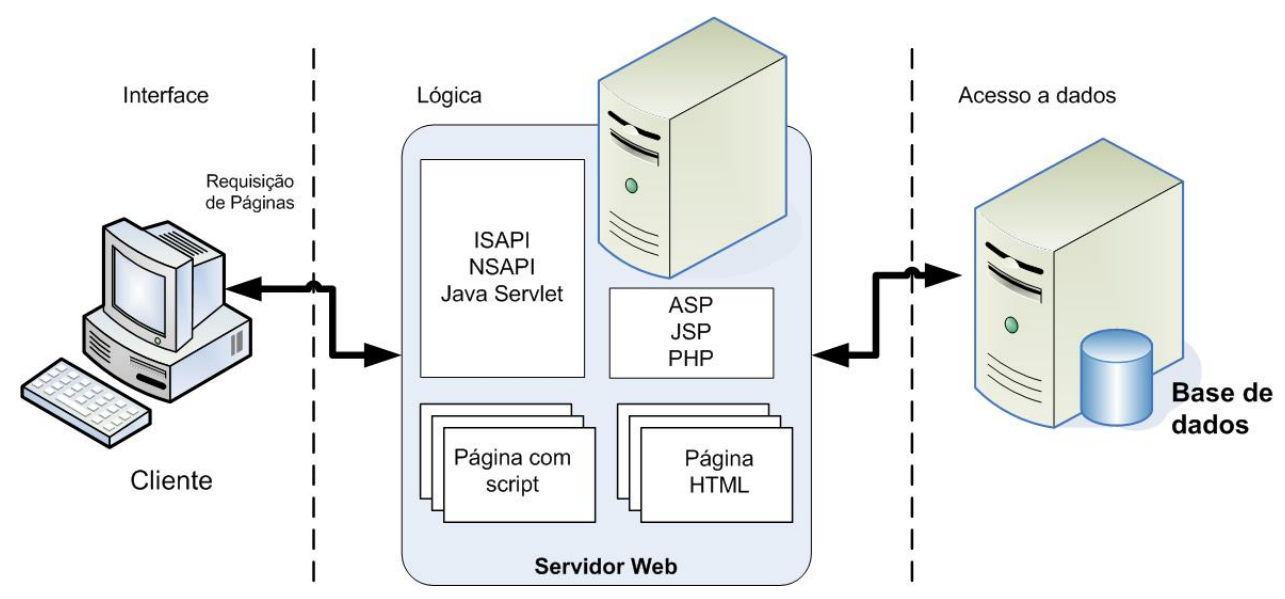

Figura 2.1: Tecnologias para o desenvolvimento de aplicações Web (Conallen, 2002).

Um exemplo de estilo de arquitetura padrão em três camadas utilizada no desenvolvimento de aplicações Web é o MVC (Model-View-Controller), o qual separa a funcionalidade envolvida no processamento e apresentação dos dados de uma aplicação. Na arquitetura MVC, o modelo ( $M o d e l$ ) representa os dados da aplicação e a lógica de negócio que regem o acesso aos dados. O modelo mantém o estado persistente dos dados e fornece ao controlador (Controller) a capacidade de ter acesso às funcionalidades da aplicação, encapsuladas pelo próprio modelo. O componente de visualização ( View) apresenta o conteúdo de um modelo e coleta os dados para o modelo; especifica como esses dados devem ser apresentados e encaminha para o controlador as ações do usuário. O controlador é o componente que define o comportamento da aplicação, ou seja, ele interpreta as ações do usuário e as traduz para ações do modelo que, por exemplo, ativam processos da lógica de negócio ou alteram o estado do modelo. O controlador encarrega-se de selecionar qual visualização será mostrada a partir da interação com o usuário (Sun Microsystems, 2003).

Ressalta-se que o conhecimento da arquitetura das aplicações Web influencia todos os passos de um método de desenvolvimento, pois fornece regras e limites que devem ser respeitados para a construção da aplicação, e de certo modo, como o problema deve ser solucionado.

\subsubsection{Características}

Apesar de oferecer funcionalidade equiparável, as aplicações Web possuem características próprias que as diferem de aplicações de software tradicional. Diferenciam-se das aplicações tradicionais, principalmente em relação às questões sobre navegação, organização da 
interface e implementação. Além dessas questões, Ginige e Murugesan (2001b) relacionam as seguintes características de uma aplicação Web:

- A maioria das aplicações Web são orientadas a documentos, pois são constituídas de documentos conhecidos por páginas Web, podendo ser tanto estáticas quanto dinâmicas;

- Aplicações Web são focadas na aparência e exigem criatividade visual e incorporação de recursos multimídia (gráficos, imagens, áudio e vídeo), tanto na apresentação quanto na interface. Além disso, tais recursos podem acarretar implicações no desempenho da aplicação;

- A maioria das aplicações Web são dirigidas ao conteúdo, pois herdam características de sites Web, que tinham por objetivo originalmente apresentar informações. Portanto, as aplicações envolvem também o desenvolvimento de conteúdo;

- Multiplicidade de perfis de usuários. As aplicações Web podem atender a uma comunidade de usuários numerosa, com usuários de diferentes perfis, que possuem diferentes habilidades e capacidades, o que dificulta a interação homem-computador, a interface com o usuário e a apresentação de informações;

- O conjunto de profissionais envolvidos na construção e desenvolvimento de aplicações Web é variado, tanto em sua experiência, habilidades, conhecimento e compreensão do sistema, bem como em sua percepção da Web e da qualidade das aplicações envolvidas;

- As aplicações Web são executadas em um ambiente mais imprevisível do que o meio onde são executadas as aplicações de software tradicionais;

- A maioria das aplicações Web precisam ser desenvolvidas em um curto espaço de tempo (imediatismo), tornando difícil a adoção do mesmo nível de rigor no planejamento e teste utilizados em aplicações tradicionais; e

- Requisitos de segurança e privacidade em uma aplicação baseada na Web são mais exigidos do que em aplicações de software convencionais.

Ressalta-se uma característica importante não relacionada por Ginige e Murugesan (2001b): a evolução continuada (Pressman, 2005). Diferentemente da maioria das aplicações de software tradicional, que evolui por meio de versões planejadas e espaçadas cronologicamente (seu ciclo de vida), as aplicações Web evoluem continuamente, ou seja, sempre requerem modificações em sua estrutura e novo conteúdo. Isso se deve ao fato de que em muitos casos não é possível especificar o que uma aplicação Web deve conter 
no início de seu processo de desenvolvimento, uma vez que seus requisitos podem variar, especialmente após ser colocada em uso. Gerenciar a evolução de uma aplicação Web é o maior desafio técnico, organizacional e gerencial para os desenvolvedores (Murugesan e Ginige, 2005).

\subsection{Engenharia Web}

A Engenharia Web é a aplicação de abordagens sistemáticas, disciplinadas e quantificáveis para o desenvolvimento, operação e manutenção de aplicações baseadas na Web (Deshpande et al., 2003).

Embora a Engenharia Web envolva o desenvolvimento de software e adote conceitos fundamentais da Engenharia de Software, o desenvolvimento de aplicações Web é diferente, pois considera as características inerentes às aplicações Web (Seção 2.2.3). Como exemplo, pode-se citar a natureza orientada a documentos (páginas estáticas ou dinâmicas) de uma aplicação Web, que exige um estudo detalhado de questões de navegabilidade e usabilidade. A adaptação de métodos e técnicas, em função das características das aplicações Web, torna a Engenharia Web um campo multidisciplinar que incorpora entradas de diversas áreas da Engenharia de Software, bem como as áreas de interação usuário-computador, gerenciamento de projetos, multimídia, hipermídia e projeto gráfico (Murugesan e Deshpande, 2000).

De um modo geral, os elementos que compreendem a Engenharia Web acabam mesclando atividades e aspectos encontrados na Engenharia de Software com atividades e aspectos únicos. Os elementos que podem ser listados para a Engenharia Web são (Murugesan et al., 1999):

- Especificação e análise de requisitos;

- Desenvolvimento de métodos e técnicas para as aplicações Web;

- Integração com sistema legados;

- Migração de sistemas legados para o ambiente Web;

- Desenvolvimento de aplicações Web de tempo real;

- Validação, verificação e teste de aplicações Web;

- Garantia e controle de qualidade;

- Gerência de configuração e de projeto;

- Métricas Web - métricas para estimativas dos esforços de desenvolvimento; 
- Especificação e avaliação de desempenho;

- Atualização e manutenção;

- Desenvolvimento de equipes e modelos;

- Aspectos humanos e culturais;

- Desenvolvimento centrado no usuário, envolvimento e verificação de feedback do usuário;

- Desenvolvimento de aplicação de uso facilitado ao usuário; e

- Treinamento e educação.

Atividades como integração e migração de sistemas legados, elementos como métricas Web e aspectos humanos e culturais surgem para a Engenharia Web, criando novos desafios para os desenvolvedores e profissionais da área. Além disso, algumas atividades relacionadas, também utilizadas pela Engenharia de Software, apresentam mudanças devido às características das aplicações Web (Seção 2.2.3), diferenciando a Engenharia de Software tradicional da Engenharia Web. Por exemplo, as atividade de Validação, Verificação e Teste devem ter suas técnicas adaptadas para que abordem características como o ambiente Web e questões de navegabilidade.

Na próxima seção são relacionados possíveis modelos para um processo de desenvolvimento para as aplicações Web, que se baseiam nas características e atividades dessas aplicações.

\subsection{Processo de Desenvolvimento}

Para que os elementos listados na seção anterior possam ter seus objetivos cumpridos, elas devem ser executadas de acordo com um processo de desenvolvimento. Pressman (2005) sugere um processo evolutivo e incremental, similar ao modelo de ciclo de vida espiral da Engenharia de Software tradicional. O processo inicia-se com a atividade de formulação que consiste em identificar as metas e objetivos da aplicação Web e estabelece o escopo inicial. Na atividade seguinte, o planejamento, é estimado o custo global do projeto e são avaliados riscos associados com o esforço de desenvolvimento e ainda são definidos cronogramas para as fases iniciais e fases subseqüentes. Na análise são estabelecidos requisitos técnicos de uma aplicação Web e são identificados os itens de conteúdo que serão incorporados, além de requisitos de estética. A atividade de engenharia incorpora duas tarefas paralelas, uma consiste no projeto, produção de conteúdo de texto, gráficos, áudio e vídeo, e outra tarefa consiste no projeto técnico. Na atividade de Geração de Páginas 
faz-se uso de ferramentas para a criação de aplicações Web, combinando os projetos de interface, de arquitetura e de navegação para produzir páginas executáveis que possam ser testadas na atividade de teste. Por fim, na atividade de avaliação pelo cliente, podem ser solicitadas modificações, que incidem no escopo do projeto e que são integradas em uma futura iteração, por meio do fluxo de processo evolutivo. Na Figura 2.2 é possível observar o modelo de processo proposto por Pressman (2005).

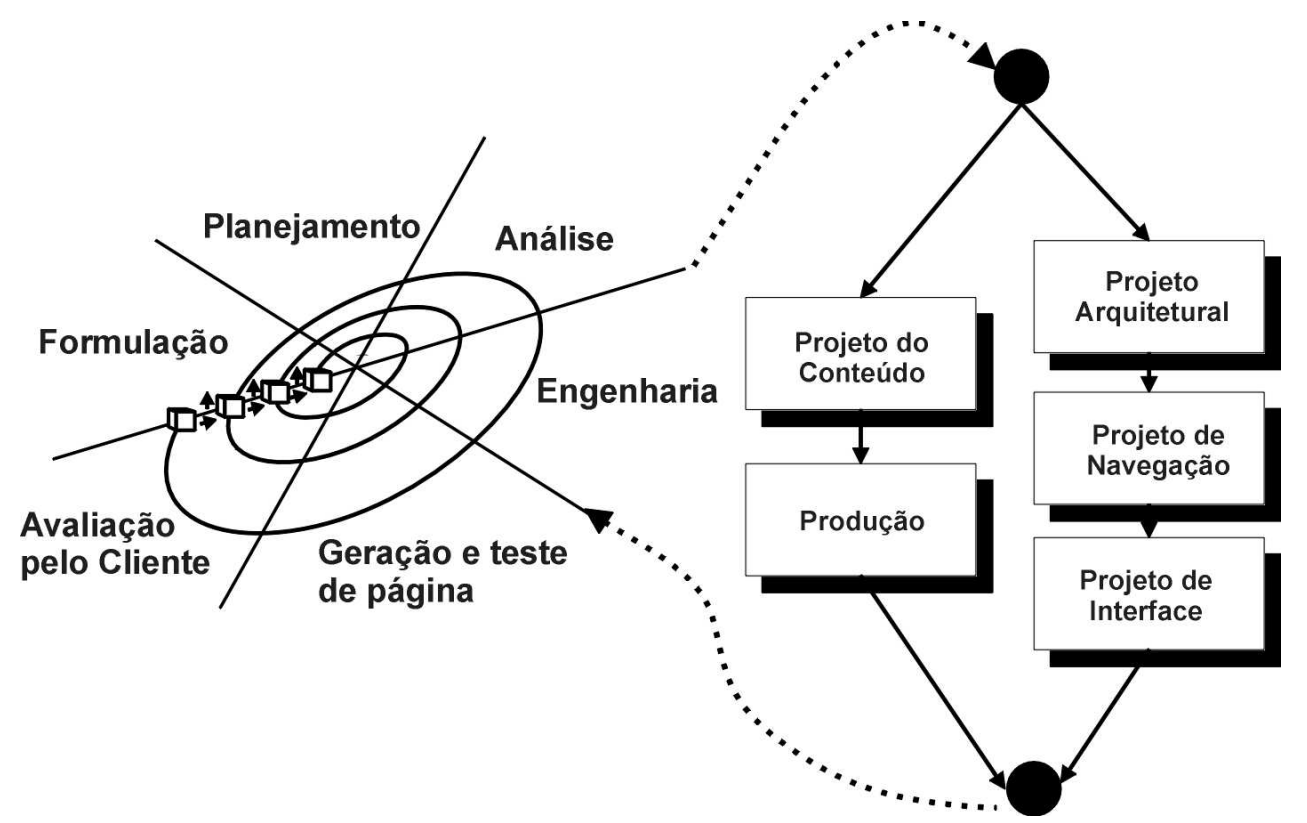

Figura 2.2: Modelo de processo de desenvolvimento de aplicações Web proposto por Pressman (2005)

Outro processo que procura considerar os aspectos particulares das aplicações Web é o processo proposto por Murugesan e Ginige (2005). Assim como o processo anteriormente apresentado, esse processo também é considerado evolutivo, dado que essa característica do processo é útil para a compreensão do contexto no qual a aplicação será desenvolvida, facilita a elicitação de requisitos, ajuda na integração entre diferentes disciplinas e auxilia na comunicação entre diferentes membros. Além disso, também apóia a evolução continuada, facilita o gerenciamento de conteúdo e de um modo geral ajuda a controlar a complexidade e diversidade inerente ao processo de desenvolvimento das aplicações Web (Ginige e Murugesan, 2001a).

No processo proposto por Murugesan e Ginige (2005), o primeiro passo, e mais importante, é a análise de contexto, na qual os objetivos, os requisitos e as necessidades dos usuários e da organização que precisa da aplicação são levantados. Nesse passo, a percepção de que os requisitos podem mudar e evoluir é uma questão chave para o sucesso do processo. No projeto da arquitetura do sistema devem ser considerados requisitos funcionais, não funcionais e técnicos, além de atributos de qualidade como escalabilidade, manutenibilidade e requisitos de desempenho, pois de acordo com o autor do processo 
pode ser difícil ou impossível adicionar esses elementos em fases posteriores do processo. Em conjunto com o projeto da arquitetura do sistema, um modelo conceitual do projeto deve ser construído para elucidar os principais requisitos e objetivos do sistema. Após as fases de levantamento e análise de requisitos, segue a construção de um plano de projetos, para iniciar o desenvolvimento da aplicação. Após o desenvolvimento há a entrega da aplicação, e por fim, a aplicação mantém-se sob constante avaliação e manutenção. Aliado a essas fases, somam-se atividades de apoio como gerenciamento de projeto, garantia e controle de qualidade e documentação. Na Figura 2.3 pode-se ter uma visão geral desse modelo de processo e verificar como suas atividades estão conectadas.

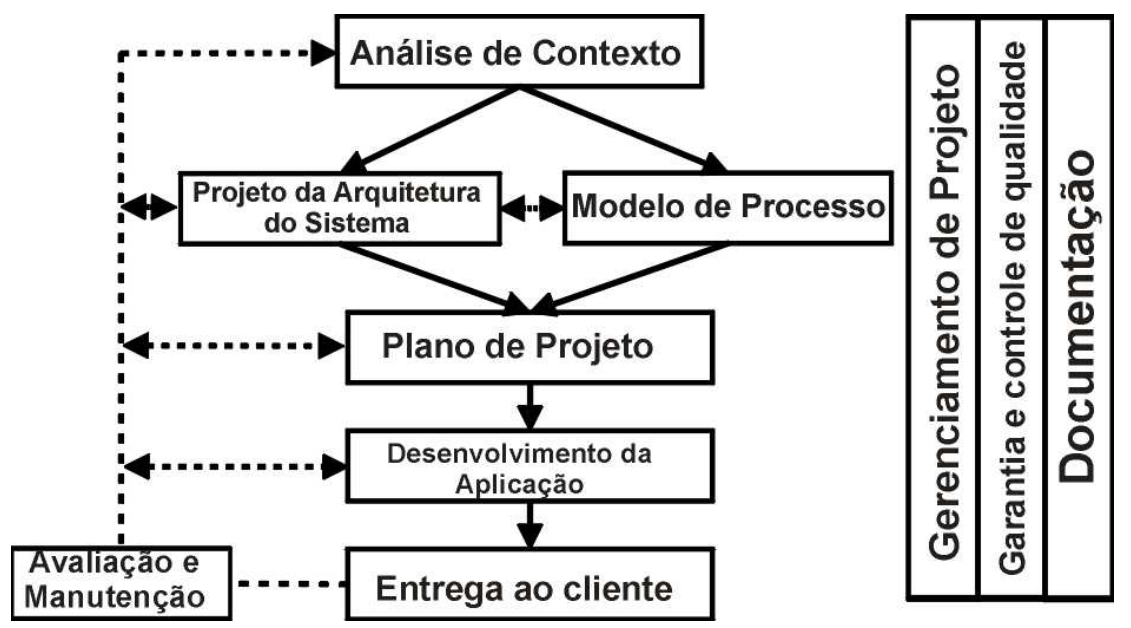

Figura 2.3: Modelo de desenvolvimento de aplicações Web proposto por Murugesan e Ginige (2005)

As etapas abordadas por esses processos, dão ênfase às fases iniciais, de um modo geral à análise de requisitos e o planejamento do projeto. Desse modo, procuram minimizar o possível impacto de futuras alterações e de novos requisitos. Além dessa semelhança, encontramos também o fato de serem processos evolutivos, que procuram adequar-se a característica evolutiva das aplicações Web. Outras características das aplicações Web (Seção 2.2.3) também são consideradas entre as etapas dos processos, com destaque para a fase de engenharia apresentada por Pressman (2005) e a fase do projeto de arquitetura do sistema de Murugesan e Ginige (2005). Por exemplo, na fase de engenharia proposta por Pressman (2005), é dedicada uma atividade para cuidar do conteúdo da aplicação Web (Projeto de Conteúdo), assim como organizar os elementos visuais (Projeto de Navegação e de Interface). Em relação ao tipo do processo, no processo proposto por Murugesan e Ginige (2005), as etapas de projeto não são organizadas em um modelo espiral como o proposto por Pressman (2005), mas apresentam-se em um modelo mais próximo ao cascata, permitindo que etapas já realizadas sejam revisitadas, tornando-o iterativo.

Contudo, salienta-se que os dois modelos de processos propostos não especificam nenhuma técnica de modelagem ou método para sua utilização. Devido a essa restrição, 
na próxima seção, serão apresentados métodos que podem ser utilizados nesses processos apresentados e em outros processos para desenvolvimento de aplicações Web.

\subsection{Métodos de Desenvolvimento de aplicações Web}

Para gerenciar o desenvolvimento e manutenção de uma aplicação Web, um método de desenvolvimento deve ser estabelecido, combinando técnicas e princípios tradicionais da engenharia de software com os aspectos específicos da Web (Brambilla et al., 2002), aspectos esses não abordados por métodos de desenvolvimento conhecidos, como a OMT (Rumbaugh et al., 1991), ou linguagens de modelagem, como a UML (Rumbaugh et al., 1998).

De modo geral, os métodos atuais de desenvolvimento Web estendem métodos clássicos de desenvolvimento de software pela adição de algum modelo de navegação para especificar as características navegacionais de uma aplicação Web. Um procedimento similar também é utilizado para a adaptação de linguagens de modelagem extensíveis, como a UML, ao contexto das aplicações Web. Esses modelos definem visões navegacionais de um sistema e relacionam-se a grupos de usuários. Geralmente, descrições navegacionais são representadas por grafos que especificam visões sobre os dados de uma aplicação e funcionalidades definidas em modelos estruturais. Os nós desses grafos representam visões do sistema e podem ser relacionados por ligações navegacionais (links) (Torres et al., 2004).

Nos últimos anos, surgiram diversos métodos que procuram adequar tecnologias conhecidas ao desenvolvimento de aplicações Web (Griffiths et al., 2002). Além disso, características como o curto prazo de tempo requisitado para o desenvolvimento de aplicações Web, o imediatismo, podem sugerir a utilização de outros métodos, como os métodos ágeis (Fowler, 2000), pois, entre seus princípios, encontra-se a entrega de versões do software, que funcionam adequadamente, em curtos períodos de tempo (Cagnin et al., 2005).

Para tornar o desenvolvimento de aplicações Web efetivo, segundo Gu et al. (2002), um método deve considerar dois aspectos de arquitetura técnica dessas aplicações: a arquitetura funcional e a arquitetura de informação ( arquitetura de como os dados são apresentados). Diante dessas características, Gu et al. (2002) conduziram uma breve comparação entre seis métodos existentes. Os métodos escolhidos foram o OOHDM (Schwabe e Rossi, 1998), WebML (Ceri et al., 2000b), UWE (Koch, 2000; Koch e Mandel, 1999), extensões da UML por Conallen (2002), W2000 (Baresi et al., 2001b) e HDM-Lite/Autoweb (Fraternali e Paolini, 2000). A comparação conduzida resumiu-se em uma lista de checagem, em que foi evidenciado se cada método abordava completamente, parcialmente ou não abordava os aspectos funcional e de informação mencionados anteriormente.

Para uma comparação mais completa, acredita-se que além de verificar se determinadas características estão presentes nos métodos avaliados, seria relevante considerar o 
propósito dos tipos de aplicações Web existentes, pois para cada tipo de aplicação Web (Seção 2.2) deve-se analisar suas característica e verificar se os métodos são aplicáveis aos propósitos das aplicações. Além disso, poderiam ser incluídos outros métodos encontrados na literatura (Baresi et al., 2000; Griffiths et al., 2002; Koch et al., 2003) bem como a condução de estudos empíricos na avaliação poderiam fornecer outras informações a respeito de características práticas, como tempo de desenvolvimento e curva de aprendizagem de determinado método.

Nas próximas seções serão apresentados métodos encontrados na literatura. São citadas suas principais técnicas, como são fundamentados na Engenharia de Software e os conceitos neles abordados. Entre os métodos relacionados, os métodos WAE, W2000, WebML e o OO-H possuem uma descrição mais detalhada uma vez que foram escolhidos, a partir do estudo de Gu et al. (2002), para a condução deste trabalho.

\subsubsection{HDM}

O Hypermedia Design Model (HDM) (Garzotto et al., 1993) é conhecido como um dos primeiros métodos para especificar e modelar aplicações hipermídia. Preocupa-se essencialmente com a modelagem do domínio da aplicação. A utilização do método HDM é realizada pela definição de um esquema que contém classes de elementos de informação, com a descrição de suas características de apresentação, suas estruturas organizacionais internas e seus tipos de interconexões. Depois de definido um esquema, é gerada uma instância desse esquema para uma situação em particular e por fim uma semântica de navegação é definida, para determinar como os objetos serão apresentados a um desenvolvedor.

Uma aplicação, para o método HDM, consiste em estruturas dimensionáveis de informação chamadas Entidades. Uma Entidade denota um objeto físico ou conceitual de um domínio. As Entidades podem ser classificadas em tipos. Além disso, uma Entidade é a menor porção "autônoma" de informação que pode ser introduzida ou removida de uma aplicação. Nesse contexto, "autônoma" significa que sua existência não está condicionada a existência de outros objetos de informação. No HDM apenas às Entidades são autônomas.

Uma Entidade é formada por uma hierarquia de Componentes, que por sua vez são feitos por Unidades. Cada unidade exibe o conteúdo e um componente sob uma perspectiva única. Assim, entidades derivam seu conteúdo de informação a partir de seus componentes, e esses derivam seu conteúdo de suas unidades. Unidades são a menor porção de informação que pode ser visualizada em uma aplicação HDM e representam o mesmo conceito de nós do hipertexto. 
As estruturas mencionadas do HDM podem ser interconectadas por ligações (links). Existem três tipos de ligações: de estrutura, de aplicação e de perspectiva. As ligações de estrutura conectam componentes pertencentes a uma mesma entidade. Ligações de perspectiva conectam diferentes unidades do mesmo componente e ligações de aplicação denotam relações de domínio dependentes e conectam componentes e entidades, de diferentes tipos ou não, em padrões escolhidos pelo projetista. Ligações de aplicação devem ser classificadas em tipos, enquanto que as demais ligações não exigem nenhuma especificação explícita, contanto que possam ser derivadas automaticamente da estrutura das entidades.

Algumas ligações de aplicação podem ser derivadas explorando propriedades semânticas das correspondentes relações do domínio. Além disso, existem ainda estruturas de acesso que definem pontos de entrada usados para orientar um projetista no processo de navegação e para tornar mais rápido e direto o acesso às informações. Tais estruturas podem ser chamadas de outlines, que são estruturas tipo índice, ou os roteiros guiados.

Assim como em outros métodos de modelagem, o HDM faz uma distinção clara entre a noção de esquema e a noção de instância de um esquema. Um esquema é uma coleção de definição de tipos que descrevem uma aplicação em um nível global; uma instância de um esquema é a coleção de componentes, entidades e ligações que satisfazem as definições de um esquema.

O HDM define uma semântica de navegação padrão que, por um processo de compilação permite transformar a especificação da instância do esquema HDM em um modelo intermediário baseado em grafos (modelo de nós e ligações). Em seguida, os nós e as ligações devem ser mapeados diretamente para objetos do sistema hiperdocumento destino, o qual é responsável por especificar o comportamento dinâmico e as propriedades de visualização das informações. Assim, para uma mesma especificação estática HDM podem-se definir diferentes semânticas de navegação, permitindo que o mesmo hiperdocumento tenha comportamentos dinâmicos diferentes ou que seja implementado em diferentes sistemas hiperdocumento.

\subsubsection{RMM}

O Relationship Management Methodology (RMM) (Isakowitz et al., 1995) é um método para o projeto estruturado e construção de aplicações hipermídia baseado no Modelo Entidade-Relacionamento (ME-R) (Chen, 1976). Esse método é composto por de 9 etapas (Figura 2.4):

- Análise de Possibilidades;

- Análise de Requisitos; 
- Escolha de Hardware;

- Projeto e Especificação: inclui o projeto de E-R, projeto de fatias e projeto navegacional;

- Projeto de interface com o usuário;

- Projeto de protocolos de conversão;

- Projeto de comportamento em tempo de execução;

- Construção; e

- Teste.

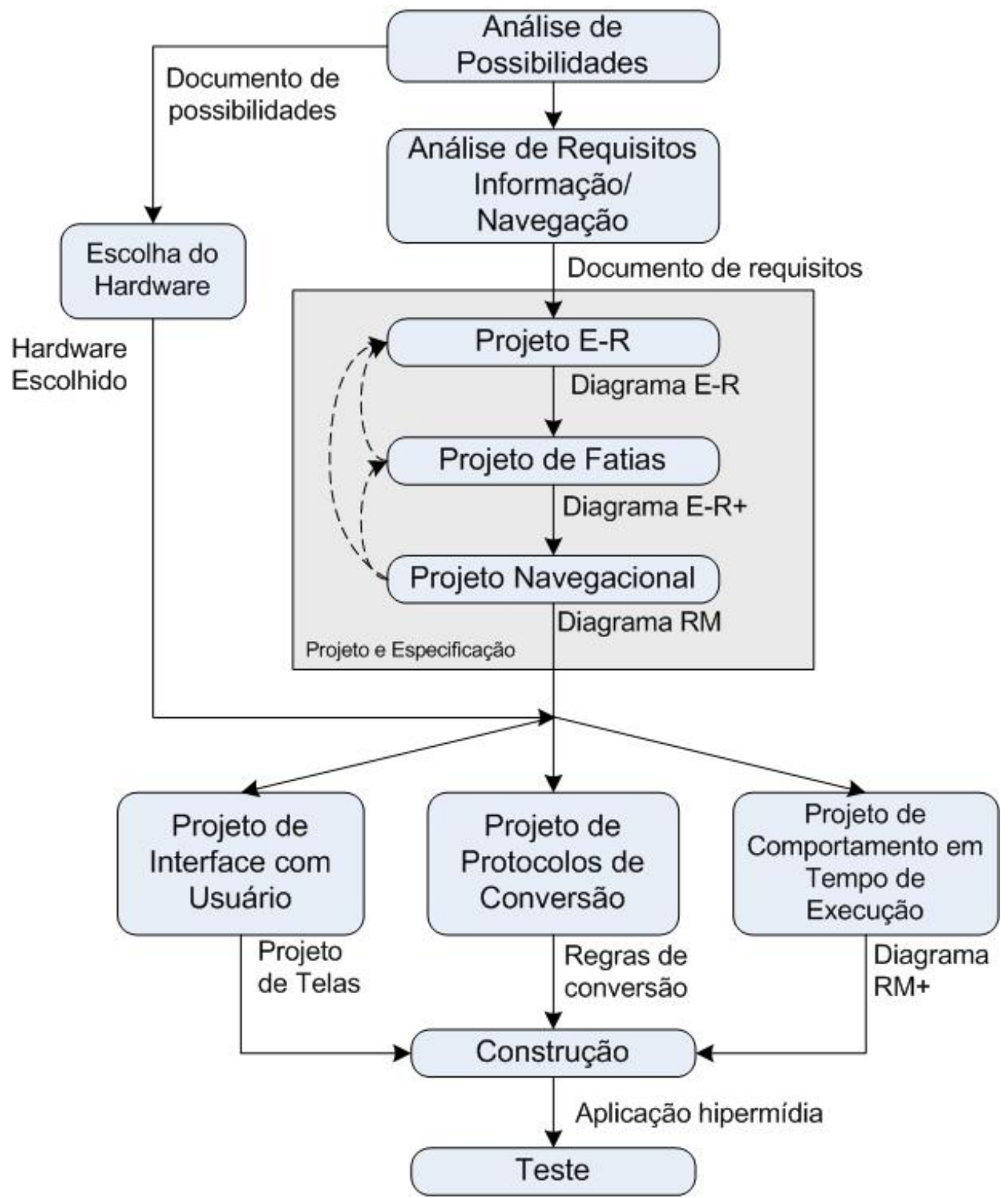

Figura 2.4: Etapas do Método RMM (Isakowitz et al., 1995) 
Na etapa do projeto E-R, um modelo E-R é desenvolvido para descrever as informações do domínio da aplicação. As entidades e relacionamentos desse projeto formam a base da aplicação hipermídia a ser desenvolvida. As entidades do modelo E-R podem ser divididas em fatias ou slices que agrupam um ou mais atributos de uma entidade. Essa divisão gera um diagrama E-R estendido, que compreende o ME-R inicial enriquecido pelo diagrama de fatias gerado para cada entidade.

Na etapa do projeto navegacional, o diagrama estendido ganha estruturas para representar a navegação, passando a ser denominado como RMDM (Relationship Management Data Model) e fornece uma linguagem gráfica para denotar a semântica do domínio, dada pelas primitivas do domínio e para denotar os mecanismos de navegação, fornecidos pelas primitivas de acesso. As primitivas do domínio modelam as informações referentes ao domínio da aplicação e dividem-se em primitivas do domínio E-R, que incluem as entidades, atributos e relacionamentos associativos e primitivas do domínio RMDM, que são as fatias. As entidades e seus atributos representam objetos físicos ou abstratos do domínio, como por exemplo, pessoas ou contas bancárias. Os relacionamentos associativos descrevem associações entre diferentes tipos de entidades. Os atributos das entidades são formados por diferentes tipos e podem ser apresentados de maneira distinta, podendo ser agrupados em fatias inter-relacionadas, que modelam como a informação será apresentada.

Para modelar a navegação entre os hiperdocumentos, são utilizadas as primitivas de acesso. No RMDM existem seis primitivas de acesso: (i) ligação unidirecional; (ii) ligação bidirecional; (iii) índice; (iv) roteiro guiado; (v) roteiro guiado indexado; e (vi) agrupamento.

As ligações uni e bidirecionais são utilizadas para modelar o acesso entre as fatias de uma mesma entidade e para diferentes entidades são utilizadas as demais primitivas de acesso.

De posse do RMDM, a próxima etapa é o Projeto de Interface com o usuário, onde é definido como as informações serão apresentadas ao usuário e como o conteúdo definido nas etapas do Projeto de Fatias e Projetos Navegacional será visualizado na tela. Na etapa do Projeto de Comportamento em tempo de execução, são definidos a inclusão de facilidades adicionais ao usuário, como por exemplo, a possibilidade de retornar a um nó já visitado e registro da navegação realizada. Na etapa do Projeto de Protocolos de conversão um conjunto de regras para a conversão dos componentes do RMDM em objetos físicos (arquivos HTML) é produzido. Na etapa de construção há a codificação, em uma linguagem de programação, das regras de negócio do projeto, e por fim, segue a etapa de teste onde todos os componentes produzidos, como links de navegação e comportamento da aplicação deverão ser minunciosamente testados. 
O RMM possui limitações para o desenvolvimento de aplicações mais complexas e ganhou extensões (Isakowitz et al., 1997, 1998), por meio do acréscimo de novas primitivas de domínio, como por exemplo as fatias-m ( $m$-slices $)$.

\subsubsection{OOHDM}

O Object Oriented Hypermedia Design Method (OOHDM) (Rossi, 1996), é um método voltado para a construção de aplicações hipermídia baseado no paradigma de orientação a objetos(OO). Compreende quatro fases de desenvolvimento (Tabela 2.2): projeto conceitual, projeto navegacional, projeto de interface abstrata e implementação. O projeto conceitual consiste na modelagem da semântica do domínio da aplicação, expressa geralmente em um diagrama de classes, similar ao existente na UML (Fowler e Scott, 2000). O projeto navegacional define a estrutura de navegação de uma aplicação, considerando o perfil dos usuários e suas tarefas. O projeto de interface abstrata modela objetos perceptíveis da interface, como formulários, botões e etiquetas de texto, fornecendo informações às reações desses objetos com o usuário e transformações da interface. A implementação é a construção da aplicação executável.

Cada fase propicia a separação de tarefas, facilitando a comunicação entre diversos grupos de projetistas, além de possuir mecanismos de abstração existentes na OO, como agregação, generalização e especialização. Entre os diagramas existentes no OOHDM, o diagrama de esquema navegacional mostra de maneira simples o fluxo de navegação de uma aplicação.

O OOHDM á apoiado por uma ferramenta denominada OOHDM-Web (Schwabe e Pontes, 1998; Schwabe et al., 1999) que permite a prototipagem rápida de aplicações hipermídia projetadas com o OOHDM. Fornece um mapeamento direto de construções de navegação e de interface para uma biblioteca de funções no ambiente de programação CGI estendido para acesso a bancos de dados. Permite a implementação de aplicações na forma de scripts CGI que produzem páginas geradas dinamicamente.

\subsubsection{UWE}

O UWE (UML-based Web Engineering) (Koch, 2000) consiste em um método de desenvolvimento de aplicações Web que enfatiza um projeto sistemático, personalização e geração semi-automática da aplicação Web. É totalmente baseado na UML (Fowler e Scott, 2000) e utiliza suas notações e mecanismos de extensão. É um método orientado a objetos iterativo, centrado em uma abordagem incremental e também é baseado no Rational Unified Process (RUP) (Kruchten, 1998).

As principais atividades são a análise requisitos, a modelagem conceitual, a modelagem navegacional e modelagem de apresentação, apoiados por diagramas de tarefas e 
Tabela 2.2: Sumário das Fases do Método OOHDM (Rossi, 1996)

\begin{tabular}{|c|c|c|c|}
\hline Fases & Produtos & Mecanismos & $\begin{array}{l}\text { Interesses do } \\
\text { Projeto }\end{array}$ \\
\hline $\begin{array}{c}\text { Projeto } \\
\text { Conceitual }\end{array}$ & $\begin{array}{c}\text { Classes, } \\
\text { subsistemas, } \\
\text { relacionamentos e } \\
\text { perspectivas de } \\
\text { atributos }\end{array}$ & $\begin{array}{l}\text { Classificação, } \\
\text { composição, } \\
\text { generalização e } \\
\text { especialização }\end{array}$ & $\begin{array}{l}\text { Modela a semântica } \\
\text { do domínio de } \\
\text { aplicação }\end{array}$ \\
\hline $\begin{array}{l}\text { Projeto de } \\
\text { Navegação }\end{array}$ & $\begin{array}{l}\text { Nós, ligações, } \\
\text { estruturas de acesso, } \\
\text { contextos de } \\
\text { navegação e } \\
\text { transformações } \\
\text { navegacionais }\end{array}$ & $\begin{array}{l}\text { Mapeamento entre } \\
\text { objetos conceituais e } \\
\text { de navegação. } \\
\text { Padrões de } \\
\text { navegação para a } \\
\text { descrição da } \\
\text { estrutura geral da } \\
\text { aplicação }\end{array}$ & $\begin{array}{c}\text { Considera o perfil do } \\
\text { usuário e as tarefas; } \\
\text { enfatiza os aspectos } \\
\text { cognitivos e } \\
\text { arquiteturais }\end{array}$ \\
\hline $\begin{array}{l}\text { Projeto de } \\
\text { Interface } \\
\text { Abstrata }\end{array}$ & $\begin{array}{l}\text { Objetos de interface } \\
\text { abstrata, reações a } \\
\text { eventos externos e } \\
\text { transformações de } \\
\text { interface }\end{array}$ & $\begin{array}{l}\text { Mapeamento entre } \\
\text { objetos de } \\
\text { navegação e objetos } \\
\text { de interface }\end{array}$ & $\begin{array}{c}\text { Modela objetos } \\
\text { perceptíveis, } \\
\text { implementa } \\
\text { metáforas } \\
\text { escolhidas, descreve } \\
\text { a interface para } \\
\text { objetos } \\
\text { navegacionais }\end{array}$ \\
\hline Implementação & Aplicação executável & $\begin{array}{l}\text { Recursos fornecidos } \\
\text { pela plataforma de } \\
\text { destino }\end{array}$ & $\begin{array}{c}\text { Promove o } \\
\text { desempenho e a } \\
\text { completitude }\end{array}$ \\
\hline
\end{tabular}

StateCharts (Harel, 1987). Os diagramas de tarefas e os StateCharts são utilizados para a compreensão de aspectos dinâmicos de uma aplicação Web. Na modelagem conceitual é utilizado o diagrama de classes da UML que representa uma visão estática dos elementos do domínio da aplicação. A modelagem navegacional de uma aplicação Web é constituída do modelo navegacional de espaço e do modelo navegacional de estrutura. O modelo navegacional de espaço especifica quais elementos são alcançados pela navegação. E o modelo navegacional de estrutura define como esses elementos são alcançados. Na modelagem de apresentação é utilizado um tipo próprio de diagrama de classes.

Outro princípio abordado pelo UWE é geração semi-automática de aplicações Web a partir de modelo de projeto, que consiste na codificação a partir de modelos visuais. Para satisfazer essa característica, uma extensão da ferramenta ArgoUML foi desenvolvida, a ArgoUWE, que permite a modelagem visual de todos os diagramas necessários, e a partir desses diagramas, cria arquivos padrão XML para intercâmbio dos dados e subseqüente geração de código. Na Figura 2.5 pode-se observar um diagrama de classes UML que 
representa o processo UWE, de suas etapas iniciais até a geração de código da aplicação Web.

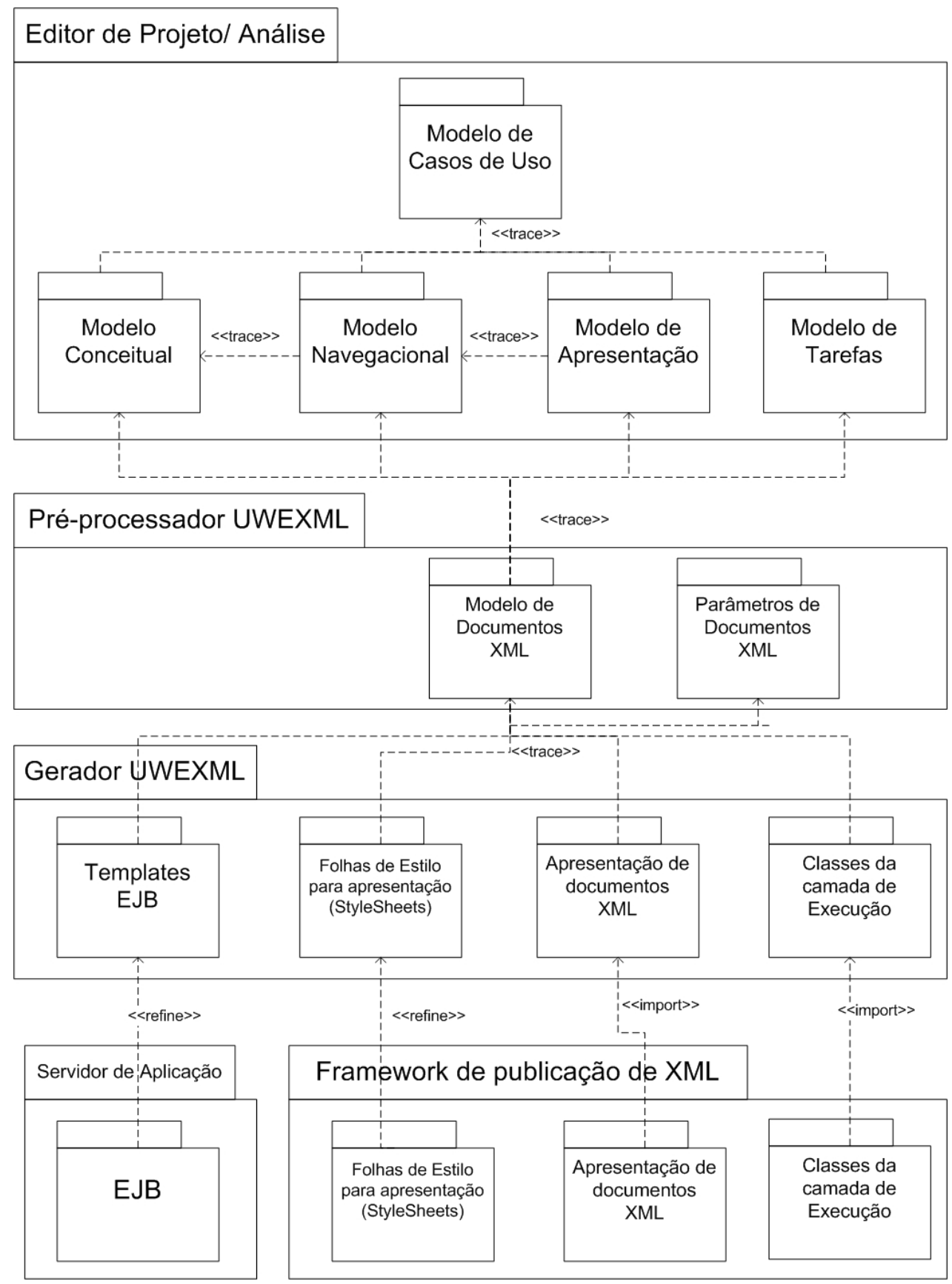

Figura 2.5: Processo do método UWE (Koch, 2000).

\section{$2.5 .5 \quad \mathrm{OO}-\mathrm{H}$}

O método Object-oriented hypermedia (OO-H) (Gómez et al., 2001) fornece um arcabouço padrão para a captura das propriedades relevante envolvidas no modelagem e implementação de aplicações Web. Basicamente seu processo de modelagem consiste na adição 
de duas visões que complementam a modelagem conceitual tradicional de um método de desenvolvimento de software compatível com a UML, denominado OO-Method (Pastor et al., 1998), um ambiente de desenvolvimento automático. Nesse ambiente são considerados no método OO-H um conjunto de visões que capturam a estrutura do sistema (elementos estáticos), seu comportamento (elementos dinâmicos) e possui um modelo de compilação que gera fonte de dados e módulos lógicos em um ambiente de implementação.

As visões que complementam o OO-method são a visão navegacional e a visão de apresentação. A visão navegacional, representada pelo navigational access diagram (NAD) estende um diagrama de classes incluindo características navegacionais de hipermídia, e a segunda, a visão de apresentação, representada pelo abstract presentation diagram (APD) utiliza diferentes elementos que consideram a aparência da interface e seu comportamento para modelar uma série de estruturas expressadas em XML. As atividades do método inicia-se no processo de projeto onde são construídos diagramas de classe, seguidos pelos dos NAD. Os NAD por sua por sua vez são refinados pelos APD, que em linhas gerais são um modelo intermediário para a codificação da aplicação por meio da geração automática de código-fonte, fornecida pelo compilador do método OO-H, que pode apresentar-se como arquivos codificados em HTML ou JSP, por exemplo.

Os modelos NAD apresentam setas que interligam objetos do domínio da aplicação, chamados então de classes navegacionais, representado assim os links existentes em uma aplicação Web. Essas setas possuem atributos que fornecem conteúdo semântico, para facilitar a compreensão da aplicação. Por exemplo, um link de uma aplicação, representado por uma seta, pode ser do tipo requirement, indicando que é requisito para uma determinada seção da aplicação. Podem ainda possuir filtros, descritos sobre as setas utilizando expressões restritivos, por exemplo, em uma situação que é necessário a verificação das credenciais de uma usuário para que a navegação de uma seção de aplicação à outra aconteça, é necessário descrever uma restrição como login.is Valid $==$ true.

Além disso, o OO-H conta com um catálogo de padrões que provê uma linguagem de padrões de interface hipermídia, que pode ser vista como uma coleção parcialmente ordenada de padrões relacionados que trabalham em conjunto no contexto das aplicações hipermídia. Na Figura 2.6, observa-se o método OO-H e os elementos que o compõem. Destaca-se que o resultado da aplicação do método é uma aplicação Web de três camadas (Seção 2.2.2).

\subsubsection{OOWS}

O OOWS (Object-Oriented Web Solution) (Fons et al., 2003), considerado uma evolução do OO-H (Seção 2.5.5), é outro método que estende o método orientado a objetos co- 


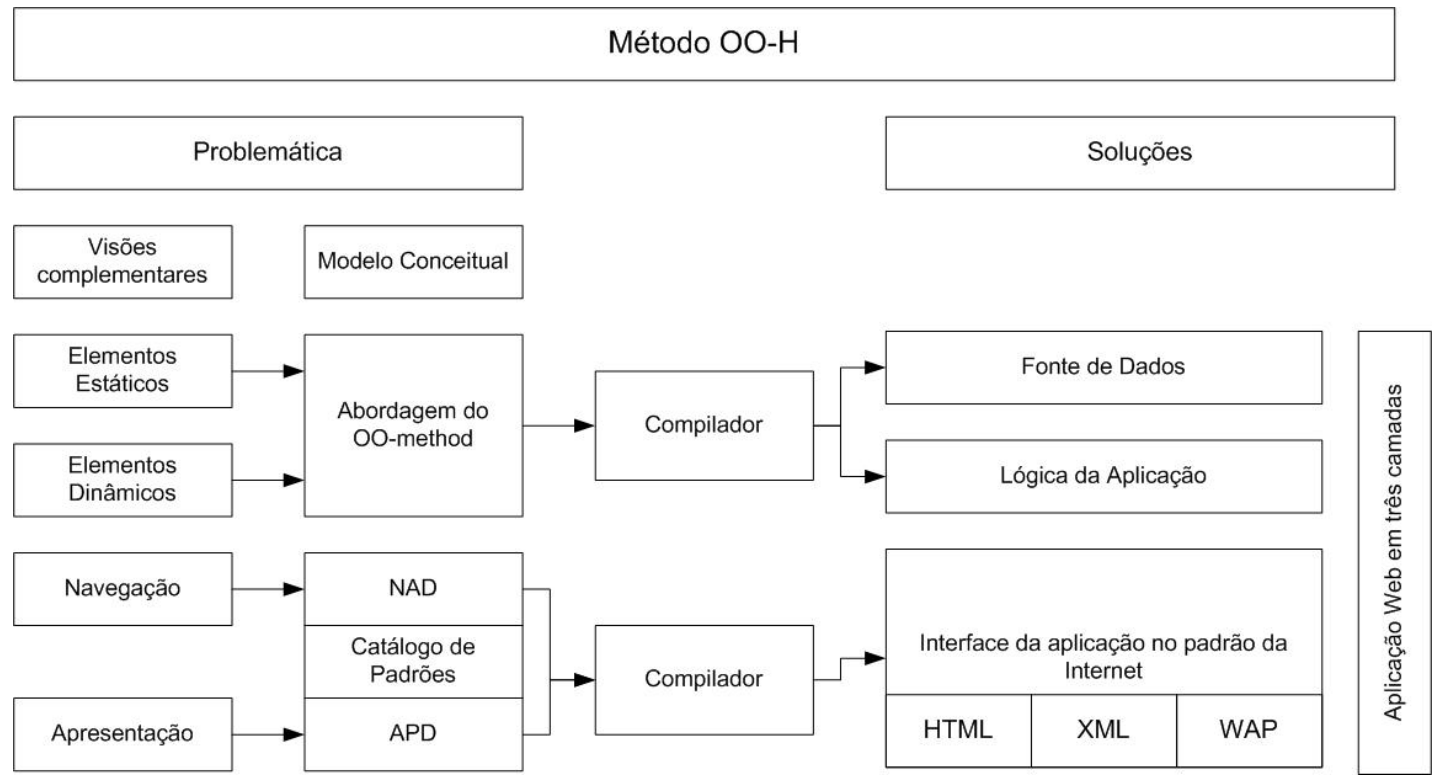

Figura 2.6: Uma visão geral do método OO-H (Gómez et al., 2001).

nhecido por OO-Method (Pastor et al., 1998) por meio da inclusão de mecanismos para captura de requisitos de navegação e apresentação da aplicação Web.

O método compreende duas etapas principais: especificação do sistema e desenvolvimento da solução. No primeiro, uma especificação completa dos requisitos do usuário é construída enquanto que na segunda uma estratégia orientada leva a geração de componentes que constituem a aplicação final (Figura 2.7).

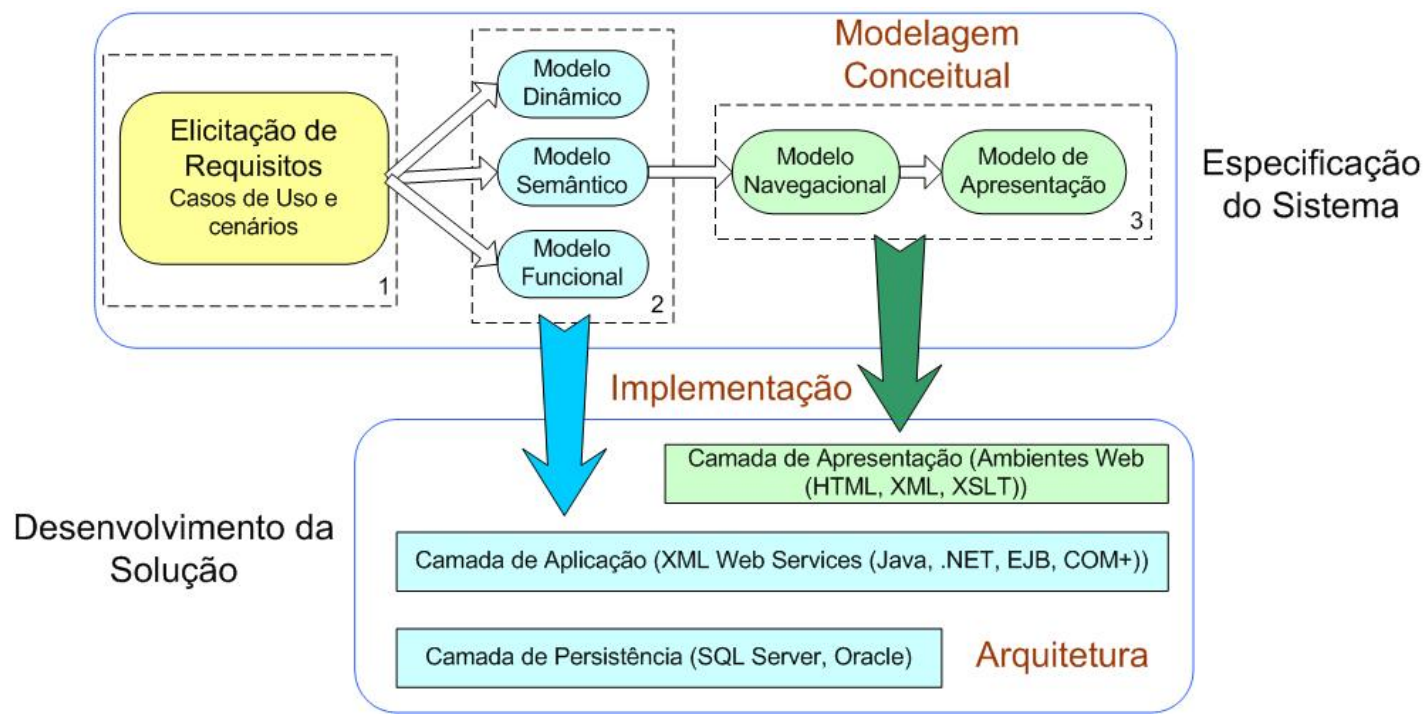

Figura 2.7: Abordagem do método OOWS (Fons et al., 2003)

Na especificação do sistema são construídos modelos para capturar apropriadamente os requisitos da aplicação Web. As técnicas utilizadas permitem especificar requisitos estruturas, funcionais e navegacionais e de apresentação. A modelagem é dividida em duas fases: 
- Elicitação de requisitos funcionais: técnicas baseadas um casos de uso e cenários são aplicadas para a construção de um esquema conceitual (Diagramas de classe, seqüência e de estado);

- Atividades de modelagem conceitual: Um conjunto de modelos permitem a captura e representação de requisitos a partir de três diferentes pontos de vista: (i) um modelo semântico que define a estrutura do sistema (suas classes, operações e atributos) e relacionamentos estruturas entre as classes (especialização, associação e agregação), enfim, um diagrama de classes; (ii) um modelo dinâmico que descreve as diferentes seqüências válidas da vida de um objeto para cada classe da aplicação usando diagramas de estado e, além disso, nesse modelo interações entre objetos são representados por um diagrama de seqüência; (iii) um modelo funcional que captura a semântica das mudanças de estado, usando especificação textual a partir de uma especificação OO formal.

Ainda na modelagem conceitual, existe o modelo navegacional que é construído para representar os requisitos de navegação, tomando por base os diagramas de classes e o modelo de apresentação, baseado no modelo anterior, que captura os requisitos de apresentação utilizando um conjunto pré-definido de padrões.

A etapa do desenvolvimento da solução define um guia para a passagem do espaço de problemas para o espaço das soluções. É formado por duas fases:

- Projeto Arquitetural: uma arquitetura multi-camadas é proposta levando-se em consideração a natureza das aplicações Web e a arquiteturas de seus componentes. As camadas que compõem a arquitetura são (i) a camada de apresentação que inclui os componentes da interface gráfica para a interação com o usuário; (ii) a camada de aplicação que define a lógica de negócios na forma de Web Services XML que implementam a estrutura e funcionalidades das classes do modelo conceitual; e (iii) a camada de persistência que implementa o acesso ao repositório de dados para as camadas anteriores.

- Implementação: Um conjunto de correspondências (regras de transformação) entre as abstrações conceituais e os elementos de software que implementam cada camada da arquitetura é definido, fazendo uso intensivo de padrões de projeto.

\subsubsection{WebML}

A WebML (Web Modelling Language) (Ceri et al., 2000b) é uma notação para especificação aplicações Web complexas em um nível conceitual. Utiliza uma descrição de alto nível de uma aplicação sob dimensões ortogonais distintas: seu conteúdo de informação (modelo estrutural); as páginas que compõe uma aplicação Web (modelo de composição); 
a topologia dos links entre as páginas (modelo navegacional); o formato e os requisitos gráficos para a apresentação (modelo de apresentação); e atributos de personalização, para entrega de conteúdo exclusivo a um determinado usuário (modelo de apresentação). A seguir uma breve descrição de cada dimensão:

1. Modelo Estrutural: representa o conteúdo de dados, a informação, de uma aplicação Web, em termos de entidades relevantes e seus relacionamentos. É compatível com notações clássicas como o modelo E/R, o modelo orientado a objetos da ODMG e diagramas de classe da UML;

2. Modelo Hipertexto: esse modelo descreve um ou mais hipertextos que podem compor uma aplicação Web. Cada hipertexto define um então chamado site view. Descrições de site views por sua vez compreendem dois sub-modelos:

- Modelo de composição: especifica quais páginas compõem o hipertexto, e qual a unidade de conteúdo que preencherá uma página. Existem 6 tipos possíveis de unidades de conteúdo: dados, múltiplos dados, índice, filtro, scroller e unidades diretas. As unidades de dados são usadas para publicar a informação de um único objeto (por exemplo, de um álbum musical); as outras unidades representam modos alternativos de navegação entre um conjunto de objetos (por exemplo, o conjunto das músicas de um álbum). As unidades de conteúdo estão definidas no topo do esquema estrutural de um site; o projetista descreve para cada entidade ou relacionamento a unidade na qual está baseado; e

- Modelo navegacional: expressa como as páginas e unidades de conteúdo estão ligadas (os links) para formar o hipertexto. Os links podem ser não-contextuais, quando conectam páginas semanticamente independentes (por exemplo, a página de um artista à página de uma gravadora), ou contextual, onde o conteúdo do destino de um link depende do conteúdo apresentado pela página em que se encontra (por exemplo, uma página que mostra os dados de um artista está ligada por um link contextual à uma página de reviews de um determinado artista).

3. Modelo de Apresentação: expressa a disposição e aparência gráfica das páginas, independentemente do dispositivo de exibição ou linguagem na qual foi elaborada, uma vez que descreve tal disposição utilizando uma linguagem XML abstrata. As especificações de apresentação podem ser tanto para uma página em específico quanto para páginas diversas;

4. Modelo de Personalização: usuários e grupos de usuários são explicitamente modelados dentro do esquema de estrutura, na forma de entidades predefinidas 
chamadas "User" e "Group". Os atributos dessas entidades podem ser utilizados para armazenar conteúdo individual ou de um grupo, como sugestões de compra, lista de favoritos e recursos para adaptação de gráficos.

Além do modelo de apresentação, os outros modelos da WebML também podem ser representados tanto pela notação gráfica quanto pela representação textual por meio de uma linguagem XML abstrata. Além disso, as especificações são independentes tanto para uma linguagem client-side (que é executada no cliente) quanto para uma linguagem server-side (que é executada no servidor).

\subsubsection{HMBS/M}

O método Hypertext Model Based on Statecharts/Method (HMBS/M) (Carvalho, 1998; Carvalho et al., 1999) é utilizado para o desenvolvimento estruturado de aplicações Web. Para tal, faz uso de primitivas do método Fusion (Coleman et al., 1994) para representar o domínio da aplicação e o modelo HMBS (Turine, 1998) para a modelagem navegacional por meio do uso de Statecharts.

O método HMBS/M é composto por quatro fases. A primeira fase é a modelagem conceitual que tem como objetivo analisar o domínio da aplicação e representá-lo em modelos que auxiliem na identificação de informações da aplicação. A próxima fase é a modelagem navegacional, onde são especificados os contextos de navegação, o modelo navegacional de tipos e o modelo navegacional de instâncias. Os contextos de navegação definem formas de se navegar pela aplicação. O modelo navegacional de tipos permite modelar os tipos de contextos definidos pelas estruturas de acesso. O modelo navegacional de instâncias modela as instâncias das classes e dos relacionamentos do modelo navegacional de tipos em termos de estados e transições. Nessa fase é que o modelo HMBS é utilizado para representar a semântica de navegação da aplicação. Em seguida tem-se a fase de modelagem da interface onde são definidas as características genéricas da interface, que não dependem do ambiente de programação. A aplicação hipermídia, propriamente dita, é resultado do mapeamento dos modelos navegacionais e de interface em objetos concretos em um determinado ambiente ou plataforma destino. E por fim, a última fase é a de implementação e teste, onde o objetivo é mapear os modelos navegacional e de interface em objetos concretos, cujo resultado é a aplicação hipermídia propriamente dita. Como apoio computacional para a modelagem navegacional de instâncias, o HMBS/M é apoiado pela ferramenta HySCharts (Turine et al., 1999).

Na Figura 2.8 observa-se que em cada fase do HMBS-M há produtos que são construídos, incrementados ou melhorados, favorecendo o desenvolvimento iterativo.

Procurando desenvolver uma ferramenta de apoio ao desenvolvimento de aplicações Web, Brito (2003) estendeu o método HBMS/M, criando o método HBMS/M Estendido e 


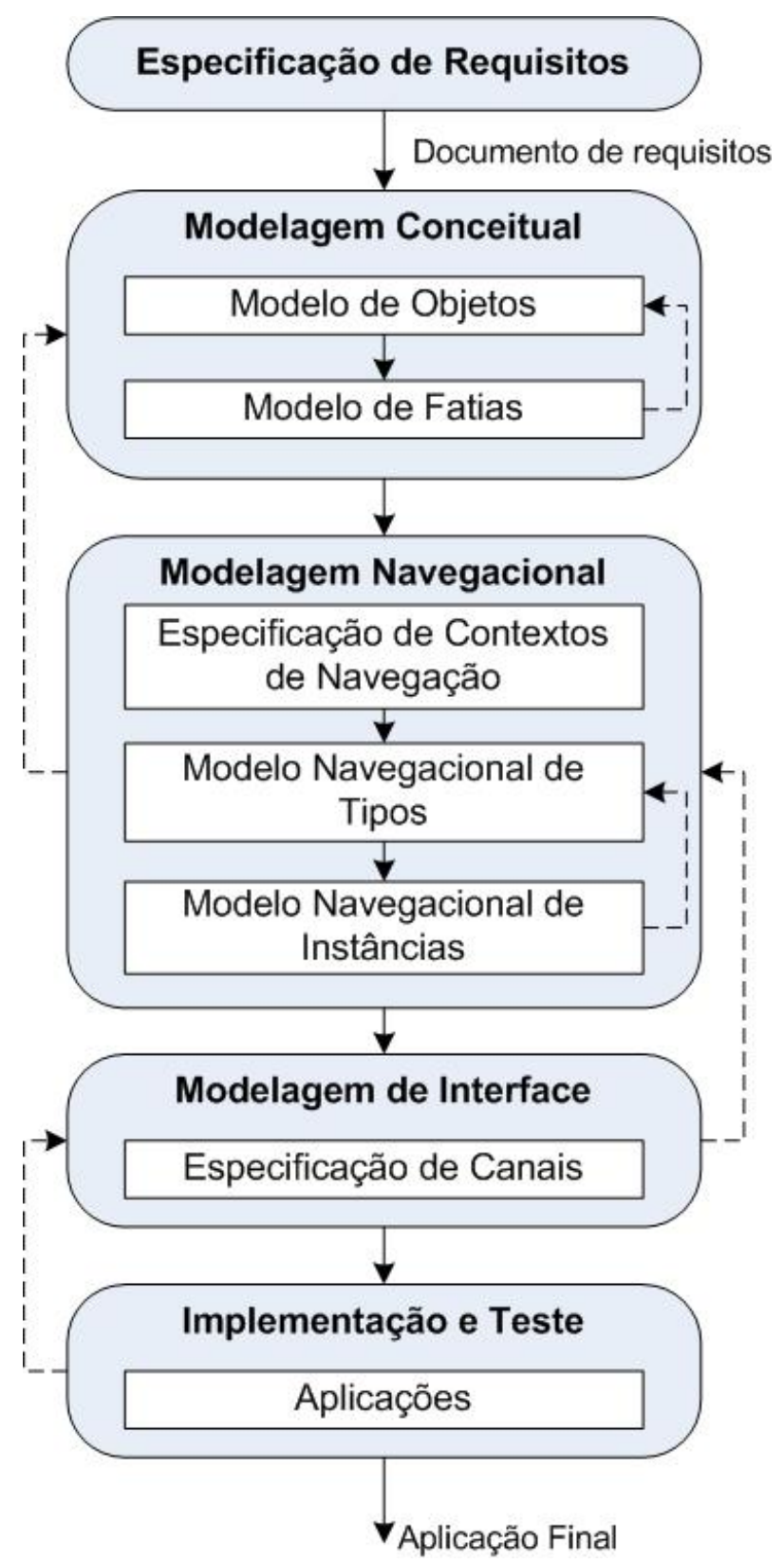

Figura 2.8: Fases do Método HMBS/M (Carvalho, 1998)

a ferramenta WebSCharts. Em sua versão estendida, o HMBS/M apresenta fases similares ao original. As alterações mais relevantes são o uso da linguagem UML ao invés do método Fusion na modelagem do domínio e a adoção de um novo modelo na etapa de modelagem navegacional, o modelo de composição onde é especificada a estrutura navegacional da aplicação Web com ênfase na inclusão dos elementos de navegação na página Web. Todos os contextos navegacionais definidos anteriormente são agregados nas páginas Web para projetar a versão final da aplicação. 


\subsubsection{W2000}

O método W2000 (Baresi et al., 2001a) baseia-se em dois componentes já existentes: a linguagem UML (Rumbaugh et al., 1998) e o HDM (Garzotto et al., 1993). A integração entre esses componentes, consiste na definição de estereótipos e adaptações de diagramas para modelagem HDM com UML, a especificação de diretrizes para uso da UML como uma maneira de especificar aspectos dinâmicos e operacionais das aplicações Web e refinamento de diagramas de caso de uso para descrever requisitos do usuário em alto nível, relacionando-os tanto com aspectos funcionais como aspectos navegacionais. Ressalta-se que no W2000 não é considerada a modelagem de interface, dado que se trata de uma tarefa por si só complexa.

O método organiza a atividade de modelagem em tarefas interdependentes, como pode ser visto na Figura 2.9. Cada atividade produz um modelo (conjunto de diagramas relacionados), que descreve alguns aspectos das aplicações Web. A primeira atividade é a análise de requisitos, que estende a análise de requisitos convencional para aplicações hipermídia. É formada por duas atividades: análise de requisitos funcional e navegacional. A primeira identifica as operações do sistema enquanto a segunda define as possibilidades de visão a acesso às informações para cada classe de atores. Nessa atividade são utilizados diagramas de caso de uso da UML para os requisitos funcionais e casos de uso estendidos para os requisitos navegacionais. O projeto de evolução de estados complementa a análise de requisitos e define como o conteúdo da aplicação desenvolve-se. Utiliza diagrama de estados da UML.

A próxima atividade é o projeto de hipermídia, que consiste no projeto de informação e projeto de navegação. Utilizando-se de mecanismos de extensão da UML, o autor do método criou estereótipos para projetar o modelo conhecido por hyperbase, que é dividido em projeto informacional e navegacional. No projeto informacional são utilizados estereótipos chamados entity types e semantic association types, representando entidades da aplicação e como elas são percebidas pelos usuários da mesma. No projeto navegacional essas mesmas entidades derivam novos componentes, apresentados também como estereótipos da UML, chamados navigational nodes e navigational links que modelam como a informação é navegada pelos usuários. Após essa fase, normalmente os modelos do projeto navegacional são convertidos em páginas que podem ser exibidas em um navegador. Além desses modelos, há ainda o access layer, que também divide-se em projeto informacional e navegacional. O projeto informacional do access layer tem por objetivo prover organizações alternativas do conteúdo da aplicação, para que o usuário compreenda melhor a estrutura do modelo de hyperbase, e o modelo do projeto navegacional consiste na definição de links navegacionais correspondentes às estruturas do projeto de informação. De maneira geral, ambos os modelos mencionados acima, o hyperbase e o access layer modelam a estrutura 
navegacional da aplicação, sendo em níveis de granularidades diferentes. O hyperbase em um nível de granularidade maior e o access layer em uma granularidade menor.

Em seguida encontra-se o projeto funcional que especifica as principais operações do usuário na aplicação, estendendo as especificações de funções padrão com aspectos de hipermídia. Utiliza diagrama de interação da UML (tanto o diagrama de seqüência como diagramas de colaboração). E por fim, no projeto de visibilidade são definidas as diferentes visões ou perspectivas da aplicação, sob o ponto de vista dos diferentes atores envolvidos. As visões têm como objetivo agrupar informações, operações, estruturas de acesso e navegação e determinar quais desses elementos devem estar disponíveis para quais atores.

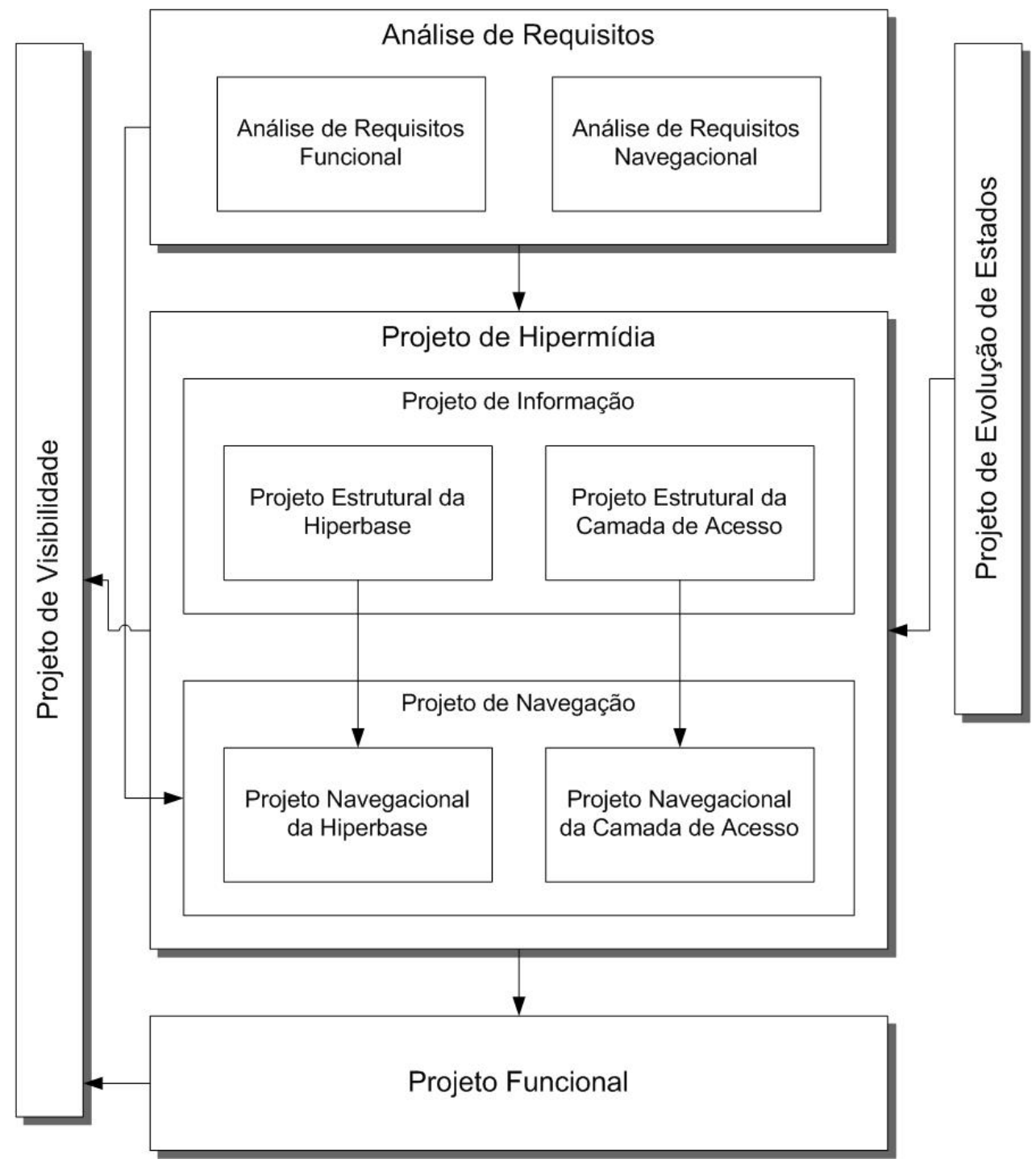

Figura 2.9: Estrutura do método W2000 (Baresi et al., 2001a). 


\subsubsection{WAE}

O Web Application Extension (WAE) (Conallen, 2002) é um conjunto de novos elementos que estendem a linguagem de modelagem UML, similar ao UWE (Seção 2.5.4). A extensão da linguagem ocorre pela elaboração de novos estereótipos para representar elementos de aplicações Web como diferentes tipos de nós (páginas), elementos de interface (formulários e framesets) e tipos de relacionamentos (links e submits ). Além de elaborar os mecanismos citados, Conallen (2002) também sugere um conjunto de atividades, baseadas na estrutura do Rational Unified Process (RUP) (Kruchten, 2000).

Segundo Conallen (2002), a construção de uma aplicação Web inicia-se com uma análise do problema, desenvolvimento de um modelo do domínio (por meio da notação UML), desenvolvimento de um documento de visão (escopo e proposta do projeto) e desenvolvimento do plano de projeto. No plano de projeto deve existir um plano de iteração, que descreve detalhadamente as atividades que são esperadas no decorrer do projeto, os artefatos que devem ser produzidos ao final de cada atividade e seus critérios de aprovação. Após o desenvolvimento desses produtos de trabalho, seguem as etapas para o desenvolvimento da arquitetura e projeto da aplicação, seguido de sua implementação e teste.

Para o desenvolvimento da arquitetura são utilizados os recursos disponíveis na UML como o diagrama de casos de uso, de classes, de atividade, de seqüência. Além desses, o autor elaborou um novo recurso: o modelo UX ((do inglês $\boldsymbol{U}$ ser e $\boldsymbol{X}$ perience)). No modelo UX é possível modelar o fluxo de informações da aplicação, por meio da determinação das principais rotas de navegação entre as páginas Web que compõem a aplicação, além de gerenciar e organizar a estrutura do conteúdo das páginas.

O modelo UX é composto por definições de telas, roteiros e mapas de navegação. A principal entidade a ser modelada é a tela. Uma tela é um elemento que é apresentado ao usuário e contém a infra-estrutura padrão da interface com o usuário, como menus e controles, assim como o conteúdo referente ao negócio propriamente modelado. Salienta-se que o conceito de tela não deve ser confundido com o conceito de páginas Web, que são os elementos que produzem as telas. A representação desse elemento no modelo UX é uma classe dada pelo estereótipo <<screen>>. Além da representação escrita há também a representação gráfica por meio de um ícone como mostrado na figura 2.10 .

Entre os elementos tela, há o fluxo de navegação que é a transição de uma tela à outra. Caminhos entre telas compõe cenários, que formam elementos arquitetônicos importantes em conjunto à análise de requisitos. No modelo UX tais caminhos são modelados por associações entre as classes estereotipadas e podem possuir nomes que ajudam a explicar a intenção do usuário ou a ação que resultou na navegação de uma tela para outra. Além do estereótipo <<screen>>, existem o estereótipo <<inputform>>, utilizado para representar 


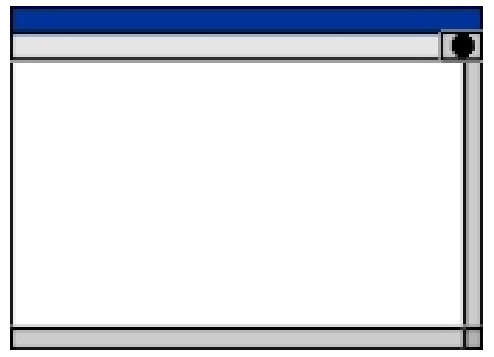

Figura 2.10: Representação em ícone de estereótipo criado no método WAE.

a tela de entrada de dados do usuário, e o estereótipo <<screencompartiment >>, utilizado para representar porções reutilizáveis de tela ou subtelas. Os roteiros do modelo UX mapeiam um cenário de um caso de uso utilizando-se das telas previamente definidas em conjunto com as associações e o mapa de navegação apresenta-se como um diagrama similar ao roteiro, porém simplificado, pois não inclui detalhes, por exemplo, como as propriedades das telas. O WAE ainda inclui estereótipos para o chamado modelo de projeto. Esse modelo consiste em projetar componentes que vão desde código executado pelo servidor até elementos internos à páginas.

Além dessas atividades, o método é composto por atividades de apoio como, por exemplo, a gerência de configuração, que gerencia as versões dos artefatos produzidos. Permite também um desenvolvimento iterativo ao propor revisões e melhorias no plano de iteração inicial, durante o ciclo de desenvolvimento.

\subsubsection{SWM}

O Simple Web Method ou SWM (pronuncia-se "swim") (Griffiths et al., 2002) é um método de desenvolvimento similar aos mencionados anteriormente, porém foca sua estrutura baseando-se em dois argumentos. O primeiro é o interesse dos autores em métodos voltados para o ensino, que sejam mais simples em relação aos métodos existentes, por exemplo, aos citados em seções anteriores. O outro argumento está relacionado ao conceito de simplicidade. Sendo simples, um método pode ser útil tanto para estudantes quanto para qualquer interessado. Além disso, é de interesse da indústria uma vez que pode facilitar e estimular o uso de métodos por desenvolvedores Web novatos.

Observando outros métodos existentes os autores do SWM optaram por utilizar as melhores práticas desses métodos, integrando-as de acordo com suas próprias experiências. O resultado dessa integração é um método composto por cinco estágios: Planejamento, Análise, Projeto, Implementação e Manutenção.

A fase de Planejamento preocupa-se com o planejamento do projeto. As tarefas do projeto e suas interdependências são identificadas, a duração das tarefas é estimada e recursos alocados. É elaborado um diagrama de rede ou de Gantt com o caminho crítico identificado. 
A fase Análise define os stakeholders, tanto primários quanto secundários, produzindo cenários de uso considerando a acessibilidade. Também analisa o conteúdo em termos genéricos, identificando o conteúdo requisitado, o que é disponibilizado (e em qual formato) e quem deverá prover o conteúdo. Restrições são analisadas, como o uso de determinados pacotes de software, nível técnico de desenvolvedores e questões de copyright. O mercado também é analisado, procurando encontrar dados a respeito de produto semelhantes e, por fim, uma declaração de proposta é redigida.

A fase de projeto define a arquitetura Web a ser utilizada por meio de um diagrama de navegação. Define também um estilo visual, inicialmente como um conjunto de esboços mostrando possíveis combinações de cores, planos de fundo, fontes, ícones, gráficos, etc. A metáfora de interface é definida, por exemplo, livro, hierarquia ou jogo. O estilo de navegação é projetado, considerando questões como se haverá uma barra de navegação ou será pelo contexto. As páginas da aplicação são projetadas como um conjunto de storyboards.

A fase de Implementação continuação o processo, estabelecendo estruturas de diretório, convenções de nome de arquivos e método para controle de versão. O conteúdo então é preparado, como textos, gráficos e vídeos. A aplicação então é construída, testada, avaliada, lançada e, por fim, inicia-se a fase de Manutenção.

\subsubsection{ECO}

O método ECO (Ecosystem of Agile Software Development) (Figueiredo, 2005) é um método ágil (Fowler, 2000) especializado em atender as características das aplicações Web. Assim como qualquer método ágil o ECO foca seu processo na velocidade de entrega de resultados ao invés da robustez do produto.

É composto por três atividades (Figura 2.11). A atividade de Aquisição tem como principal objetivo a formalização de um contrato. No ECO existem dois modelos de contrato: (i) por Escopo, em que se define o objetivo do projeto, suas funcionalidades e estima-se o esforço necessário para criar o escopo definido; (ii) por Esforço/Alocação onde não há definição clara de um escopo, apenas um determinado volume de horas alocadas por período. Essa atividade encerra-se com a formalização do contrato. Uma vez fechado o contrato, inicia-se a atividade de Entrega, cujo objetivo é a entrega da Aplicação Web definida e contratada na atividade anterior. É nessa atividade que se concentra o foco dos métodos ágeis e os Ciclos de Desenvolvimento. Após o término do período estipulado no contrato estabelecido como resultado da atividade de Aquisição, executa-se a atividade de Encerramento. Esta atividade tem dois objetivos primordiais, quais sejam: a consolidação do conhecimento adquirido com o projeto e a finalização formal do mesmo. 


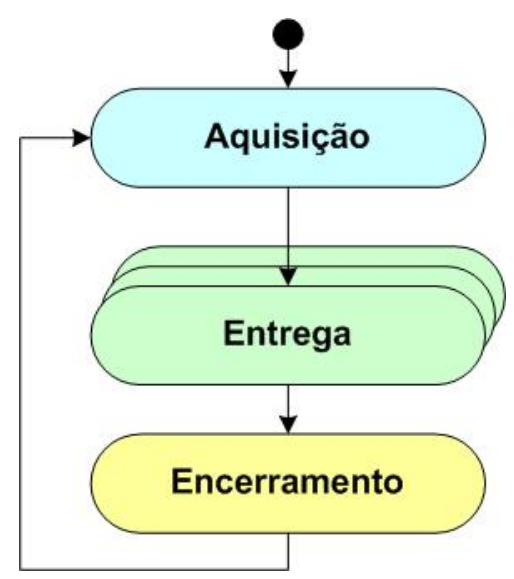

Figura 2.11: Atividades do método ECO (Figueiredo, 2005)

Para a atividade de Entrega, o ECO não especifica alguma técnica para a construção de produtos de trabalho, principalmente a modelagem de domínio. Destaca duas técnicas: a utilização de padrões de projeto (Design Patterns) (Fowler, 2003) e a DNC (Domain-Neutral-Component) (Coad et al., 1999), uma técnica que utiliza cores e a linguagem UML.

\subsection{Análise, comparação e avaliação de métodos de de- senvolvimento Web com base na literatura}

A análise e comparação entre métodos de desenvolvimento, seja de aplicações Web ou aplicações convencionais, não é uma atividade trivial. O propósito dos métodos de desenvolvimento pode ser relativamente diferente. Há métodos que abordam muitos aspectos de um processo de desenvolvimento, como por exemplo, o ciclo de vida de um software, além de modelagem conceitual de seu domínio, enquanto que outros apenas procuram modelar o domínio.

Desse modo, nas próximas seções serão apresentados estudos comparativos encontrados na literatura e propostas de mecanismos de avaliação para métodos de desenvolvimento hipermídia e de desenvolvimento de aplicações em geral.

\subsubsection{Comparação entre atributos gerais}

A comparação entre os atributos gerais de um método de desenvolvimento é resultado do estudo de Domingues (2005) que por sua vez estendeu os estudos de Koch (2000) e Lee et al. (1998). Esse estudo consistiu na observação dos seguintes atributos em cada método: etapas utilizadas no uso do método, técnica de modelagem necessária, representações gráficas utilizadas, notação dos modelos e existência de ferramenta de apoio. No Capítulo 
3, a tabela que sintetiza esse estudo é apresentada, acrescida de métodos estudados durante a realização deste trabalho, não presentes no estudo original.

\subsubsection{Comparação entre etapas de desenvolvimento}

A comparação entre as etapas de desenvolvimento também é um estudo de Domingues (2005), que baseou-se por sua vez no estudo de Koch (2000). Nesse estudo, são consideradas etapas do processo de desenvolvimento proposto por Pressman (2005) (Seção 2.4), além disso, foi também considerada a subdivisão da etapa de projeto em três partes: projeto arquitetural, projeto navegacional e projeto de interface. E ainda a etapa de geração e teste de páginas foi separada, formando as etapas de geração de páginas e teste de páginas. Foram então utilizadas as seguintes etapas: formulação, planejamento, análise, projeto (arquitetural, navegacional e de interface), geração, teste e avaliação. No Capítulo 3, é apresentada a tabela que resume esse estudo acrescida de métodos estudados durante a realização deste trabalho, não utilizados na comparação original.

\subsubsection{Comparação entre aspectos de informação e funcional}

Como mencionado na Seção 2.5, Gu et al. (2002) realizaram uma comparação entre métodos de desenvolvimento Web, tomando por base aspectos de informação e funcional. Dentro de cada um desses aspectos foram relacionadas características que podem ser adotadas pelos método existentes ou por novos métodos. As características da arquitetura funcional de uma aplicação Web impõem requisitos aos métodos utilizados, relacionados a uma determinada funcionalidade. Como exemplo, cita-se a habilidade para modelar a integração e conectividade a sub-sistemas e regras de negócio de uma organização; ou a habilidade em representar conceitos de modo independente a alguma tecnologia. As características da arquitetura da informação investigam aspectos de como o conteúdo é gerenciado, estruturado e disponibilizado; modos de visão da informação e questões de apresentação; navegação. Exemplificando essas características, citam-se a habilidade em modelar o comportamento e estrutura navegacional, ou a habilidade para modelar a interação do usuário com a informação apresentada. Para interagir as características dos aspectos funcionais com as características de aspectos da informação, são necessárias características gerais. Entre elas, pode-se citar a habilidade de modelar conceitos do domínio de negócios ou a habilidade de manter a integridade do sistema. Além do apoio que um método deve oferecer sob ambos os aspectos citados, um outro ponto crítico considerado é a capacidade de interligar a informação e a funcionalidade de modo consistente e coeso.

Em relação aos aspectos de informação, as seguintes características devem estar evidentes em um método:

- modelar conceitos do nível de apresentação; 
- modelar o comportamento e a estrutura navegacional;

- modelar a interação do usuário com a informação;

- modelar grupos de usuários e seus papéis; e

- modelar o conteúdo.

Do ponto de vista dos aspectos funcionais, são relacionadas as seguintes características:

- modelar a conectividade e a integração;

- apoiar a modelagem com padrões;

- representar os conceitos em uma tecnologia independente; e

- modelar funcionalidades complexas da aplicação.

Após a relação de características que devem estar presentes nos métodos, são listadas características que devem estar presentes, de modo a interligar os aspectos de informação e funcional:

- modelar conceitos do domínio de negócio;

- ligar o modelo de negócio com a arquitetura técnica;

- ligar informação com funcionalidade;

- manter a integridade do sistema;

- apoiar o entendimento e a comunicação;

- ser um processo independente; e

- apoiar o gerenciamento do ciclo de vida da aplicação.

Durante a comparação realizada, Gu et al. (2002) relacionaram limitações encontradas nos métodos, frente aos aspectos utilizados na comparação. As limitações encontradas foram:

- Falta de habilidade em modelar funcionalidades sofisticadas: para métodos fundamentados em abordagens hipermídia o foco tem sido na organização, apresentação e navegação. Regras de negócio como transações de missão crítica são freqüentemente negligenciadas. Para abordagens baseadas em métodos orientados a objeto, é observada uma falta de apreciação em funcionalidades específicas de aplicações Web. Normalmente tais métodos modelam aplicações de maneira similar a aplicações convencionais de software, ou simplesmente definem algumas extensões no nível de implementação; 
- Desconexão entre os aspectos funcionais e de informação: A maioria dos métodos possui abordagens baseadas na hipermídia, e geralmente possuem estruturas ricas e sofisticadas que apóiam a arquitetura de informação, em particular a modelagem da navegação ou apresentação, porém, oferecem capacidades limitadas para facilitar o projeto funcional das aplicações. Essa diferença no nível de detalhamento entre as capacidades funcionais e de informação dificulta a integração desses dois aspectos fundamentais das aplicações Web;

- Desconexão entre os modelos de negócio e a arquitetura técnica: a desconexão entre os modelos de negócio e arquitetura técnica ocorre, pois muitos métodos facilitam o projeto e implementação dos de aplicações, enquanto requisitos de engenharia e modelos de negócio não são abordados. Outros fatores que mantém essa limitação são as características únicas das aplicações Web (Seção 2.2.1), incluindo a incerteza do negócio e a velocidade na mudança dos requisitos de usuário, pois não existem métodos que capturem efetivamente essas características;

- Possível uso indevido de mecanismos de extensão da UML: Alguns métodos como a abordagem de Koch (2000) e Conallen (2002) são extensões de notações UML existentes. Independente de possuírem ou não as habilidades desejadas, mencionadas anteriormente, esses métodos tendem a demonstrar questões relacionadas à extensão de linguagens de modelagem, como o uso incorreto de estereótipos ( $\mathrm{Gu}$ et al., 2002) apud (Henderson-Sellers, 2002); e

- Inabilidade para apoiar o gerenciamento do ciclo de vida da aplicação: Em resposta a natureza dinâmica das aplicações Web e a ênfase na manutenção das mesmas, os métodos de desenvolvimento precisam fornecer capacidade para apoiar o gerenciamento do ciclo de vida da aplicação, incluindo documentação de todos os seus produtos de trabalho. Muitos dos métodos concentram-se em prover notações para as fases de projeto e implementação, enquanto a engenharia de requisitos e manutenção são abordadas em poucos detalhes.

Nesse trabalho de Gu et al. (2002), notou-se que as características citadas tanto para os aspectos de informação quanto para os aspectos funcionais não apresentaram características específicas em relação a notação dos métodos e aspectos técnicos. Além disso, as descrições de cada uma delas nem sempre são claras e objetivas, exigindo maior esforço para compreensão do estudo realizado pelos autores. Notou-se também que não há menção alguma de como cada característica pode ser identificada durante a avaliação de um método de desenvolvimento. Por fim, no Capítulo 3, na Figura 3.1, há a síntese do estudo de $\mathrm{Gu}$ et al. (2002) com a adição de métodos não utilizados originalmente na época em que o estudo foi conduzido. 


\subsubsection{Avaliação de métodos para aplicações hipermídia}

Nota-se que atualmente os esforços em pesquisas relacionados à Engenharia Web estão voltados para a definição de processos que consigam modelar todos os aspectos das aplicações Web. Em relação à avaliação de métodos de desenvolvimento de aplicações Web, pode-se citar o trabalho já descrito anteriormente de Gu et al. (2002) na comparação entre métodos de desenvolvimento a partir de aspectos funcionais e de informação 2.6.3.

Nessa linha, há também o trabalho de Christodoulou et al. (1998) que realizou uma comparação entre métodos para o desenvolvimento de aplicações hipermídia, por meio da elaboração de um conjunto de critérios, criados a partir da necessidade de usuários. Os critérios elaborados estão categorizados para avaliação dos métodos, avaliação do ambiente de desenvolvimento e avaliação do sistema. As duas primeiras categorias incluem critérios quantificáveis. A primeira categoria, de avaliação de métodos, inclui critérios baseados em fases encontradas na maioria dos métodos, como por exemplo, o projeto conceitual, o projeto de navegação abstrata, projeto de interface e implementação. Exemplos de critérios dessa categoria são: capacidade de modelagem de limites estruturais, capacidade de evolução do projeto, habilidade de reúso, adição de atributos aos elos de ligação(links), capacidade de especificar tipos semânticos aos links, existência de visões globais e locais do sistema, existência de estruturas de acesso, existência de mecanismo para conversão de objetos navegacionais em objetos de interface, entre outros. Na categoria de avaliação do ambiente são analisados atributos exigidos para o ambiente de desenvolvimento, como distribuição, capacidade de extensão e recuperação de informação. Exemplos de critérios nessa categoria são: possibilidade de integração de ferramentas externas no ambiente, capacidade de importação de dados a partir de base de dados, existência de mecanismos de recuperação de informação, apoio do ambiente à realização de teste de qualidade, existência de controle de versões e de colaboração interativa, existência de manuais e de tutoriais, entre outros. Por fim, na categoria de avaliação do sistema, exemplos de critérios elaborados são: qual a abordagem do método, tipos de aplicações hipermídia suportadas, plataformas suportadas, entre outros.

Em todos os critérios existentes no trabalho de Christodoulou et al. (1998), é notória a ênfase dada aos critérios de hipermídia, similares aos aspectos de informação de Gu et al. (2002), e portanto seria interessante o acréscimo de critérios voltados a aspectos funcionais. Finalmente, a comparação realizada por Christodoulou et al. (1998) utilizou um estudo de caso (Wohlin et al., 2000) para atingir seus objetivos. O estudo de caso envolveu 3 tipos de aplicações, onde para cada aplicação foram indicados requisitos específicos e esses foram confrontados aos critérios previamente estabelecidos dos métodos avaliados. 


\subsubsection{Arcabouço para linguagens visuais de modelagem}

Seguindo a proposta de mecanismos de avaliação, há também o trabalho de Bobkowska (2005) que é a criação de um arcabouço para avaliação de linguagens visuais de modelagem. Sua proposta é oferecer uma estrutura universal composta por oito áreas principais. Essas área procuram cobrir aspectos essenciais da descrição da metodologia e assegurar flexibilidade para futuros avanços no arcabouço.

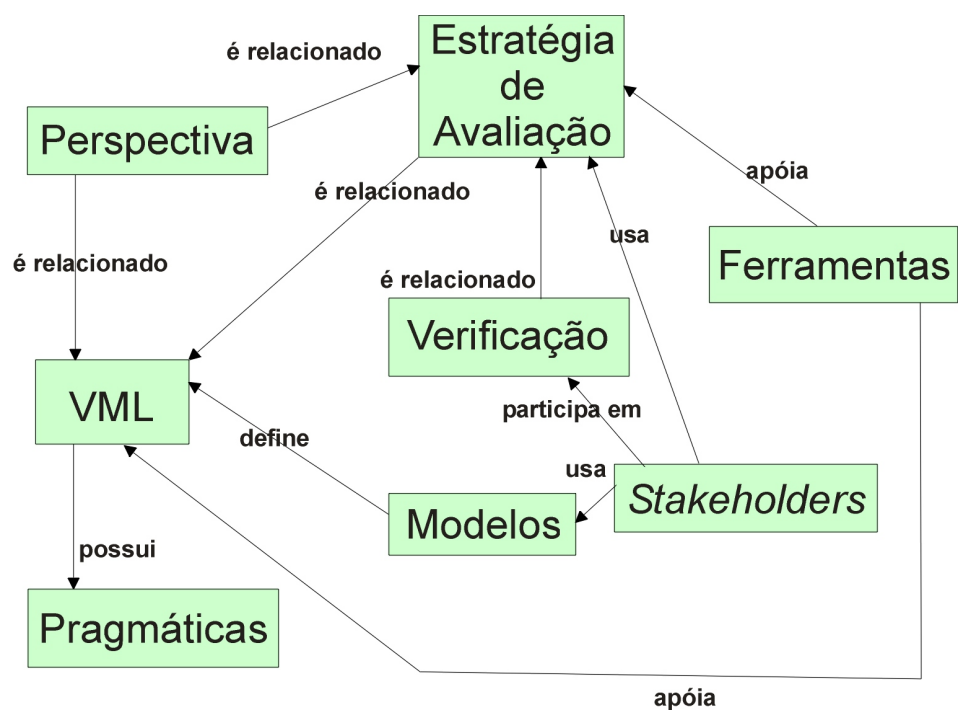

Figura 2.12: Estrutura do arcabouço para avaliação de linguagens de modelagem visuais com as oito áreas que o compõem.

Na Figura 2.12 as oito áreas são apresentadas e os relacionamentos entre elas. Uma estratégia de avaliação representa um questionário, um procedimento, um projeto de estudo empírico, um método de análise ou até um estudo ontológico, por exemplo. Uma VML (linguagem visual de modelagem) é uma classe de linguagens como a UML, utilizadas para a especificação, visualização, construção e documentação de artefatos de sistemas de software. Modelos são representações de sistemas reais ou projetados, que são construídos com o uso de uma VML para uma dada proposta e descrevem um sistema em um determinado nível de abstração. Pragmatismos descrevem o contexto de uso uma VML em conjunto com estratégias implicítas e expectativas concentradas na modelagem. O contexto padrão de uso de uma VML, por exemplo, é a criação de modelos. Ferramentas são aplicativos que apóiam a modelagem, executando avaliações e transformações automáticas, por exemplo, de modelos para código-fonte e vice-versa. Uma perspectiva pode estar relacionada a uma estratégia de avaliação de uma VML ou uma própria VML. Na relação com a estratégia de avaliação, significa perspectiva de uma avaliação, por exemplo, expressividade de certos aspectos ou maneira cognitiva. Já na relação com as VML, significa a perspectiva de compreensão da VML, como comunicação, linguistica ou processamento de informação visual. O conceito de stakeholders considera todos os envolvidos com a 
avaliação de VML e apóia a pesquisa em gerência de conhecimento. Os envolvidos podem ser os projetistas ou comitês de padrões que podem procurar por estratégias de avaliação de VML enquanto executam seu próprio projeto de VML, modificação ou melhoria. Há também os pesquisadores, que desenvolvem novas linguagens de modelagem e fazem sua verificação e ou perfis de usuários como desenvolvedores, estudantes, professores e representantes de clientes que lêem documentação de software. Por fim, há a área de verificação que é um importante componente, segundo o autor, pois o arcabouço deve possuir um sólido background e prover evidências de como sabemos o que pensamos saber. Em geral, inclui teorias, hipóteses, evidências baseadas no conhecimento e em outras disciplinas, bem como em estudos empíricos e análises de estudos relacionados.

Ressalta-se ainda os trabalhos em desenvolvimento do grupo de Engenharia de Software do ICMC-USP/São Carlos (LabES), na área de Engenharia Web, como por exemplo trabalho de Domingues (2005), que tem como objetivo geral definir critérios e estratégias de teste para aplicações Web. Outro trabalho do grupo é o de Costa (2005), mencionado anteriormente, que tem como objetivo contribuir para a utlização do conhecimento relacionado ao teste de aplicações Web por meio de um Portal de Conhecimento, com uma estrutura bem definida e um conjunto de funcionalidades que permitem a agregação, evolução e disseminação do conhecimento associado a critérios, estratégias e ferramentas de teste para aplicações Web.

\subsection{Considerações Finais}

Neste capítulo foram apresentadas a classificação, a arquitetura e as características das aplicações Web. Como visto, a classificação de aplicações Web pode ser abrangente, porém no contexto deste trabalho, e de acordo com as classificações apresentadas, as aplicações Web consideradas serão aquelas que apóiam transação de negócios.

Além das características e arquitetura das aplicações Web, neste capítulo também foi apresentada a definição de Engenharia Web e propostas de processos de desenvolvimento. Mostrou também que na literatura podem ser encontrados diversos métodos de desenvolvimento, o que torna difícil a escolha por um desenvolvedor. Muitos desses estendem métodos tradicionais da Engenharia de Software, adicionando novas perspectivas e abordagens, oriundas da área de hipermídia ou oriundas da área de gerenciamento de projetos. Todas procuram agregar fases ou estágios que, de algum modo, descrevam os atributos específicos das aplicações Web. Além disso, foram mostrados exemplos de estudos comparativos entre os métodos, procurando mostrar como os métodos existentes satisfazem atributos das aplicações Web.

Salienta-se que especificamente para os métodos de desenvolvimento de aplicações Web, os mecanismos de avaliação estudados podem ser evoluídos sob certos aspectos. 
No caso do trabalho de Gu et al. (2002), apesar das características e dos critérios levantados, há a ausência de características que reflitam aspectos técnicos, como recursos de notação do método, não há menção de como tais características são identificadas em cada método e em algumas características, suas descrições não são exatas e demandam estudo aprofundado sobre como identificá-las em um método. No caso dos trabalhos de Bobkowska (2005) e Christodoulou et al. (1998), ambos trazem características tanto pertinentes a recursos técnicos de métodos quanto características pertinentes a processos de desenvolvimento, porém não tratam especificamente de aplicações Web, não levando em consideração características próprias desse tipo de aplicação, por exemplo multiplicidade do perfil de usuários e ambiente de execução imprevisível, entre outras (Seção 2.2.3). Em todos os trabalhos citados, também verifica-se que nenhum deles considera o domínio de aplicação Web que utilizará o método de desenvolvimento. Não considerar o domínio da aplicação Web que será desenvolvida pode fazer, por exemplo, que um método provido de recursos para integração da lógica de negócios à camada de aplicação, seja utilizado em uma aplicaçao de pequeno porte, sem acesso a base de dados, e não necessitará de todos os recursos presente no método.

No próximo capítulo é apresentado o arcabouço de avaliação proposto e as etapas realizadas para sua concepção, como o uso de estudos comparativos apresentados neste capítulo, o estudo de caso realizado com o Portal de Conhecimento, levantamento das características e, após sua definição, um exemplo de uso do arcabouço. 



플

\section{Arcabouço para a avaliação de métodos}

\subsection{Considerações Iniciais}

A procura por um método que possa suprir as necessidades do projetista ou desenvolvedor é uma tarefa que exige observação e análise entre diversos métodos existentes, tanto na literatura quanto na indústria. A observação e análise exigem prévio conhecimento sobre a disciplinas correlacionadas como análise e projeto de software, conhecimento obtido por meio da prática na utilização dos métodos disponíveis.

Neste capítulo é apresentado o arcabouço de avaliação proposto para métodos de desenvolvimento de aplicações Web. O arcabouço é composto por um conjunto de características, associado a um sistema de valores e pesos. Esse sistema permite a projetistas ou demais interessados direcionarem a avaliação de métodos de acordo com o domínio da aplicação que pretende-se desenvolver. Para a elaboração do arcabouço de avaliação proposto, inicialmente, estudos comparativos anteriores foram utilizados, por intermédio da inclusão de novos métodos não presentes originalmente em tais estudos. Além disso, para maior compreensão dos métodos e do domínio avaliado, um estudo prático foi realizado, que compreendeu a análise de requisitos e modelagem de um Portal de Conhecimento Web. Após essas etapas, as pricipais características encontradas foram relacionadas e categorizadas em características de notação e características de modelos de engenharia. Para exemplificação do uso do arcabouço de avaliação, valores e pesos foram atribuídos ao conjunto de características, baseado no estudo prático realizado. 


\subsection{Etapas de elaboração do arcabouço de avaliação}

\subsubsection{Estudos comparativos}

A etapa inicial da elaboração do arcabouço proposto neste trabalho foi o levantamento, estudo e observação desses métodos. Essa etapa deu-se pelo uso de estudos comparativos encontrados na literatura, apresentadas no capítulo anterior (Seção 2.6). Nesses estudos, foram adicionados os métodos OOWS(Fons et al., 2003), SWM(Griffiths et al., 2002) e ECO(Figueiredo, 2005) não avaliados na comparação original. A atualização dos estudos comparativos apresentados nas seções seguintes foram publicados pelo grupo de Engenharia de Software do ICMC/USP (Labes)(Domingues et al., 2007).

\subsubsection{Comparação entre atributos gerais}

O primeiro estudo foi a comparação entre atributos gerais apresentada na Seção 2.6.1, representada pela Tabela 3.1. Nessa tabela, estão sintetizados os atributos dos métodos. Para melhor compreensão, na quarta coluna da tabela estão numerados as representações gráficas e na quinta coluna a mesma numeração é utilizada para relacionar qual notação é utilizada para cada representação.

Tabela 3.1: Comparação entre Métodos de Desenvolvimento: Atributos Gerais (Domingues et al., 2007)

\begin{tabular}{|c|c|c|c|c|c|}
\hline Método & Processo & Técnica & $\begin{array}{c}\text { Representação } \\
\text { Gráfica }\end{array}$ & Notação & Ferramenta \\
\hline HDM & $\begin{array}{l}\text { 1. Esquema HDM } \\
\text { 2. Instanciação do } \\
\text { esquema HDM } \\
\text { 3. Definição da } \\
\text { semântica de navega- } \\
\text { ção }\end{array}$ & E-R & $\begin{array}{l}\text { 1. Diagrama E-R } \\
\text { 2. Diagrama E-R } \\
\text { 3. Diagrama E-R }\end{array}$ & $\begin{array}{l}\text { 1. E-R } \\
\text { 2. E-R } \\
\text { 3. E-R }\end{array}$ & \\
\hline
\end{tabular}


CAPÍTULO 3. ARCABOUÇO PARA A AVALIAÇÃO DE MÉTODOS

Tabela 3.1: Comparação entre Métodos de Desenvolvimento: Atributos Gerais

\begin{tabular}{|c|c|c|c|c|c|}
\hline Método & Processo & Técnica & $\begin{array}{c}\text { Representação } \\
\text { Gráfica }\end{array}$ & Notação & Ferramenta \\
\hline RMM & $\begin{array}{l}\text { 1. Projeto E-R } \\
\text { 2. Projeto de fatias } \\
\text { 3. Projeto navegacio- } \\
\text { nal } \\
\text { 4. Projeto de } \\
\text { interface com o usuá- } \\
\text { rio } \\
\text { 5. Projeto de } \\
\text { protocolos de conver- } \\
\text { são } \\
\text { 6. Projeto de } \\
\text { comportamento em } \\
\text { tempo real } \\
\text { 7. Construção e teste }\end{array}$ & E-R & $\begin{array}{l}\text { 1. Diagrama E-R } \\
\text { 2. Diagrama de fatias } \\
\text { 3. Diagrama RMDM }\end{array}$ & $\begin{array}{l}\text { 1. E-R } \\
\text { 2. própria } \\
\text { 3. própria }\end{array}$ & \\
\hline OOHDM & $\begin{array}{l}\text { 1. Projeto conceitual } \\
\text { 2. Projeto navegacio- } \\
\text { nal } \\
\text { 3. Projeto de } \\
\text { interface abstrata } \\
\text { 4. Implementação }\end{array}$ & $\mathrm{OO}$ & $\begin{array}{l}\text { 1. Diagrama de clas- } \\
\text { ses } \\
\text { 2. Classes navegacio- } \\
\text { nais } \\
\text { e esquema navegacio- } \\
\text { nal } \\
\text { 3. ADVs e ADV- } \\
\text { Charts }\end{array}$ & $\begin{array}{l}\text { 1. UML } \\
\text { 2. própria } \\
\text { 3. própria }\end{array}$ & $\begin{array}{l}\text { OOHDM- } \\
\text { Web }\end{array}$ \\
\hline HMBS & $\begin{array}{l}\text { 1. Modelagem } \\
\text { conceitual } \\
\text { 2. Modelagem } \\
\text { navegacional } \\
\text { 3. Modelagem de } \\
\text { interface } \\
\text { 4. Implementação e } \\
\text { teste }\end{array}$ & $\begin{array}{c}\mathrm{OO} \text { e } \\
\text { estados }\end{array}$ & $\begin{array}{l}\text { 1. Modelo de objetos } \\
\text { e modelo de fatias } \\
\text { 2. Contextos de } \\
\text { navegação; } \\
\text { modelo navegacional } \\
\text { de } \\
\text { tipos; e de instâncias } \\
\text { 3. Canais de } \\
\text { apresentação }\end{array}$ & $\begin{array}{l}\text { 1. Fusion } \\
\text { 2. State- } \\
\text { charts } \\
\text { 3. própria }\end{array}$ & $\begin{array}{c}\text { HySCharts } \\
\text { e WebS- } \\
\text { charts } \\
\text { (HMBS/M } \\
\text { Estendido) }\end{array}$ \\
\hline W2000 & $\begin{array}{l}\text { 1. Análise de requisi- } \\
\text { tos } \\
\text { 2. Projeto de } \\
\text { evolução de estados } \\
\text { 3. Projeto de hipermí- } \\
\text { dia } \\
\text { 4. Projeto funcional } \\
\text { 5. Projeto de } \\
\text { visibilidade }\end{array}$ & E-R e $\mathrm{OO}$ & $\begin{array}{l}\text { 1. Casos de uso } \\
\text { 2. Casos de } \\
\text { uso estendido } \\
\text { 3. Esquemas e } \\
\text { diagrama de classes } \\
\text { 4. Cenários e } \\
\text { diagramas de intera- } \\
\text { ção } \\
\text { 5. Visões do sistema }\end{array}$ & $\begin{array}{l}\text { 1. UML } \\
\text { 2. UML } \\
\text { 3. HDM; e } \\
\mathrm{UML} \\
\text { 4. UML } \\
\text { 5. própria }\end{array}$ & \\
\hline
\end{tabular}


CAPÍTULO 3. ARCABOUÇO PARA A AVALIAÇÃO DE MÉTODOS

Tabela 3.1: Comparação entre Métodos de Desenvolvimento: Atributos Gerais

\begin{tabular}{|c|c|c|c|c|c|}
\hline Método & Processo & Técnica & $\begin{array}{c}\text { Representação } \\
\text { Gráfica }\end{array}$ & Notação & Ferramenta \\
\hline UWE & $\begin{array}{l}\text { 1. Análise de requisi- } \\
\text { tos } \\
\text { 2. Modelagem } \\
\text { conceitual } \\
\text { 3. Modelagem } \\
\text { navegacional } \\
\text { 4. Modelagem de } \\
\text { apresentação }\end{array}$ & $\mathrm{OO}$ & $\begin{array}{l}\text { 1. Casos de uso } \\
\text { 2. Modelo de classes } \\
\text { 3. Modelo navegacio- } \\
\text { nal de espaço; e de es- } \\
\text { trutura } \\
\text { 4. Diagrama de clas- } \\
\text { ses }\end{array}$ & $\begin{array}{l}\text { 1. UML } \\
\text { 2. UML } \\
\text { 3. própria } \\
\text { 4. própria }\end{array}$ & ArgoUWE \\
\hline WebML & $\begin{array}{l}\text { 1. Modelagem estru- } \\
\text { tural } \\
\text { 2. Modelagem de } \\
\text { hipertexto } \\
\text { 3. Modelagem de } \\
\text { apresentação } \\
\text { 4. Modelagem de } \\
\text { personalização }\end{array}$ & E-R & $\begin{array}{l}\text { 1. Organização } \\
\text { conceitual dos dados; } \\
\text { e } \\
\text { diagrama de classes } \\
\text { 2. Modelo de } \\
\text { composição; e } \\
\text { de navegação } \\
\text { 3. Modelo navegacio- } \\
\text { nal de espaço; e de es- } \\
\text { trutura } \\
\text { 4. Modelo de } \\
\text { entidade pré-definida }\end{array}$ & $\begin{array}{l}\text { 1. E-R; } \\
\text { 2. própria } \\
\text { 3. própria } \\
\text { 4. própria }\end{array}$ & WebRatio \\
\hline WAE & $\begin{array}{l}\text { 1. Gerenciamento de } \\
\text { projeto } \\
\text { 2. Obtenção de } \\
\text { requisitos } \\
\text { 3. Análise } \\
\text { 4. Projeto } \\
\text { 5. Implementação } \\
\text { 6. Teste } \\
\text { 7. Implantação }\end{array}$ & $\mathrm{OO}$ & $\begin{array}{l}\text { 1. Plano de projeto; } \\
\text { de iteração; e } \\
\text { de gerenciamento de } \\
\text { alteração } \\
\text { 2. Documento de de- } \\
\text { claração de visão; } \\
\text { casos de uso e modelo } \\
\text { UX } \\
\text { 3. Modelo conceitual; } \\
\text { diagramas de seqüên- } \\
\text { cia; } \\
\text { de estado; e modelo } \\
\text { UX } \\
4 . \\
\text { classe; Diagramas de } \\
\text { de sequiência; } \\
\text { de estado e modelo } \\
\text { UX }\end{array}$ & $\begin{array}{l}\text { 1. própria } \\
\text { 2. própria; e } \\
\text { UML } \\
\text { 3. UML } \\
\text { 4. UML }\end{array}$ & \\
\hline
\end{tabular}


Tabela 3.1: Comparação entre Métodos de Desenvolvimento: Atributos Gerais

\begin{tabular}{|c|c|c|c|c|c|}
\hline Método & Processo & Técnica & $\begin{array}{c}\text { Representação } \\
\text { Gráfica }\end{array}$ & Notação & Ferramenta \\
\hline OO-H & $\begin{array}{l}\text { 1. Modelagem Con- } \\
\text { ceitual } \\
\text { 2. Projeto de } \\
\text { Navegação } \\
\text { 3. Projeto de Inter- } \\
\text { face }\end{array}$ & $\mathrm{OO}$ & $\begin{array}{l}\text { 1. Diagrama de Clas- } \\
\text { ses } \\
\text { 2. Diagrama de } \\
\text { Acesso Navegacional } \\
\text { 3. Diagrama Abstrato } \\
\text { de Apresentação }\end{array}$ & $\begin{array}{l}\text { 1. UML } \\
\text { 2. própria } \\
\text { 3. própria }\end{array}$ & Oliva NOVA \\
\hline OOWS & $\begin{array}{l}\text { 1. Modelagem Con- } \\
\text { ceitual } \\
\text { 2. Desenvolvimento } \\
\text { da Solução }\end{array}$ & $\mathrm{OO}$ & $\begin{array}{l}\text { 1. Diagrama de Caso } \\
\text { de Uso } \\
\text { Cenários } \\
\text { 2. Diagrama de Clas- } \\
\text { ses } \\
\text { 3. Diagrama de Es- } \\
\text { tado } \\
\text { Diagrama de Seqüên- } \\
\text { cia } 4 \text {. Diagrama Na- } \\
\text { vagacional (Navigatio- } \\
\text { nal Map) }\end{array}$ & $\begin{array}{l}\text { 1. UML } \\
\text { 2. UML } \\
\text { 3. UML } \\
\text { 4. UML }\end{array}$ & Oliva NOVA \\
\hline SWM & $\begin{array}{l}\text { 1. Planejamento } \\
\text { 2. Análise } \\
\text { 3. Projeto } \\
\text { 4. Implementação } 5 . \\
\text { Manutenção }\end{array}$ & DFD & $\begin{array}{l}\text { 1. Especificação de } \\
\text { projeto conceitual } \\
\text { 2. Especificação de } \\
\text { projeto do site }\end{array}$ & $\begin{array}{l}\text { 1. DFD } \\
\text { 2. DFD }\end{array}$ & ASCENT \\
\hline $\mathrm{ECO}$ & $\begin{array}{l}\text { 1. Aquisição } \\
\text { 2. Entrega } \\
\text { 3. Encerramento }\end{array}$ & $\mathrm{OO}$ & $\begin{array}{l}\text { 1. Mapa de Navega- } \\
\text { ção } \\
\text { 2. Modelos de Grade } \\
\text { 3. Diagrama de Com- } \\
\text { ponentes } \\
\text { 4. Modelo de Domínio }\end{array}$ & $\begin{array}{l}\text { 1. própria } \\
\text { 2. UML } \\
\text { 3. UML } \\
\text { 4. UML } \\
\text { /Domain } \\
\text { Neutral } \\
\text { Component }\end{array}$ & \\
\hline
\end{tabular}

Observou-se que, de um modo geral, os métodos abrangem fases similares, como análise inicial de seu domínio, seguido de projeto na estrutura e navegação da aplicação e por fim elaboração de interface da aplicação e sua construção e teste. Notou-se que esse fato é conseqüência da herança de métodos tradicionais de desenvolvimento de software, já utilizados e testados tanto em meios acadêmicos como meios industriais. Os métodos adicionados nesse estudo não apresentaram atributos com diferenças significativas em relação aos métodos avaliados anteriormente. Salienta-se que o método SWM (Griffiths et al., 2002) faz uso da técnica DFD, já utilizada para a construção de sistemas hoje 
considerados legados e apresenta no atributo processo etapas genéricas de desenvolvimento (Planejamento, Análise, Projeto, Implementação e Manutenção). Tanto o uso da técnica e etapas mencionadas, refletem a premissa do autor desse método de construir um método simples que pode ser utilizado para fins de ensino.

\subsubsection{Comparação entre etapas de desenvolvimento}

Outro estudo de comparação utilizado foi a comparação entre etapas de desenvolvimento (Seção 2.6.2), aqui representado na Tabela 3.2.

Tabela 3.2: Comparação entre Métodos de Desenvolvimento: Etapas de Processo (Domingues et al., 2007)

\begin{tabular}{|c|c|c|c|c|c|c|c|c|c|}
\hline & \multirow{2}{*}{$\begin{array}{c}\text { Formu- } \\
\text { lação }\end{array}$} & \multirow{2}{*}{ Plan. } & \multirow{2}{*}{ Análise } & \multicolumn{3}{|c|}{ Projeto } & \multirow{2}{*}{ Geração } & \multirow{2}{*}{ Teste } & \multirow{2}{*}{$\begin{array}{l}\text { Ava- } \\
\text { liação }\end{array}$} \\
\hline & & & & Arquit. & Naveg. & Interf. & & & \\
\hline HDM & & & & $\checkmark$ & $\checkmark$ & & & & \\
\hline RMM & & & & $\checkmark$ & $\checkmark$ & $\checkmark$ & $\checkmark$ & & \\
\hline OOHDM & & & & $\checkmark$ & $\checkmark$ & $\checkmark$ & $\checkmark$ & & \\
\hline HMBS & & & & $\checkmark$ & $\checkmark$ & $\checkmark$ & $\checkmark$ & $\checkmark$ & \\
\hline W2000 & & & $\checkmark$ & $\checkmark$ & $\checkmark$ & $\checkmark$ & & & \\
\hline UWE & & & $\checkmark$ & $\checkmark$ & $\checkmark$ & $\checkmark$ & & & \\
\hline WebML & & & & $\checkmark$ & $\checkmark$ & $\checkmark$ & $\checkmark$ & & \\
\hline WAE & & $\checkmark$ & $\checkmark$ & $\checkmark$ & $\checkmark$ & $\checkmark$ & $\checkmark$ & $\checkmark$ & \\
\hline $\mathrm{OO}-\mathrm{H}$ & & & $\checkmark$ & $\checkmark$ & $\checkmark$ & $\checkmark$ & $\checkmark$ & & \\
\hline OOWS & & & $\checkmark$ & $\checkmark$ & $\checkmark$ & $\checkmark$ & $\checkmark$ & & \\
\hline SWM & $\checkmark$ & $\checkmark$ & $\checkmark$ & $\checkmark$ & $\checkmark$ & $\checkmark$ & $\checkmark$ & $\checkmark$ & \\
\hline $\mathrm{ECO}$ & & $\checkmark$ & $\checkmark$ & $\checkmark$ & $\checkmark$ & $\checkmark$ & $\checkmark$ & & \\
\hline
\end{tabular}

Nessa comparação, Domingues et al. (2007) destacaram que a comparação direta sob as etapas de desenvolvimento pode omitir aspectos importantes, uma vez que o foco de um método em uma determinada atividade é maior do que em outra. Esse fato também pôde ser notado após o acréscimo de métodos não avaliados na ocasião da comparação original. Por exemplo, há métodos que somente propõem um conjunto de diretrizes de maneira textual, enquanto que outros provêem até ferramentas de apoio ao desenvolvimento de determinada etapa. A principal crítica em relação às etapas dos métodos de desenvolvimento de aplicações é a ausência ou foco mínimo na atividade de verificação, validação e teste da engenharia de software. Fato demonstrado pela revisão sistemática de Conte et al. (2005), onde não há relato de utilização de atividades de VV\&T nos métodos de desenvolvimento.

\subsubsection{Comparação entre entre aspectos de informação e funcionais}

Outro trabalho comparativo utilizado foi a comparação entre aspectos de informação e funcionais de $\mathrm{Gu}$ et al. (2002), apresentado na Figura 3.1. Nessa figura, observa-se que há uma área de interesse, sombreada, que indica que um método apropriado para o 
desenvolvimento de aplicações Web deve estar situado nessa área, com elevado apoio tanto aos aspectos de informação quanto aos aspectos funcionais. Além disso, em (Domingues et al., 2007) o estudo de $\mathrm{Gu}$ et al. (2002) foi atualizado, por meio da adição do método WAE(2002) (Conallen, 2002) que incorpora o modelo UX (Seção 2.5.10) ao contrário de sua edição anterior WAE (1999)(Conallen, 1999).

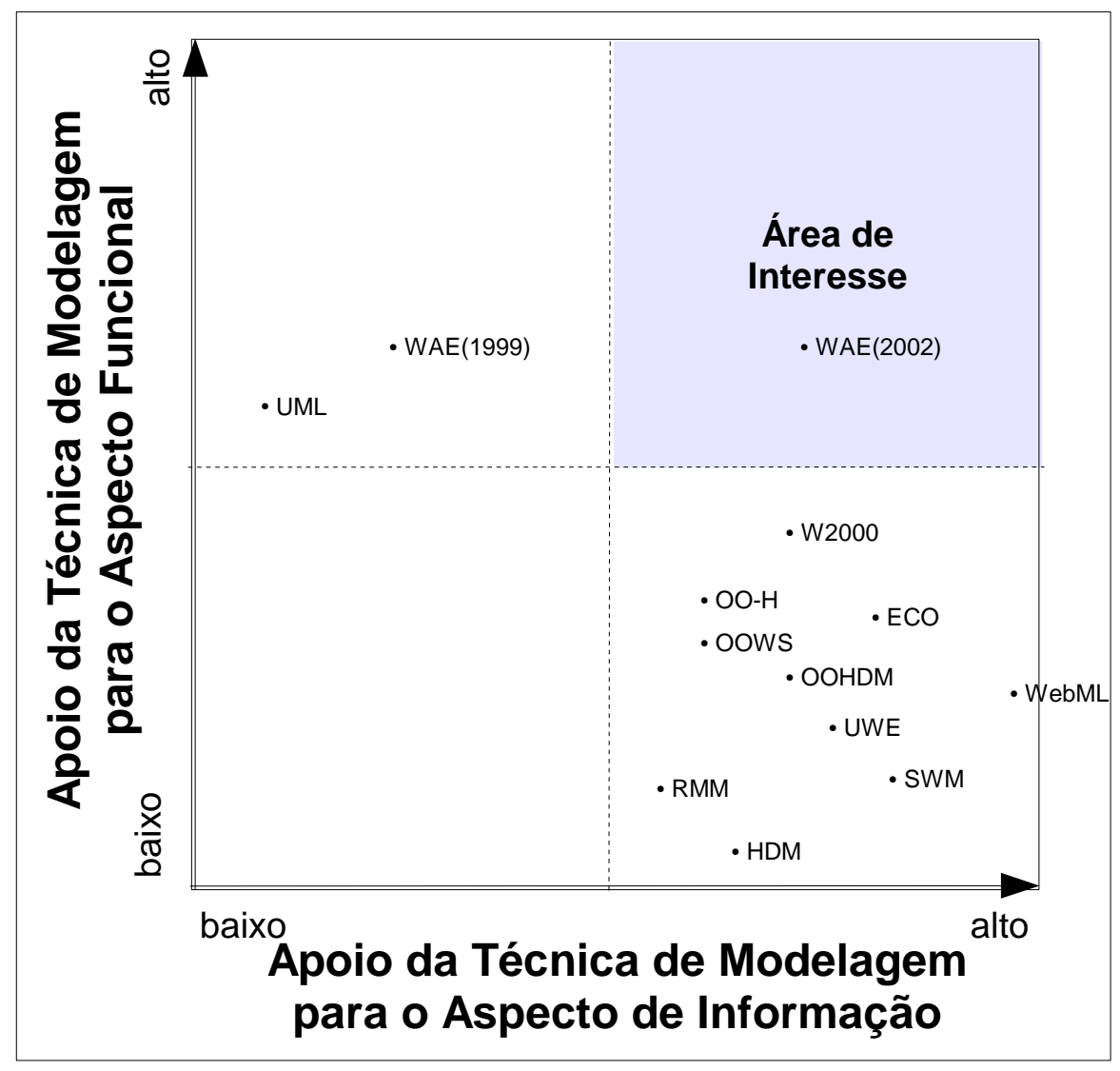

Figura 3.1: Comparação entre Métodos de Desenvolvimento: Aspectos de Informação e Funcional (Domingues et al., 2007)

Como já mencionado na Seção 2.7, as características apresentadas no trabalho de Gu et al. (2002), apesar de abrangentes, apresentam descrições geralmente confusas e não são suficientes para a completa identificação de cada característica no método. Desse modo, para a atualização desse estudo com novos métodos (OOWS, SWM e ECO), foi necessário a compreensão dos métodos avaliados originalmente e como obtiveram sua classificação. Ou seja, a partir do resultado final apresentado por Gu et al. (2002), foi necessário confrontar os critérios avaliados de cada método com as descrições fornecidas, para então compreender o processo de avaliação utilizado pelos autores. Uma vez compreendido o processo de avaliação, os métodos OOWS, SWM e ECO foram adicionados à avaliação, e seu posicionamento em relação aos outros métodos, também pode ser observado na Figura 3.1 . 


\subsubsection{Estudo prático}

Para melhor conhecimento e prática dos métodos avaliados, foi realizado um estudo prático. Esse estudo consistiu na modelagem de uma mesma aplicação utilizando métodos diferentes, o que permitiu observar as dificuldades encontradas e características não percebidas desses métodos em estudos anteriores (Seção 3.2.1). Foi utilizado o mesmo documento de requisitos para todos os métodos (Apêndice A.1). Desse modo foi possível explorar de maneira mais completa e comparativa os recursos disponíveis em cada método. Algumas dessas observações reforçam as mencionadas em estudos anteriores (Capítulo 2).

A aplicação escolhida foi o Portal de Conhecimento de Ferramentas, Estratégias, Técnicas e Critérios de Teste de Aplicações Web, desenvolvida no escopo do mestrado de Costa (2005). Portais de Conhecimento são aplicações Web, consideradas como uma infra-estrutura, que por meio de um único ponto de acesso integra usuários, aplicações e serviços. Possibilitam também gerência, compartilhamento e utilização de informação como textos, páginas Web, vídeos, imagens e som. Para tal tarefa é necessário que esses portais forneçam seus serviços de forma segura e personalizável, de modo que facilite a visualização de informação relevante a diferentes perfis de usuários. Desse modo, um portal deve trabalhar com recursos técnicos como manipulação de arquivos, integração com ferramentas externas, lógica de negócio apurada e uso de multimídia para interfaces ricas.

O Portal de Conhecimento supracitado tem como principal finalidade fornecer à comunidade acadêmica e à indústria conhecimento obtido sobre testes de aplicações Web, como ferramentas, técnicas e critérios de teste que possam auxiliar a execução das atividades nessa área. O portal deve permitir a interação de usuários de modo que esses possam incluir informações a respeito de ferramentas, técnicas e critérios de teste de aplicações web e realizar consultas sobre o conteúdo existente no portal, além de permitir a inclusão de comentários sobre os dados incluidos a fim de abrir diálogo e comunicação entre usuários. O ambiente do portal é constituído por quatro módulos: módulo de conhecimento, módulo de colaboração, módulo de comunicação e módulo de consulta. O módulo de conhecimento refere-se a informações que o usuário cadastra sobre processos de teste. No módulo de colaboração, usuários inserem dados associados aos processos existentes na base de dados. Esses dados inseridos são denominados de Material de Apoio, e comumente contém informações sobre o uso de ferramentas, manuais de procedimentos, pacotes de laboratório sobre estudos experimentais, etc. O módulo de comunicação permite interação entre os usuários do portal e por fim o módulo de consulta permita a execução de buscas sobre o conhecimento armazenado de acordo com chaves de buscas.

Além da descrição das funcionalidades e módulos do Portal de Conhecimento, há também um conjunto de papéis para usuários, que possuem diferentes níveis de permissão e acesso. Esses papéis são: 
- Visitante: usuário que acessa o portal para obter informações sobre o conteúdo existente, e eventualmente pode solicitar permissão para acessar módulos internos ao Portal;

- Usuário Cadastrado: usuário que já possui permissão para acesso aos módulo de colaboração e de comunicação, pode ver as informações existentes e comunicar-se com os demais usuários do Portal;

- Especialista: usuário que possui permissão para acesso aos módulos de conhecimento, colaboração e comunicação, e portanto, além da permissões atribuídas ao usuário cadastrado, pode incluir as informações sobre ontologias de processos de teste; e

- Administrador: usuário que possui permissão para acesso ao módulo de administração do Portal.

Os métodos escolhidos para o estudo prático foram: WAE, WebML, W2000 e OO-H. Esses métodos foram escolhidos a partir do posicionamento dos mesmos na Figura 3.1. O WAE foi selecionado por aparecer na área de interesse sombreada. Os métodos W2000 e OO-H foram selecionados por estarem mais próximos da área de interesse e o WebML foi selecionado por estar no extremo mais alto do eixo dos critérios de informação. Além disso, todos esses métodos também possuem material detalhado disponível na literatura com exemplos de uso. O método OOWS poderia ter sido escolhido ao invés do OO-H, pois além de serem parecidos, possuem uma origem em comum, mas não o foi pois o material encontrado para o método OO-H, à época do estudo prático, era mais completo do que o do OOWS.

Em geral, esses métodos fazem uso da UML para a criação dos modelos de requisitos e apresentam recursos similares para a modelagem conceitual da solução do problema, representados por diagramas de classes, com exceção do WebML, uma vez que usa modelo entidade-relacionamento. Dessa maneira foi possível utilizar um mesmo modelo criado na análise em todos os métodos (os modelos de análise estão no Apêndice A.2). Os recursos para a navegação da aplicação são os que apresentam diferentes soluções para essa característica. Isso pôde ser observado na Tabela 3.1, onde é possível verificar que a maioria dos métodos em suas representações de modelos de navegação utilizam em alguns casos diagramas de classes estereotipados, em outros, notações próprias. Os modelos criados nesse estudo prático estão apresentados no Apêndice B. Nas próximas seções, apresenta-se uma descrição do comportamento de cada método durante sua utilização no estudo prático. 


\subsubsection{WAE}

O método WAE possui uma fase de análise longa, pois utiliza além dos casos de uso, diagramas de atividade que complementam a análise, procurando compreender o fluxo pelo qual os possíveis uso da aplicação são realizados.

Apesar do modelo UX possuir um diagrama estendido dos diagramas de classes convencionais, tal diagrama é desconexo com qualquer diagrama de classes que represente o domínio do sistema, ou seja, não há a representação ou instância de alguma classe do diagramas de classes. Isso acontece pois o diagrama do modelo UX representa exclusivamente as páginas pelas quais o usuário pode navegar e elementos inerentes a ela, como divisão de blocos da tela, formulário, campos de entrada e outro elementos presentes em uma página Web. Por esse modelo, é claro perceber a visão do autor em oferecer um modelo destinado a uma equipe especializada na construção de página Web composta por Web designers e profissionais com experiência em hipermídia. Para aplicações onde o projetista ou uma equipe de projetistas trabalham em todas as fases da elaboração de uma aplicação, é necessário que para a construção do modelo UX esses profissionais possuam já uma visão da aplicação em termos das páginas que a compõe, afim de que construa corretamente o modelo. Um ponto controverso a essa observação, é que o mesmo profissional que construa o modelo o UX e detenha conhecimento em hipermídia e áreas afins, conheça a própria estrutura de um diagrama de classes, pois uma vez que o diagrama existente nesse modelo estende um diagrama de classes, esse diagrama estendido contém toda a semântica e recursos que existem no original. Complementando as descrições de tela existentes no diagrama estendido de classes, é necessário para o modelo UX que sejam construídos os roteiros guiados que auxiliam a compreensão das definições das telas e o fluxo de informação da aplicação.

\subsubsection{WebML}

O uso do método WebML foi facilitado pela ferramenta WebRatio, facilmente encontrada na Web, e em sua última versão. Reutilizando análise realizada em métodos anteriores, a partir de um diagrama de classes do domínio da aplicação, foi construído um diagrama E/R, com recursos da própria ferramenta WebRatio. Essa tarefa consistiu na conversão das classes e relacionamentos e cardinalidades dos elementos para a notação do diagrama $\mathrm{E} / \mathrm{R}$.

A tarefa seguinte foi a construção do modelo de navegação da WebML. A construção desse modelo utilizando-se papel e lápis é uma tarefa complicada, comparando-se com os outros métodos, uma vez que possui símbolos rebuscados, com muitos detalhes. Com essa característica, a ferramenta WebRatio facilitou o trabalho de desenho desses símbolos agilizando o processo de modelagem. Porém, mesmo com um conjunto de símbolos mais 
complexos, a notação empregada pelo método abordou itens como operações entre páginas e formulários, como por exemplo, submissão de dados por um formulário com posterior processamento desses via uma operação de inserção em banco de dados. Na figura 3.2, pode-se observar um fragmento do modelo de navegação da WebML, com ícones que representam formulário (Form_MatApoio), operações de edição (Alterar_MaterialApoio) e de remoção (Excluir_MatApoio) e por uma unidade de dados (Material de Apoio), que representa um instância de uma classe do modelo conceitual.
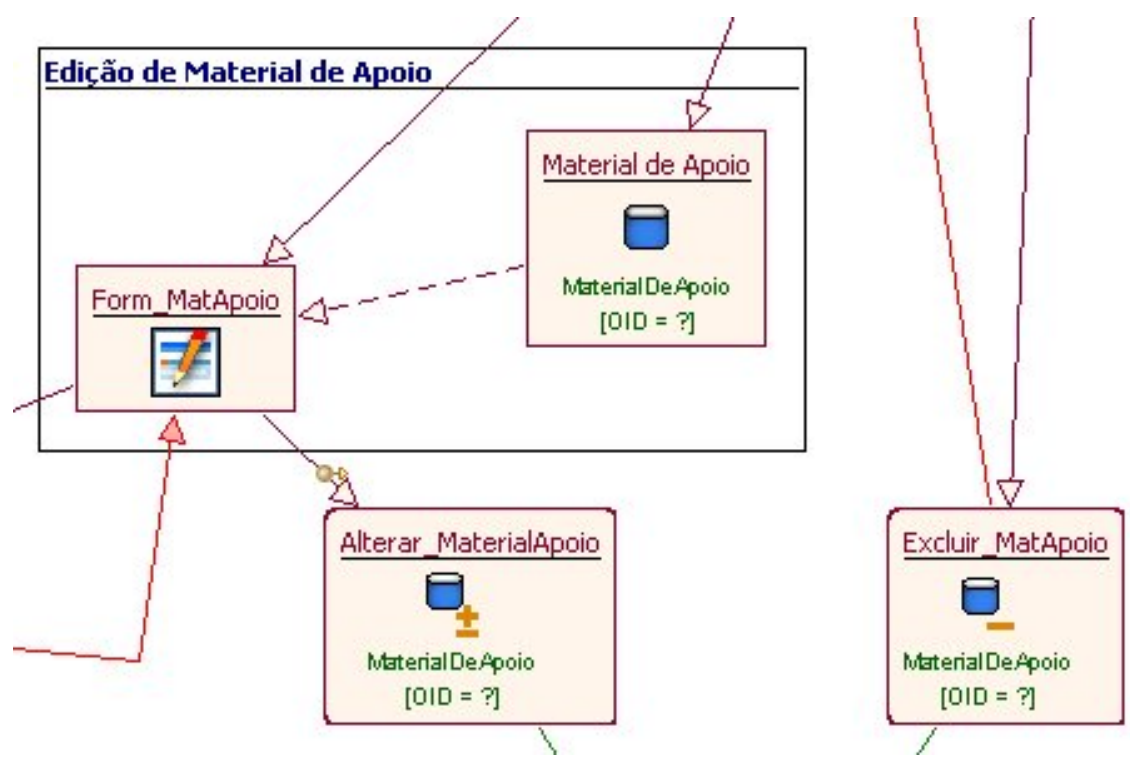

Figura 3.2: Fragmento do modelo de navegação da WebML.

\subsubsection{W2000}

O método W2000, assim como o método WAE utiliza a extensibilidade da linguagem UML para reproduzir conceitos de outro método, o HDM, como visto na Seção 2.5.9. A fase de análise de requisitos nesse método apresenta uma modificação em relação a outros métodos. Nessa etapa foi necessário a criação de um novo conjunto de diagramas de casos de uso, que refletissem os possíveis caminhos que um usuário pode navegar. Um diferencial no uso desse método em relação aos outros métodos é a modelagem do domínio do aplicação, que ocorreu diretamente no modelo hyperbase. Em linhas gerais, após o uso do método, percebeu-se que o modelo hyperbase, é um diagrama de classes estilizado para os conceitos do HDM. Por exemplo, é simples verificar a paridade de uma classe (UML) com um entidade (HDM). Ressalta-se que o prévio conhecimento do método HDM (Seção 2.5.1) facilitaria o aprendizado do W2000. 


\subsubsection{OO-H}

Assim como os métodos WAE e W2000, o método OO-H também utiliza para a modelagem de domínio, diagramas de classes. Logo, a mesma análise realizada e o diagrama de classes gerado a partir dela foram utilizados. A etapa seguinte consistiu na criação no modelo que representa a navegação da aplicação. Esse modelo sugere desde o início de sua construção a utilização de uma abordagem top-down para seu desenvolvimento. Há um diagrama inicial NAD, que apresenta de maneira geral todas as opções e caminhos que o usuário pode seguir ao entrar na aplicação. Seria o ponto de partida, uma abstração para um menu de opções. A partir desse diagrama inicial, cada possível caminho de navegação ou opção de menu gera novos diagramas, sendo mais detalhados, contendo inclusive elementos extraídos do diagrama de classes, como objetos criados a partir das classes modeladas.

Na construção do modelo de navegação, elementos comuns que compõem páginas de aplicações Web como formulários, botões e elementos de interface, são especificados pelo diagrama APD, que tem por função detalhar os NAD. Além disso, um detalhe que difere esses métodos dos demais é o tratamento dado pelo autor aos links, ao fornecer diferentes tipos com semântica diferente. Por exemplo, há links que indicam serviços (operações realizadas por uma classe que manipula dados) e há links que indicam a resposta oriunda de algum processamento ou outro ponto da aplicação.

\subsubsection{Arcabouço de avaliação: Características e sistema de pesos e valores}

As caraterísticas a seguir foram adaptadas e estendidas a partir dos trabalhos de Bobkowska (2005); Gu et al. (2002); Rumbaugh (1996); Selic (2003) e das observações realizadas durante o processo de modelagem da aplicação. Nesses trabalhos, foram apresentadas diversas classificações para as características que um método de desenvolvimento pode possuir. Entre essas classificações, podemos citar os aspectos funcional e de informação (Gu et al., 2002), as classificações de sintaxe abstrata, notação e semântica dos modelos (Bobkowska, 2005), as características de notação (Rumbaugh, 1996) e os modelos de engenharia (Selic, 2003). Procurando simplificar as classificações encontradas, foram definidas duas que agregam as características escolhidas dos autores relacionados. Dividiram-se em dois grupos: características de notação e de modelos de engenharia. As de notação são características que um método deve possuir para ser eficiente, prático e facilmente aprendido. Um método deve ser eficiente pois deve ser capaz de representar um problema do mundo real, nos aspectos relevantes que esse problema venha a apresentar. Um método deve ser prático, a fim de que os projetistas e outros envolvidos em sua produção sejam capazes de construir modelos tanto com o auxílio de ferramentas CASE, quanto construídos à mão. Quanto à facilidade de apredizagem, por mais relativa que essa característica 
seja, ela ajuda os envolvidos diretos ou indiretamente no processo de desenvolvimento. As características de modelos de engenharia representam características que um método deve possuir para que forneça recursos para a produção de uma aplicação com qualidade, como por exemplo, capacidade de abstração, previsilidade e baixo custo, entre outras. É importante ressaltar que outras características podem ser acrescidas ao arcabouço. Por exemplo, a arquitetura das aplicações Web determina e conduz o processo de desenvolvimento e considerá-la pode ser determinante para a qualidade da aplicação produzida. No caso do estudo prático realizado, foi utilizada uma mesma aplicação, a qual utilizava um arquitetura comum (Seção 2.2.2) e nenhum dos métodos analisados não considera a arquitetura um fator diferencial na elaboração da aplicação. Assim, optou-se em não considerar a arquitetura das aplicações Web, concentrando-se os esforços nas características de notação e modelos de engenharia, para a criação da versão inicial deste arcabouço.

Além da classificação das características na divisão supracitada, com o intuito de quantificar a avaliação de um método, foi estabelecido um sistema que reúne pesos e valores a essas características, estabelecendo-se assim o arcabouço de avaliação. Ressalta-se que os pesos atríbuidos a cada característica foram distribuídos de modo a representar um determinado domínio de aplicação para a qual um método pode ser utilizado. Por exemplo, no caso deste trabalho, os pesos foram distribuídos para o domínio de Portais de Conhecimento. O sistema de pesos e valores estabelecido permite que diferentes domínios sejam avaliados, com a atribuição de diferentes pesos às características, o que pode resultar em diferentes avaliações de um mesmo método em domínios diferentes.

Para cada característica é atribuído um peso de 1 a 3. Cada peso representa a importância da característica dentro de um domínio. A seguir descreve-se como são classificados os pesos:

- Peso 1 representa que a presença dessa característica no método não é essencial, porém sua existência agrega melhorias no método;

- Peso 2 significa que a característica em questão tenha presença desejada, ela não é obrigatória, mas sua ausência prejudica uma completa modelagem; e

- Peso 3 indica que a característica é mandatória.

Além dos pesos de cada característica, valores são atribuídos a cada característica, assim completando a avaliação. Esses valores auxiliam na quantificação de quanto as características são atendidas para um método, refletindo seu grau de apoio. Os valores são:

- 0: o método não atende a característica;

- 0,5: método atende a característica fracamente; e 
- 1,0: método atende plenamente a característica.

Para uma melhor visualização da classificação das notas na avaliação dos métodos, foi elaborado um gráfico tipo radar, apresentado na Figura 3.3. A gráfico tipo radar possui duas importantes contribuições: primeiro, provê uma simples representação de múltiplos indicadores de avaliação, intuitivo até mesmo para não especialistas e, segundo, a própria região composta pelos vértices pode ser também ser usada como indicador avaliação ((Mosley e Mayer, 1999)).

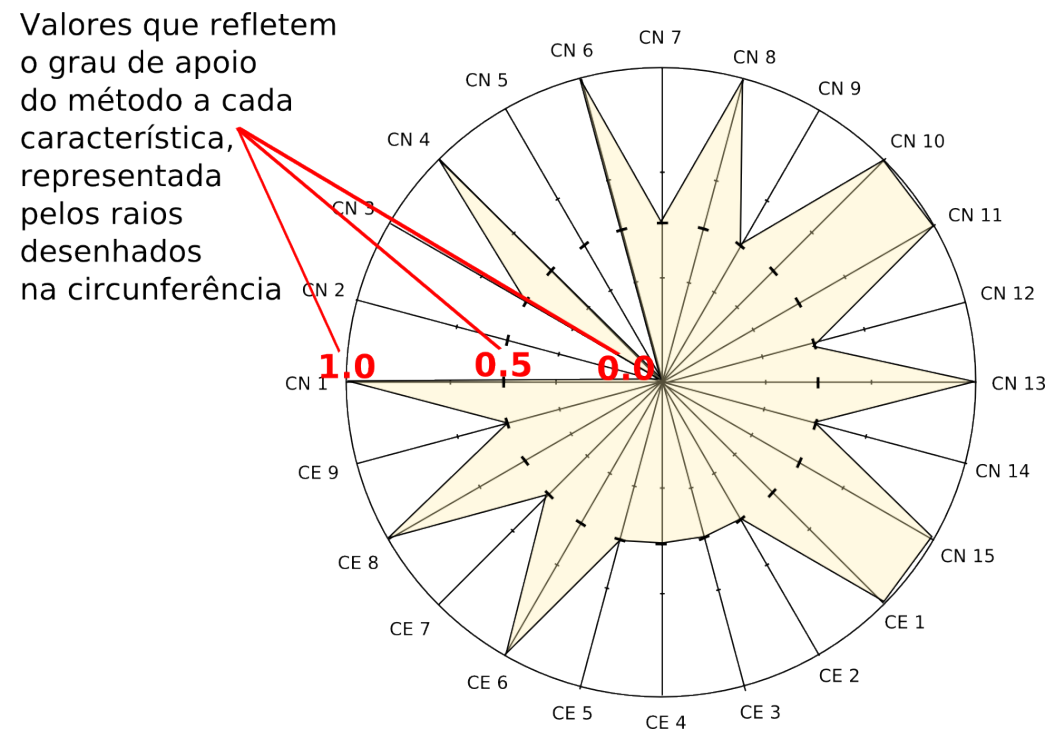

Figura 3.3: Exemplo de gráfico para visualização dos valores atribuídos para as caraterísticas de um método, com suas marcas destacadas e indicadas.

A seguir são listadas as características levantadas para a avaliação. Cada característica possui sua descrição e na Seção 3.3, pesos específicos que refletem o domínio de Portais de Conhecimento serão atríbuidos a cada uma.

\section{Características de Notação}

1.1. Desenho a mão livre: o método não depende exclusivamente de uma ferramenta CASE para modelagem. Possibilita a criação de rascunhos rápidos;

1.2. Simplicidade de símbolos: Juntamente com o critério anterior, essa característica facilita o desenho a mão livre, a visualização e a compreensão de modelos por envolvidos não técnicos;

1.3. Diferenciação não sútil de símbolos: o reúso de símbolos com modificações sutis pode confundir tanto o projetista quanto usuários que não são desenvolvedores;

1.4. Imagens monocromáticas: imagem monocromáticas trabalham com formas e símbolos que permitem o envio de faxes e cópias sem comprometer o modelo desenhado e é mais facilmente reproduzido; 
1.5. Não sobrecarga de símbolos: símbolos usados em mais de um modelo provocam sobrecarga dos mesmos, dificultando o trabalho tanto de construção como de compreensão do modelo;

1.6. Descrição visual: característica imprescindível no método, pois representa diagramas e gráficos que podem ser construído nos modelos;

1.7. Descrição textual: auxilia a compreensão de modelos, com o relato de detalhes e observações. Geralmente é acompanhada de uma descrição visual;

1.8. Modelagem Conceitual: compreensão dos conceitos e elementos que compõem o problema e suas relações. Compreensão do domínio da aplicação;

1.9. Modelagem navegacional separada da Interface: A modelagem navegacional deve ser separada da modelagem da interface. Na modelagem navegacional, é modelado como a informação navega entre os componentes da aplicação, sem a preocupação de como tal informação é apresentada e posicionada ao usuário final, tarefa essa realizada pela modelagem da interface. Salienta-se que modelando separadamente essas duas características de uma aplicação, projetistas ou equipes diferentes podem trabalhar em paralelo, uma com a modelagem da navegação e outra com a modelagem de interface;

1.10. Consideração de múltiplos papéis de usuários: característica pertinente às aplicações web que são utilizadas por usuários heterogêneos, com diferentes habilidades e propósitos de uso;

1.11. Propõe processo: Além de fornecer a técnica para modelagem, o método propõe um processo associado, que possui fases claras e definidas, não só para modelagem e projeto da aplicação, como também outras fases conhecidas da Engenharia de Software, como análise de requisitos, desenvolvimento, testes, entrega;

1.12. Links Semânticos: Links fazem parte da estrutura básica de uma aplicação Web e devem ser utilizados corretamente, obedecendo o contexto da informação que está sendo apresentada para o usuário;

1.13. Storyboards (Desenho de telas, mock-ups): recurso que realça a compreensão de elementos da interface;

1.14. Modelagem de interface: modelagem dos componentes que apresentam a informação, bem como seu posicionamento na tela para o usuário final. Considerando as aplicações Web, a modelagem de interface deve ser capaz de tratar e representar conteúdo hipermídia e multimídia;

1.15. Modelagem independente de tecnologia: é desejável que um método seja independente de qualquer tecnologia adotada na codificação da aplicação. 
2. Características de Modelos de Engenharia

2.1. Abstração: capacidade de remover ou esconder detalhes irrelevantes para um dado ponto de vista, constitui um recurso para trabalhar com complexidades;

2.2. Compreensibilidade: apresentação de modelos que diretamente remetem a nossa compreensão e assim provê a redução do esforço intelectual;

2.3. Conformidade: representação da aplicação em conformidade com o modelo real (de acordo com o resultado esperado no espaço das soluções possíveis)

2.4. Previsibilidade: possibilidade de prever características da aplicação que possam ser alteradas tanto no decorrer da fase de projeto quanto durante o ciclo de vida da aplicação;

2.5. Custo-baixo: a criação de modelos de baixo custo facilitam a recriação e correção de etapas já realizadas relacionado com a característica 1.1;

2.6. Método Iterativo: aceita a revisitação a um determinado modelo ou uma determinada fase da modelagem com o intuito de corrigir ou refinar tal modelo;

2.7. Abordagem Top-Down: O método permite a utilização da estratégia Top-Down. A partir de conceitos mais abstratos, é possível refiná-los em uma granularidade maior, o que permite a representação de detalhes.

2.8. Integração de aspectos funcionais com aspectos de informação (arquitetura da aplicação): o modo como as informações apresentadas aos usuários refletem as funções que as produzem é um ponto importante a ser verificado. Uma arquitetura comumente utilizada, a MVC (Seção 2.2.2) conecta esses dois aspectos de modo simples e modular, permitindo o trabalho colaborativo;

2.9. Uso de padrões de projeto: o uso de padrões já utilizados e comprovados pela indústria e academia fornecem subsídios para desenvolvimento ágil e prototipação rápida de aplicações.

\subsection{Exemplo de uso do arcabouço}

Após o estudo inicial que resultou no arcabouço de avaliação apresentado na seção anterior, foi realizada a avaliação dos modelos criados no estudo prático, a fim de exemplificar o arcabouço proposto. Inicialmente, a cada uma das características já citadas anteriormente, foi atribuído um peso, específico para o domínio de Portais de Conhecimento. Para a atribuição desses pesos, os desenvolvedores ou interessados que pretendem utilizar o arcabouço de avaliação devem ter conhecimento aprofundado das características e recursos próprios do domínio da aplicação a ser desenvolvida. Assim, é possível atribuir os pesos de modo a refletir tais características e necessidades de modelagem do domínio em questão. 
A seguir a relação das características e seus pesos, devidamente caracterizados para o domínio de Portais de Conhecimento:

\section{Características de Notação}

1.1. Desenho a mão livre: não é essencial, porém pode ser útil que o método permita o desenho a mão livre em possíveis brainstorms e discussões entre os projetistas - Peso 2;

1.2. Simplicidade de símbolos:É característica dos Portais de Conhecimento sua complexidade, dado os elementos que o integram, como multiplicidades de usuários e funções que agrega, portanto é importante que um modelo represente de maneira clara e simples os conceitos de um portal Web - Peso 3;

1.3. Diferenciação não sútil de símbolos: Idem ao item 1.2 - Peso 3;

1.4. Imagens monocromáticas para envio de faxes e cópias:pode facilitar trabalho remoto entre projetista e desenvolvedores - Peso 1;

1.5. Não sobrecarga de símbolos: Idem ao item 1.2 - Peso 3;

1.6. Descrição visual: característica importante para a compreensão dos modelos Peso 3;

1.7. Descrição textual: característica que deve estar presente para complementar a descrição visual - Peso 2;

1.8. Modelagem Conceitual: essencial para a compreensão dos Portais de Conhecimento - Peso 3;

1.9. Modelagem navegacional separada da Interface: ajuda na divisão de tarefas para uma equipe muitos integrantes - Peso 3;

1.10. Consideração de múltiplos papéis de usuários: atende a uma característica direta e importante dos Portais de Conhecimento - Peso3;

1.11. Propõe processo: pode orientar a condução do desenvolvimento, caso a equipe de projetistas não faça uso de um processo próprio - Peso 2;

1.12. Links Semânticos: se presente, pode ajudar na interligação de diferentes áreas do portal em desenvolvimento - Peso 1;

1.13. Storyboards (Desenho de telas, mock-ups): se presentes podem ajudar na compreensão dos modelos criados nas fases de modelagem navegacional e interface - Peso 1;

1.14. Modelagem de interface: tarefa geralmente executada por um Web Designer. Porém caso o método permita a modelagem da interface, facilitará a compreensão de conseqüente modelagem de um requisito de interface específico da aplicação - Peso 2; 
1.15. Modelagem independente de tecnologia: dado o número de tecnologias para a implementação existentes a disposição dos projetista e desenvolvedores, é necessário que a modelagem do portal seja independente de quaisquer tecnologias - Peso 3;

\section{Características de Modelos de Engenharia}

2.1. Abstração: O método deve ser capaz de abstrair conceitos e requisitos de um Portal Web - Peso 3;

2.2. Compreensibilidade: o método deve ser capaz de produzir modelos que sejam intuitivos e compreensíveis para todos os envolvidos na produção de um portal Web - Peso 3;

2.3. Conformidade: o método deve retratar o mais fielmente possível o produto final desejado - Peso 3;

2.4. Previsibilidade: o método deve prever futuras manutenções e acertos - Peso 3;

2.5. Custo-baixo: se possível oferecer meios para redução de custos - Peso 2;

2.6. Método Iterativo: a capacidade de retornar para fases anmteriores para possíveis correções é essencial para aperfeiçoamento do produto final - Peso 3;

2.7. Abordagem Top-Down: é conveniente que o método apresente a possibilidade, dependendo da complexidade do Portal em desenvolvimento, da visualização de trechos da aplicação em diferentes níveis de granularidade - Peso 2;

2.8. Integração de aspectos funcionais com aspectos de informação (arquitetura da aplicação): em um Portal Web, a integração coesa entre esses aspectos facilita o trabalho em grupo - Peso 3;

2.9. Uso de padrões de projeto: permitir o uso de padrões reconhecidos pela indústria pode agilizar o processo de desenvolvimento do Portais de Conhecimento - Peso 2;

Após a atribuição dos pesos ao conjunto de características, para cada método utilizado, valores foram atribuídos a essas características, segundo a definição do valores na Seção 3.2.3. Para a atribuição dos valores, é necessário que o avaliador possua conhecimento prévio a respeito do método avaliado. A seguir, é apresentada a atribuição dos valores de acordo com os pontos observados:

O trabalho realizado com a utilização do método WAE ocorreu sem dificuldades, uma vez que a maioria das etapas de modelagem do método praticamente fazem o uso da UML padrão. Portanto, para algum projetista ou desenvolvedor, a curva de aprendizagem do método é suave, uma vez que esses estejam familiarizados com a linguagem UML. 


\begin{tabular}{|l|l|l|l|l|l|l|l|l|l|l|l|l|l|l|}
\hline 1.1 & 1.2 & 1.3 & 1.4 & 1.5 & 1.6 & 1.7 & 1.8 & 1.9 & 1.10 & 1.11 & 1.12 & 1.13 & 1.14 & 1.15 \\
\hline 1.0 & 1.0 & 0.5 & 1.0 & 0.5 & 1.0 & 0.5 & 1.0 & 0.5 & 1.0 & 1.0 & 0.0 & 1.0 & 0.5 & 1.0 \\
\hline
\end{tabular}

Tabela 3.3: Valores das característica de notação para o método WAE.

\begin{tabular}{|l|l|l|l|l|l|l|l|l|}
\hline 2.1 & 2.2 & 2.3 & 2.4 & 2.5 & 2.6 & 2.7 & 2.8 & 2.9 \\
\hline 1.0 & 0.5 & 0.5 & 0.5 & 1.0 & 1.0 & 1.0 & 1.0 & 0.5 \\
\hline
\end{tabular}

Tabela 3.4: Valores da características de engenharia para o método WAE

Para o uso do método WebML foi necessário um tempo de estudo adicional, uma vez que esse método introduz diagramas próprios e uso acentuado da linguagem XML. A maior dificuldade encontrada no uso desse método foi a construção dos modelos a lápis e caneta, dado que as figuras que compõe o modelo apesar de não serem complexas, possuem em certos momentos, detalhes que poderiam ser omitidos. Por exemplo, para o desenho do elemento que representa uma unidade de informação para o método, é necessário desenhar um lápis em conjunto com uma figura geométrica.

\begin{tabular}{|l|l|l|l|l|l|l|l|l|l|l|l|l|l|l|}
\hline 1.1 & 1.2 & 1.3 & 1.4 & 1.5 & 1.6 & 1.7 & 1.8 & 1.9 & 1.10 & 1.11 & 1.12 & 1.13 & 1.14 & 1.15 \\
\hline 0.5 & 0.5 & 1.0 & 1.0 & 0.5 & 1.0 & 1.0 & 1.0 & 0.5 & 0.5 & 1.0 & 0.5 & 0.5 & 0.5 & 1.0 \\
\hline
\end{tabular}

Tabela 3.5: Valores das característica de notação para o método WebML.

Para o método W2000, a etapa de modelagem do domínio (por meio do modelo hyperbase) foi mais extensa que em outros métodos, pois foi necessário conhecer os estereótipos utilizados. Além disso, os projetos navegacionais tanto da hyperbase quanto da camada de acesso, com a utilização de novos estereótipos e padrões de navegação (como roteiros guiados ou índices, usados por meio de ícones inseridos no diagrama), representando elementos de navegação hipermídia como nós e links, demandaram tempo adicional para aprendizado.

O trabalho realizado com o método OO-H, de modo similar ao WAE, concentrou as etapas iniciais de análise de requisitos nos diagramas de caso de uso e de classes, da linguagem UML. Após a construção desses diagramas, o processo de modelagem com o método seguiu com a construção dos NAD (Navigation Access Diagram). Para a construção desse modelo, salienta-se que foi necessário, um tempo adicional para compreensão dos elementos que o compõem e os conceitos envolvidos. Por exemplo no método OO-H, existem os Navigation Targets, que agrupam demais elementos como classes navegacionais e coleções (abstrações do conceito de menus) para a cobertura de cada requisito de navegação do usuário. Outro ponto que necessitou maior compreensão, foram os APD (Abstract Presentation Diagrams), pois além de possuírem um diagrama padrão visual, que modifica com alguns ícones os NAD, possui associado a cada item desse diagrama, arquivos XML, com detalhes sobre a interface, como formulário, links e estilo das páginas. 


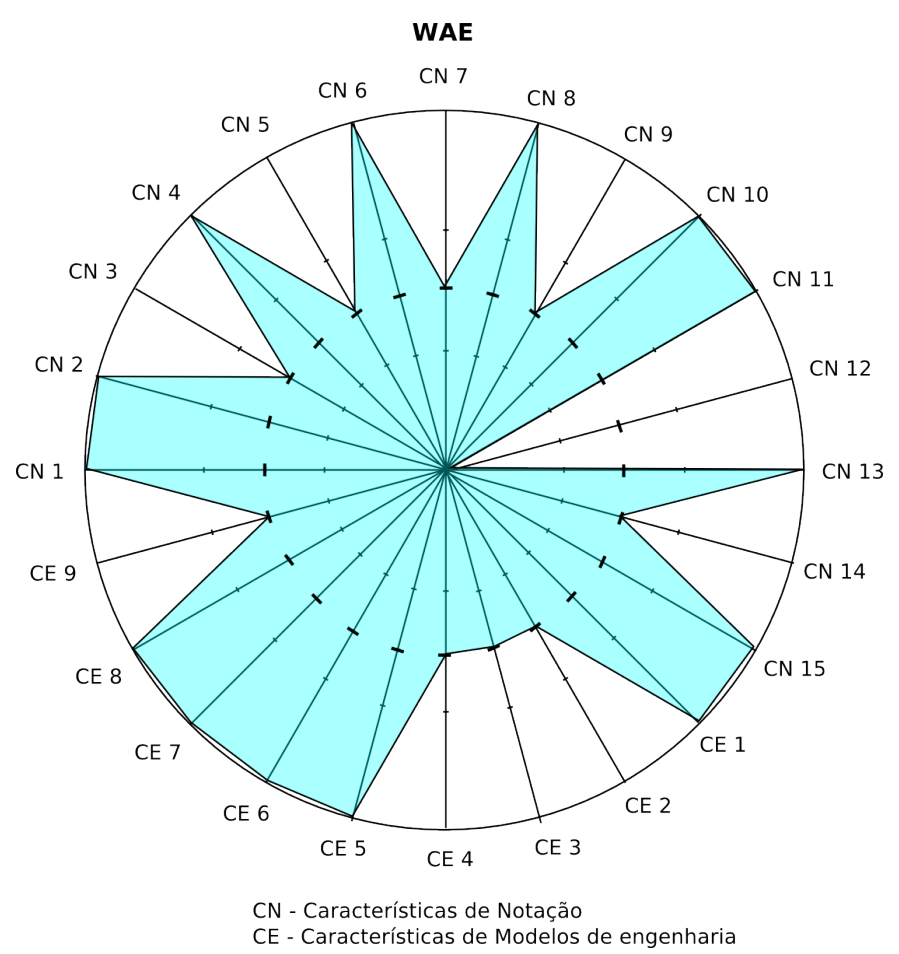

Figura 3.4: Gráfico de valores para o método WAE.

\begin{tabular}{|l|l|l|l|l|l|l|l|l|}
\hline 2.1 & 2.2 & 2.3 & 2.4 & 2.5 & 2.6 & 2.7 & 2.8 & 2.9 \\
\hline 0.5 & 0.5 & 0.5 & 0.0 & 1.0 & 1.0 & 1.0 & 0.5 & 0.5 \\
\hline
\end{tabular}

Tabela 3.6: Valores da características de engenharia para o método WebML

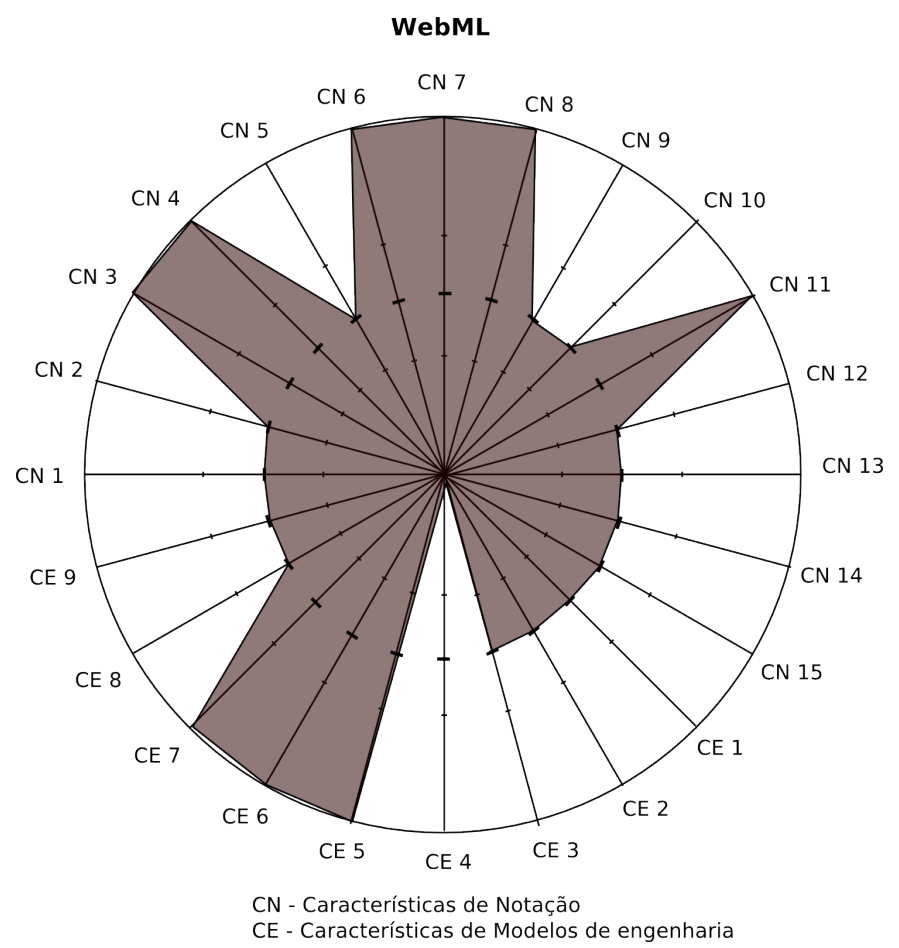

Figura 3.5: Gráfico de valores para o método WebML. 


\begin{tabular}{|l|l|l|l|l|l|l|l|l|l|l|l|l|l|l|}
\hline 1.1 & 1.2 & 1.3 & 1.4 & 1.5 & 1.6 & 1.7 & 1.8 & 1.9 & 1.10 & 1.11 & 1.12 & 1.13 & 1.14 & 1.15 \\
\hline 1.0 & 1.0 & 0.0 & 1.0 & 0.5 & 1.0 & 0.5 & 1.0 & 1.0 & 1.0 & 0.5 & 0.0 & 0.5 & 0.0 & 1.0 \\
\hline
\end{tabular}

Tabela 3.7: Valores das característica de notação para o método W2000.

\begin{tabular}{|l|l|l|l|l|l|l|l|l|}
\hline 2.1 & 2.2 & 2.3 & 2.4 & 2.5 & 2.6 & 2.7 & 2.8 & 2.9 \\
\hline 0.5 & 0.5 & 0.5 & 1.0 & 1.0 & 1.0 & 1.0 & 0.5 & 0.5 \\
\hline
\end{tabular}

Tabela 3.8: Valores da características de engenharia para o método W2000

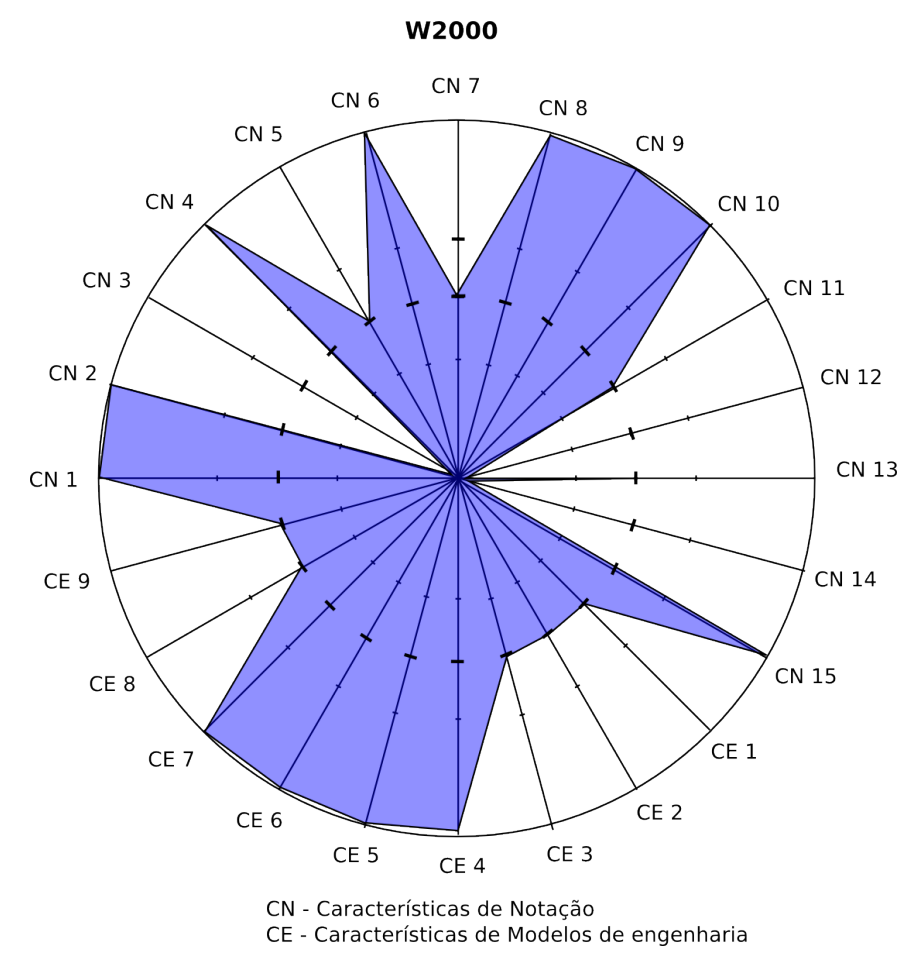

Figura 3.6: Gráfico de valores para o método W2000.

\begin{tabular}{|l|l|l|l|l|l|l|l|l|l|l|l|l|l|l|}
\hline 1.1 & 1.2 & 1.3 & 1.4 & 1.5 & 1.6 & 1.7 & 1.8 & 1.9 & 1.10 & 1.11 & 1.12 & 1.13 & 1.14 & 1.15 \\
\hline 0.5 & 1.0 & 1.0 & 1.0 & 0.5 & 0.5 & 1.0 & 1.0 & 1.0 & 1.0 & 0.5 & 1.0 & 1.0 & 0.5 & 1.0 \\
\hline
\end{tabular}

Tabela 3.9: Valores das característica de notação para o método OO-H.

\begin{tabular}{|l|l|l|l|l|l|l|l|l|}
\hline 2.1 & 2.2 & 2.3 & 2.4 & 2.5 & 2.6 & 2.7 & 2.8 & 2.9 \\
\hline 0.5 & 0.5 & 0.5 & 0.0 & 0.5 & 0.5 & 1.0 & 1.0 & 1.0 \\
\hline
\end{tabular}

Tabela 3.10: Valores da características de engenharia para o método OO-H 


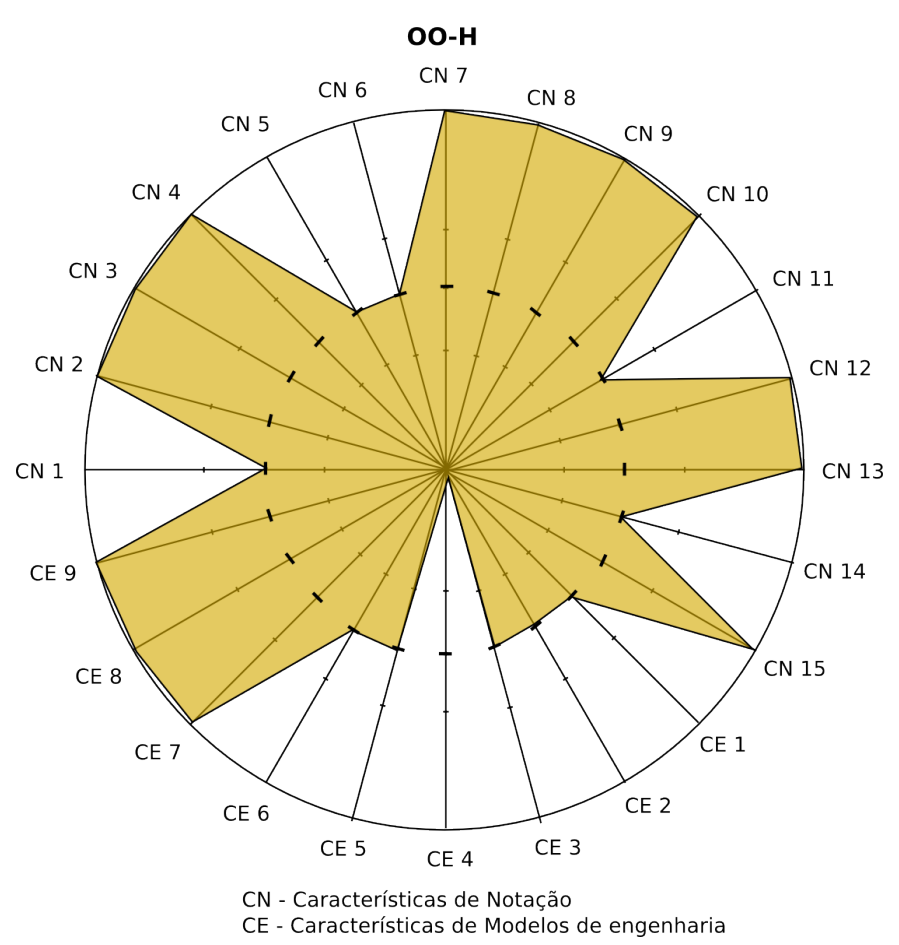

Figura 3.7: Gráfico de valores para o método OO-H

\subsubsection{Comparação de valores}

Após a revisitação dos modelos e atribuição dos valores, utilizando-se os pesos definidos na Seção 3.3, para o domínio de Portais de Conhecimento, um valor geral para cada método pôde ser computado. A seguir são exibidos os valores computados e a plotagem desses valores em um gráfico de barras.

- WAE: Características de notacao $(27,5)$, Características de modelos de engenharia $(18,5), \operatorname{total}(46)$;

- WebML: Características de notacao (25,5), Características de modelos de engenharia $(14,5), \operatorname{total}(40)$;

- W2000: Características de notacao (25), Características de modelos de engenharia $(17,5), \operatorname{total}(42,5)$;

- OO-H: Características de notacao $(27,5)$, Características de modelos de engenharia (14), $\operatorname{total}(41,5)$;

Na Figura 3.8, observa-se que nas características de modelo de notação nenhum dos métodos se sobressaiu em relação aos outros, pois os método WAE e OO-H obtiveram um empate em seus valores. Em relação às características de modelos de engenharia, o método WAE atingiu um valor maior, o que fez com que obtivesse na soma total dos valores a melhor colocação, fato observado pela barra na cor amarela do gráfico. 


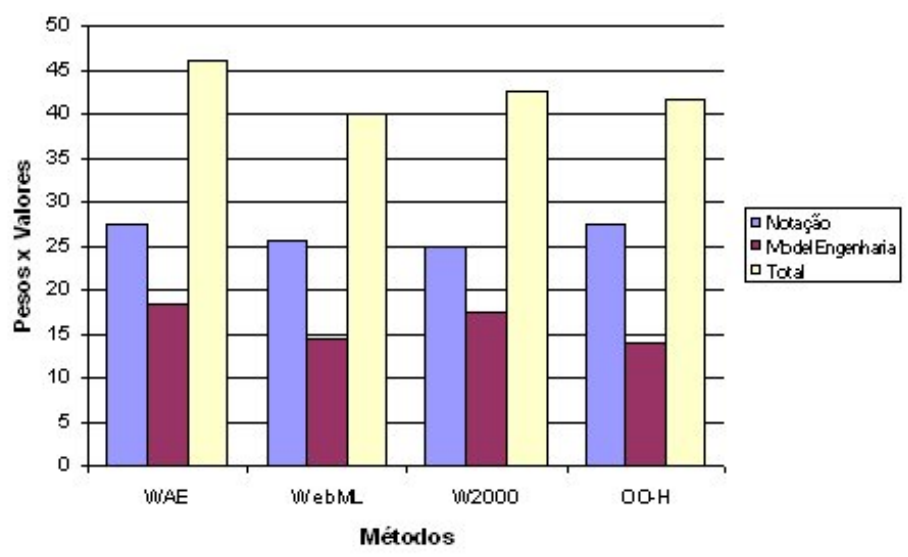

Figura 3.8: Comparação entre os valores atribuídos para as características.

\subsection{Considerações Finais}

Neste capítulo, foi apresentado um arcabouço para avaliação de métodos de desenvolvimento de aplicações Web, segundo a observação de suas características frente a um domínio específico de aplicações Web, no caso, Portais de Conhecimento.

O arcabouço foi formado pela observação de características encontradas durante a revisão bibliográfica e estudo apronfundado dos métodos. Após o estudo prático realizado, pôde-se então atribuir a cada característica um peso que representasse a importância dessa característica para o domínio de Portais Web.

No próximo capítulo, é apresentada a conclusão do trabalho e as perspectivas de trabalhos futuros. 



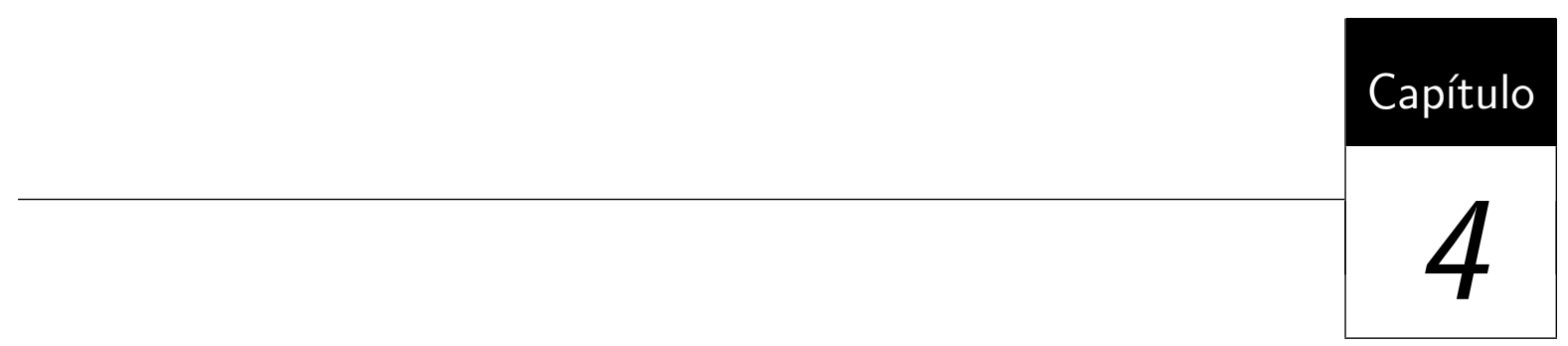

\section{Conclusão}

Como apresentado neste trabalho, as aplicações Web possuem características de uma aplicação de software convencional e, portanto, requerem o uso de métodos sólidos e confiáveis para seu desenvolvimento. Porém, essas aplicações também possuem características que as tornam distintas das outras aplicações, como requisitos de navegação, usabilidade elaborada, navegação em um ambiente imprevisível, uso de imagens, sons e animações, e exigem que os métodos disponíveis para seu desenvolvimento atendam tais características.

Nesse contexto, o estudo realizado durante o desenvolvimento deste trabalho procurou fornecer subsídios para projetistas e demais interessados na escolha de métodos apropriados para o desenvolvimento de suas aplicações Web. Como mencionado anteriormente neste trabalho, a principal motivação foi a existência de um conjunto de métodos disponíveis na literatura, que pode tornar tal escolha uma atividade não trivial. Para alcançar esse objetivo, foi necessário o levantamento, estudo e comparação desse conjunto de métodos, por meio de estudos encontrados na literatura e de um estudo prático que possibilitou estudar na prática as características próprias de cada método.

A partir dos estudos realizados, pontos importantes foram observados, como a notação utilizada pelos métodos. Métodos mais recentes utilizam como base a linguagem UML, favorecendo o processo de aprendizado, uma vez que essa linguagem é comumente empregada tanto no meio acadêmico quanto no industrial. Há outros métodos que utilizam notação própria e exigem um tempo de aprendizado dos elementos que compõem suas etapas e seus diagramas, dado que materiais de consulta disponíveis para alguns deles são escassos. Ainda em relação à notação, alguns métodos possuem notações próprias 
que não são facilmente produzidas sem o apoio de uma ferramenta de modelagem, o que torna o uso dessas ferramentas imprescindível para a produção dos diagramas existentes nos métodos.

Outro ponto a ser considerado é que poucos métodos propõem sua utilização concomitante a um processo associado. Dado que já existem processos fundamentados na indústria como o RUP, qualquer método que não sugira o uso de um processo específico, pode fazer uso de processos existentes, de acordo com instruções de um gerente de projetos, equipe de desenvolvimento ou projetista.

O resultado dos estudos realizados neste trabalho foram sintetizados no arcabouço de avaliação apresentado no Capítulo 3. Esse arcabouço foi composto por um conjunto de características, dividido em características de notação e de modelos de engenharia, e nesse conjunto procurou-se agregar o máximo de características encontradas, percebidas e exigidas para o desenvolvimento de aplicações Web durante os estudos realizados. A cada característica procurou-se estabelecer uma descrição sucinta. Foi definido um sistema de pesos e valores a essas características, que oferecem ao arcabouço a possibilidade de variação dos pesos, para diferentes domínios de aplicações Web, por exemplo, um simples fórum ou uma avançada aplicação de comércio eletrônico.

Ao final deste trabalho e como resultado direto da aplicação do arcabouço, considerando o domínio de Portais de Conhecimento Web, o método WAE obteve melhor pontuação no cálculo dos valores atribuídos, e assim, para o domínio citado, foi considerado como o método com melhores características para desenvolvimento desse tipo de aplicação. Observa-se que esse resultado é dependente da experiência do avaliador e deverá ser validado no escopo de experimentos controlados a serem planejados. Nesses experimentos poderão ser adicionados diferentes métodos não utilizados originalmente no arcabouço de avaliação e, desse modo, incluir novas características como grau de maturidade de tais métodos, por exemplo, focando nas aplicações, se comerciais ou acadêmicas, que cada possui para auxiliar sua utilização. Além disso, como mencionado anteriormente, os métodos avaliados não referenciavam a arquitetura das aplicações Web e, portanto, essa não foi considerada no arcabouço. Logo, a adição de características relacionadas à arquitetura dessas aplicações tornaria mais completa a avaliação. A utilização de diferentes domínios de aplicações Web, como comércio eletrônico, gerenciadores de e-mails e fóruns, entre outros, poderá criar novos perfis para avaliação. Ressalta-se também que outros estudos práticos ou estudos de caso envolvendo um número maior de participantes, principalmente de especialistas da área acadêmica e industrial, ou até os próprios criadores dos métodos, contribuirá para o refinamento e crítica tanto do conjunto de características quanto do sistema de pesos e valores estabelecidos. 


\section{Referências}

Araújo, A. C. M. Framework de Análise e Projeto Baseado no RUP para o Desenvolvimento de Aplicações Web. Dissertação de Mestrado, Centro de Informática, Universidade Federal de Pernambuco, 2001.

Baresi, L.; Garzotto, F.; Paolini, P. Extending uml for modeling web applications. In: 34th Annual Hawaii International Conference on System Sciences, 2001a, p. 1-10.

Baresi, L.; Garzotto, F.; Paolini, P.; Valenti, S. HDM2000: The HDM Hypertext Design Model Revisited. Relatório Técnico, Politecnico di Milano, 2000.

Baresi, L.; Garzotto, G.; Paolini, P. Extending uml for modelling web applications. In: Proceedings of the 34th Hawaii International Conference on System Sciences, 2001b.

Bobkowska, A. Modeling pragmatics for visual modeling language evaluation. In: TAMODIA '05: Proceedings of the 4th international workshop on Task models and diagrams, New York, NY, USA: ACM Press, 2005, p. 75-78.

Brambilla, M.; Comai, S.; Fraternali, P. Hypertext semantics for web applications. In: SEBD Italian National Conference on DataBase Systems, 2002.

Brito, L. S. F. Webscharts: Uma ferramenta de desenvolvimento de aplicações web baseada no HMBS/M. Dissertação de Mestrado, Univesidade Federal do Mato Grosso do Sul, Campo Grande, MS, 2003.

Cagnin, M. I.; Braga, R. T. V.; Germano, F.; Chan, A.; Maldonado, J. C. Extending Patterns with Testing Implementation. In: SugarLoafPlop'2005, V Conferencia Latino-Americana em Linguagens de Padrões para Programação, Campos do Jordão/SP - Brasil, submetido, 2005. 
Carvalho, M. R. HMBS/M - um método orientado a objetos para o projeto e o desenvolvimento de aplicações hipermídia. Dissertação de Mestrado, ICMC-USP, São Carlos, SP, 1998.

Carvalho, M. R.; Oliveira, M. C. F.; Masiero, P. C. HMBS/M - an object oriented method for hypermedia design. In: V Simpósio Brasileiro de Multimídia e Sistemas Hipermídia (SBMIDIA'99), Goiânia, GO, 1999, p. 43-62.

Ceri, S.; Fraternali, P.; Bongio, A. Web modeling language (webml): a modeling language for designing web sites. In: Proceedings of the 9th international World Wide Web conference on Computer networks : the international journal of computer and telecommunications netowrking, Amsterdam, The Netherlands, The Netherlands: North-Holland Publishing Co., 2000a, p. 137-157.

Ceri, S.; Fraternali, P.; Bongio, A. Web Modeling Language (WebML): A Modeling Language for Designing Web Sites. In: Proceedings of the 9th international World Wide Web Conference, Elsevier, 2000b.

Chen, P. P. The entity relationship model - toward a unified view of data. ACM Transactions on Database Systems, v. 1, n. 1, p. 9-36, 1976.

Christodoulou, S. P.; Styliaras, G. D.; Papatheodrou, T. S. Evaluation of hypermedia application development and management systems. In: HYPERTEXT '98: Proceedings of the ninth ACM conference on Hypertext and hypermedia : links, objects, time and space-structure in hypermedia systems, New York, NY, USA: ACM Press, 1998, p. $1-10$.

Coad, P.; Lefebvre, E.; Luca, J. D. Java modeling in color with uml. Prentice Hall, 1999.

Coleman et al., D. Object-oriented development: The fusion method. Englewood Cliffs, New Jersey, USA: Prentice Hall International, 1994.

Conallen, J. Building web applications with uml. Boston, MA, USA: Addison-Wesley Longman Publishing Co., Inc., 1999.

Conallen, J. Buildind Web applications with UML. 2nd. ed. Addison-Wesley, 2002.

Conte, T.; Mendes, E.; Travassos, G. H. Processo de desenvolvimento para aplicações web: Uma revisão sistemática. In: XI Simpósio Brasilieiro de Sistemas Multimídia e Web, Poços de Caldas, MG, submetido para avaliação, 2005. 
Costa, M. L. Portal de Conhecimento sobre Critérios, Estratégias e Ferramentas de Teste de Aplicações Web. Dissertação de Mestrado, ICMC/USP, São Carlos/SP - Brasil, em andamento, 2005.

Deshpande, Y.; Hansen, S. Web engineering: Creating a discipline among disciplines. IEEE MultiMedia, v. 8, n. 2, p. 82-87, 2001.

Deshpande, Y.; Murugesan, S.; Ginige, A.; Hansen, S.; Schwabe, D.; Gaedke, M.; White, B. Web engineering. ArXiv Computer Science e-prints, 2003.

Domingues, A. L. S. Aplicações Web: Definição e Análise de Recursos de Teste e Validação. Tese de Doutoramento, ICMC/USP, São Carlos/SP - Brasil, em andamento, 2005.

Domingues, A. L. S.; Bianchini, S. L.; Costa, M. L. S.; Ferrari, F. C.; Maldonado, J. C. Web application development methods: A comparision. In: Webmedia'200\%: Proceedings of the 13o. Brazilian Symposium on Multimedia and the Web, Gramado, Brazil, 2007.

Figueiredo, A. ECO - um ecossistema para o desenvolvimento ágil de sistemas web. Dissertação de Mestrado, ICMC/USP, São Carlos/SP - Brasil, 2005.

Finkelstein, A. C. W.; Savigni, A.; Kappel, G.; Retschitzegger, W.; Kimmerstorfer, E.; Schwinger, W. Ubiquitous web application development - a framework for understanding. In: 6th World Multiconference on Systemics, Cybernetics and Informatics, Orlando, Florida, US, 2002.

Fons, J.; Pelechano, V.; Pastor, O.; Albert, M.; Valderas, P. Extending an OO Method de Develop Web Applications. In: The Twelfth International World Wide Web Conference, 2003.

Fowler, M. The new methodology. Software Development Magazine, 2000.

Fowler, M. Patterns of enterprise application architecture. Addison-Wesley, 2003.

Fowler, M.; Scott, K. Uml distilled: Applying the standard object modeling language. 2nd ed. Addison Wesley, 2000.

Fraternali, P.; Paolini, P. Model-driven development of web applications: the autoweb system. In: ACM Transactions on Office Information Systems, 2000.

Garzotto, F.; Schwabe, D.; Paolini, P. HDM - A Model Based Approach to Hypertext Application Design. ACM Transactions on Information Systems, v. 11, n. 1, p. 1-26, 1993. 
Ginige, A. Engineering a better web site. In: Asian Pacific Web Conference, xian, China, 2000.

Ginige, A. Web engineering: managing the complexity of web systems development. In: SEKE '02: Proceedings of the 14th international conference on Software engineering and knowledge engineering, New York, NY, USA: ACM Press, 2002, p. 721-729.

Ginige, A.; Murugesan, S. Web engineering: A methodology for developing scalable, maintainable web applications. Cutter IT Journal, p. 24-35, 2001a.

Ginige, A.; Murugesan, S. Web engineering: An introduction. In: IEEE Multimedia, 2001b, p. 14-18.

Gómez, J.; Cachero, C.; Pastor, O. Conceptual modeling of device-independent web applications. IEEE MultiMedia, v. 8, n. 2, p. 26-39, 2001.

Griffiths, G.; Hebbron, B. D.; Lockyer, M. A.; Oates, B. J. A simple method \& tool for web engineering. In: SEKE '02: Proceedings of the 14th international conference on Software engineering and knowledge engineering, New York, NY, USA: ACM Press, 2002, p. 755-762.

$\mathrm{Gu}$, A.; Henderson-Sellers, B.; Lowe, D. Web modelling languages: the gap between requirements and current exemplars. In: AusWeb 2002 - The Eighth Australian World Wide Web Conference, 2002.

Harel, D. Statecharts: A visual formalism for complex systems. Science of Computer Programming, v. 8, p. 231-274, 1987.

Henderson-Sellers, B. Notes on the use of subtypes and stereotypes int the UML. In: Annals of Software Engineering, 2002.

Isakowitz, T.; Kamis, A.; Koufaris, M. Extending the capabilities of rmm: Russian dolls and hypertext. In: 30th Hawaii International Conference on System Sciences (HICSS), Hawaii, US, 1997.

Isakowitz, T.; Kamis, A.; Koufaris, M. Reconciling top-down and bottom-up design approaches in rmm. SIGMIS Database, v. 29, n. 4, p. 58-67, 1998.

Isakowitz, T.; Stohr, E. A.; Balasubramanian, P. Rmm: a methodology for structured hypermedia design. Commun. ACM, v. 38, n. 8, p. 34-44, 1995.

Koch, N. Software engineering for adaptive hypermedia systems: Reference model, modeling techniques and development process. Tese de Doutoramento, Ludwig-Maximilians University, Munich - Germany, 2000. 
Koch, N.; A.Kraus; C.Cachero; Melià, S. Modeling Web Business Processes with OO-H and UWE. Third International Workshop on Web-oriented Software Technology (IWWOST03), p. 27-50, d. Schwabe, O. Pastor, G. Rossi, and L. Olsina (Eds.), 2003.

Koch, N.; Mandel, L. Using uml to design hypermedia applications. Relatório Técnico, Ludwig-Maximilians-University, 1999.

Kruchten, P. The rational unified process: An introducution. Addison Wesley, 1998.

Kruchten, P. The rational unified process: An introduction. 2 ed. Addison Wesley, 2000.

Lee, H.; Lee, C.; Yoo, C. A scenario-based object-oriented methodology for developing hypermedia information systems. In: Hawaii International Conference on Systems Sciences (HICSS'98), 1998, p. 47-56.

Mosley, H.; Mayer, A. Benchmarking National Labour Market Performance: A Radar Chart Approach. Discussion paper, 1999.

Murugesan, S.; Deshpande, Y. Second icse workshop on web engineering (workshop session). In: ICSE '00: Proceedings of the 22nd international conference on Software engineering, New York, NY, USA: ACM Press, 2000, p. 794-795.

Murugesan, S.; Deshpande, Y.; hansen, S.; Ginige, A. Web engeneering: A new discipline for development of web-based systems. In: Proceedings of the First ICSE Workshop on Web Engineering, Los Angeles, CA, USA: ACM Press, 1999, p. 794-795.

Murugesan, S.; Ginige, A. Web engineering: Introduction and perspectives, cáp. 1 Idea Group Publishing, p. 23, 2005.

Pamplona, V. F. Web services. construindo, disponibilizando e acessando Web Services via J2SE e J2ME. online, disponível em http://www . javafree.org/content/view . jf?idContent=4 - Último acesso em 22/02/06, 2004.

Papazoglou, M. P.; Georgakopoulos, D. Introduction. Commun. ACM, v. 46, n. 10, p. 24-28, 2003.

Pastor, O.; Pelechano, V.; Insfránz, E.; Gómez, J. From object oriented conceptual modeling to automated programming in java. In: ER '98: Proceedings of the 17th International Conference on Conceptual Modeling, London, UK: Springer-Verlag, 1998, p. $183-196$. 
Powell, T.; Jones, D.; Cutts, D. Web site engineering:beyond web page design. Prentice Hall, 1998.

Pressman, R. S. Software Engineering - A Practitioner's Approach. 6 ed. McGraw-Hill, 2005.

Rossi, G. Um método orientado a objetos para o projeto de aplicação hipermídia. Tese de Doutoramento, PUC-RJ, Rio de Janeiro, RJ, 1996.

Rumbaugh, J.; Blaha, M.; Premerlani, W.; Eddy, F.; Lorensen, W. Object-Oriented Modeling and Design. Englewood Cliffs, New Jersey, USA: Prentice Hall International, 1991.

Rumbaugh, J.; Jacobson, I.; Boch, G. The unified modeling language reference manual. Addison-Wesley Object Technology Series, 1998.

Rumbaugh, J. E. Notation notes: Principles for choosing notation. JOOP, v. 9, n. 2, p. $11-14,1996$.

Schwabe, D.; Pontes, R. A. OOHDM-Web: Rapid prototyping of hypermedia applications in the $W W W . \quad$ Relatório Técnico MCC 08, PUC-Rio, Rio de Janeiro, RJ, 1998.

Schwabe, D.; Pontes, R. A.; Moura, I. OOHDM-Web: an environment for implementation of hypermedia applications in the WWW. ACM SIGWEB Newsletter, v. 8, n. 2, p. 18-34, 1999.

Schwabe, D.; Rossi, G. An Object Oriented Approach to Web-Based Application Design. Theory and Practice of Object Systems, Special Issue on the Internet 4, p. 34, 1998.

Schwabe, D.; Rossi, G.; Barbosa, S. D. J. Systematic hypermedia application design with oohdm. In: HYPERTEXT '96: Proceedings of the the seventh ACM conference on Hypertext, New York, NY, USA: ACM Press, 1996, p. 116-128.

Selic, B. The pragmatics of model-driven development. Software, IEEE, v. 20, n. 2, p. 19-25, 2003.

Sun Microsystems Interactive Web Application Architectures. online, disponível em http://java.sun.com/webservices/docs/1.2/tutorial/doc/IntroIWA2. html - Último acesso em 20/04/05, 2003.

Torres, V.; Fons, J.; Asensi, O.; Pelechano, V. Getting ready web engineering methods for the semantic web. putting ontologies into practice. In: International Workshop on Web Oriented Software Technology (IWWOST), 2004. 
Turine, M. A. S. HMBS: Um modelo baseado em statecharts para a especificação formal de hiperdocumentos. Tese de Doutoramento, IFSC-USP, São Carlos, SP, 1998.

Turine, M. A. S.; Oliveira, M. C. F. D.; Masiero, P. C. Hyscharts: A statechart-based environment for hyperdocument authoring and browsing. Multimedia Tools Application, v. 8, n. 3, p. 309-324, 1999.

W3C Web Services Description Language (WSDL) 1.1. online, disponível em http: //www.w3.org/TR/wsdl - Último acesso em 22/05/2008, 2001.

W3C World Wide Web Consortium. online, disponível em http://www.w3c.org Último acesso em 16/04/05, 2005.

W3C Extensible Markup Language (XML) 1.0 (Fourth Edition). online, disponível em http://www.w3.org/XML/Core/\#Publications - Último acesso em 22/05/2008, 2006.

W3C SOAP Version 1.2. online, disponível em http://www.w3.org/TR/2007/ REC-soap12-part1-20070427/ - Último acesso em 22/05/2008, 2007.

Wohlin, C.; Runeson, P.; Höst, M.; Ohlsson, M.; Regnell, B.; Wesslén, A. Experimentation in software engineering: an introduction. Kluwer Academic Publishers, 2000. 



\section{A.1 Requisitos funcionais}

O Portal de Conhecimento de Ferramentas, Estratégias, Técnicas e Critérios de Teste de Aplicações Web é constituído por quatro módulos: módulo de conhecimento, módulo de colaboração, módulo de comunicação e módulo de consulta. No módulo de conhecimento, o usuário insere os dados sobre os processos de teste, e os requisitos definidos para esse módulo são os seguintes:

1. O sistema deve permitir o cadastro de ferramentas de teste de aplicações web por meio da inclusão das informações no Formulário de Cadastro de Ferramentas.

1.1. Nome da Ferramenta;

1.2. Descrição resumida;

1.3. Dono/Proprietário;

1.4. Link deve permitir o direcionamento ao site que disponibiliza a ferramenta;

1.5. Upload para o caso de ferramentas com no máximo $2 \mathrm{Mb}$ que ficarão hospedadas no servidor do portal;

1.6. Técnica/Método que apóia;

1.7. Contato;

1.8. Documentação; e 
1.9. Licença;

2. O sistema deve permitir o cadastro de Processos de Teste de aplicações web por meio da inclusão das informações no Formulário de Cadastro de Processos.

2.1. Nome;

2.2. Autor/Proprietário;

2.3. Descrição Resumida;

2.4. Fases (unidade, integração, sistema, regressão);

2.5. Passos, que devem ser selecionados a partir de procedimentos previamente cadastrados;

2.6. Procedimentos, que devem ser selecionados a partir de procedimentos previamente cadastrados;

2.7. Artefatos Produzidos;

2.8. Recursos Utilizados;

2.9. Artigos;

2.10. Manuais.

3. O sistema deve permitir o cadastro de Passos de Teste de aplicações web, por meio da inclusão das informações do Formulário de Cadastro de Passos de Teste:

3.1. Nome;

3.2. Planejamento;

3.3. Projeto;

3.4. Execução;

3.5. Análise;

3.6. Tipo de Atividade.

4. O sistema deve permitir o cadastro de Procedimentos de teste de aplicações web. Os procedimentos podem ser categorizados em Métodos de Teste, Guias de Teste ou Técnicas de Teste.

5. O sistema deve permitir o cadastro de Atividades de teste de aplicações web.

6. O sistema deve permitir o cadastro de Recursos de teste de aplicações web.

7. O sistema deve permitir o cadastro de Artefatos de teste de aplicações web. 
8. O sistema deve permitir a inclusão das informações anteriores seguindo a estrutura definida pela OntoTest. Dessa forma, haverá um relacionamento bem definido entre cada uma das informações presentes na base de dados do portal.

No módulo de colaboração, os requisitos do Portal são:

1. O sistema deve permitir o cadastro de materiais de apoio relacionados ao estudo/utilização de ferramentas, critérios e estratégias de teste de aplicações web com a inclusão das seguintes informações:

1.1. Título;

1.2. Autor;

1.3. Data;

1.4. Descrição;

1.5. Palavras Chave;

1.6. Classificação, dentre as opções: Manuais, Artigos, Estudos de Caso e Pacotes de Laboratório;

1.7. Link deve permitir o direcionamento ao site que disponibiliza o material;

1.8. Upload para o caso de ferramentas com no máximo $2 \mathrm{Mb}$ que ficarão hospedadas no servidor do portal;

2. O sistema deve permitir a submissão do material de apoio segundo um processo de aprovação. O processo de aprovação consiste dos seguintes passos:

2.1. O usuário submete um conteúdo no portal;

2.2. O sistema categoriza o novo conteúdo com o status de "aguardando aprovação", e não permite a visualização por nenhum usuário;

2.3. O sistema notifica o administrador que um novo conteúdo foi adicionado;

2.4. O administrador altera o status do conteúdo para "aprovado", e o sistema permite a visualização para todos os usuários

3. O sistema deve manter um histórico (log) que registre as operações realizadas pelos usuários;

4. O sistema deve possuir em cada formulário de cadastro um campo que permita que o usuário possa relacionar o item cadastrado aos demais itens já incluídos na base de dados; 
5. O sistema deve notificar aos usuários que tenham escolhido receber informação a respeito da inclusão de novos conteúdos.

Para o módulo de comunicação, foi definido o seguinte conjunto de requisitos:

1. O sistema deve fornecer meios de colaboração entre os usuários do sistema:

1.1. O sistema deve permitir que os usuários participem da área do fórum existente no portal;

1.2. O sistema deve permitir que o usuário escolha os fóruns que quer participar, inserindo comentários, adicionando respostas e criando novos tópicos para discussão;

1.3. O sistema deve permitir que o usuário envie e-mails aos demais usuários do sistema;

2. O sistema deve permitir que os usuários registrem opiniões a respeito do conteúdo disponível e os torne visíveis aos demais usuários.

Para o módulo de consulta, os requisitos abaixo são exigidos:

1. O sistema deve possuir um formulário para a busca que permita a busca por:

1.1. Palavra chave;

1.2. Título;

1.3. Autor;

1.4. Tipo de Material;

2. O sistema deve ordenar e apresentar os resultados de busca de acordo com os itens de cada conteúdo;

3. O sistema deve permitir que o usuário visualize o conteúdo desejado e permita a realização de download desse conteúdo, de acordo com os critérios de segurança e acesso;

4. O sistema deve permitir que, na visualização de um conteúdo, exista links para os conteúdos relacionados.

Os requisitos para as tarefas administrativas, para o módulo de administração são:

1. O sistema deve permitir o cadastro de grupos de usuário no sistema. Cada grupo possui um nível de acesso diferente para cada parte do portal. Os grupos são: usuário cadastrado, especialista e administrador. O visitante não está relacionado a nenhum grupo já que não possui vínculo cadastral com o sistema; 
2. O sistema deve permitir o cadastro dos usuários no sistema, com a inclusão das seguintes informações:

2.1. Dados Pessoais;

2.2. Dados Profissionais;

2.3. Grupo;

2.4. Perfil.

3. O sistema deve permitir o acesso de usuários não cadastrados, que podem visualizar conteúdos não restritos (definidos pelo especialista) do sistema.

\section{A.2 Análise de requisitos}

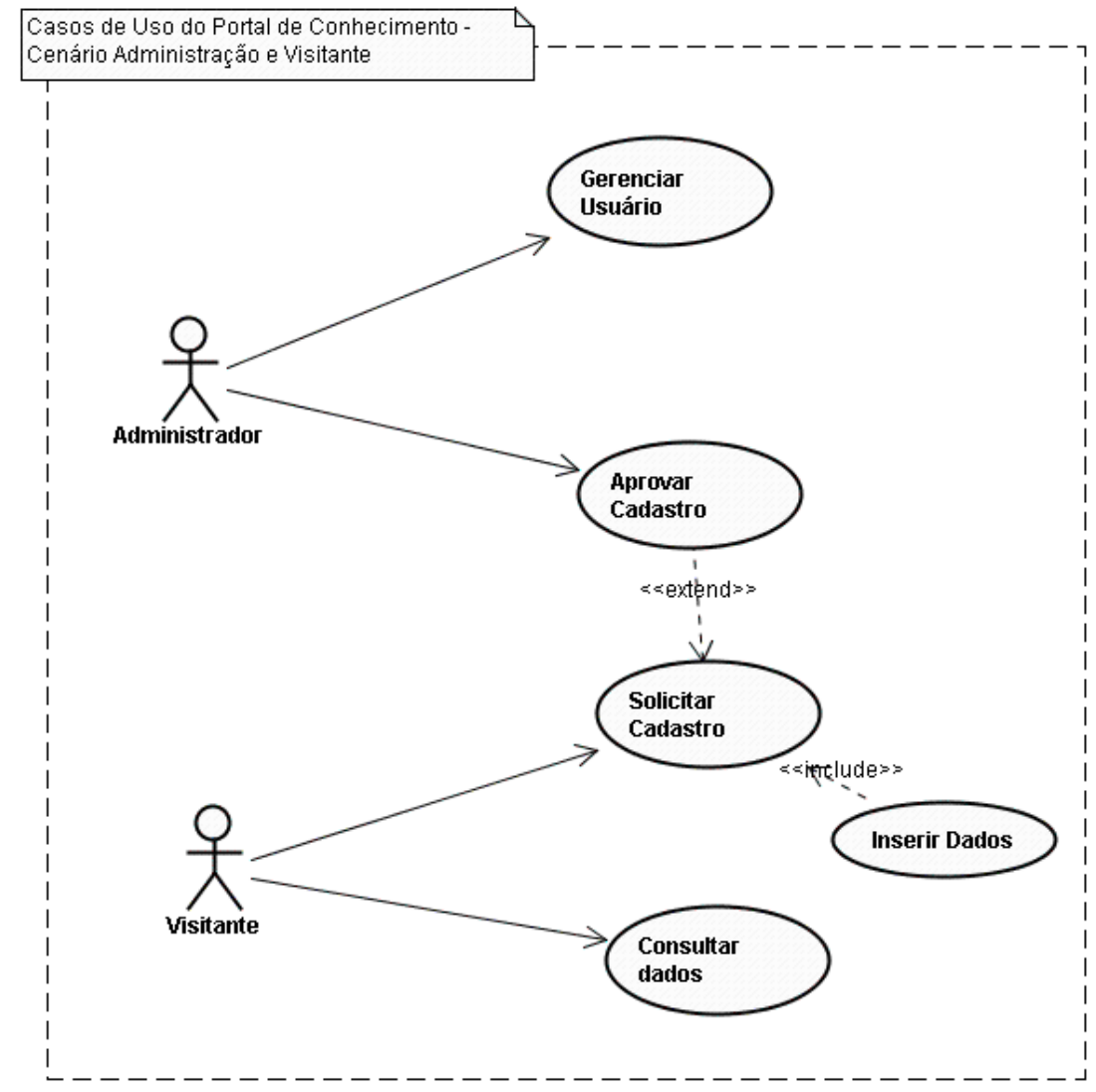

Figura A.1: Caso de uso funcional - Administrador e visitante 


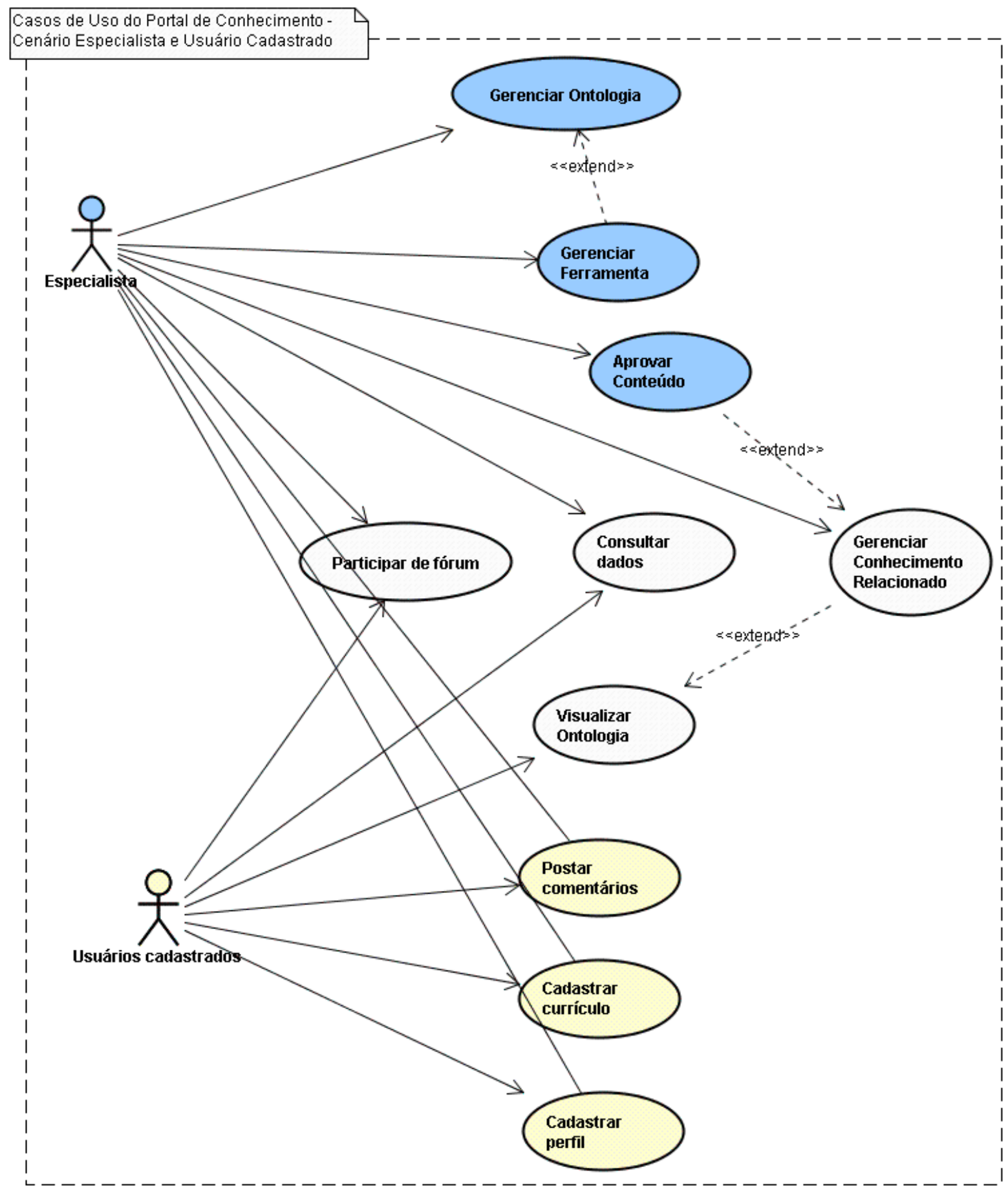

Figura A.2: Caso de uso funcional - Especialista e usuário cadastrado 


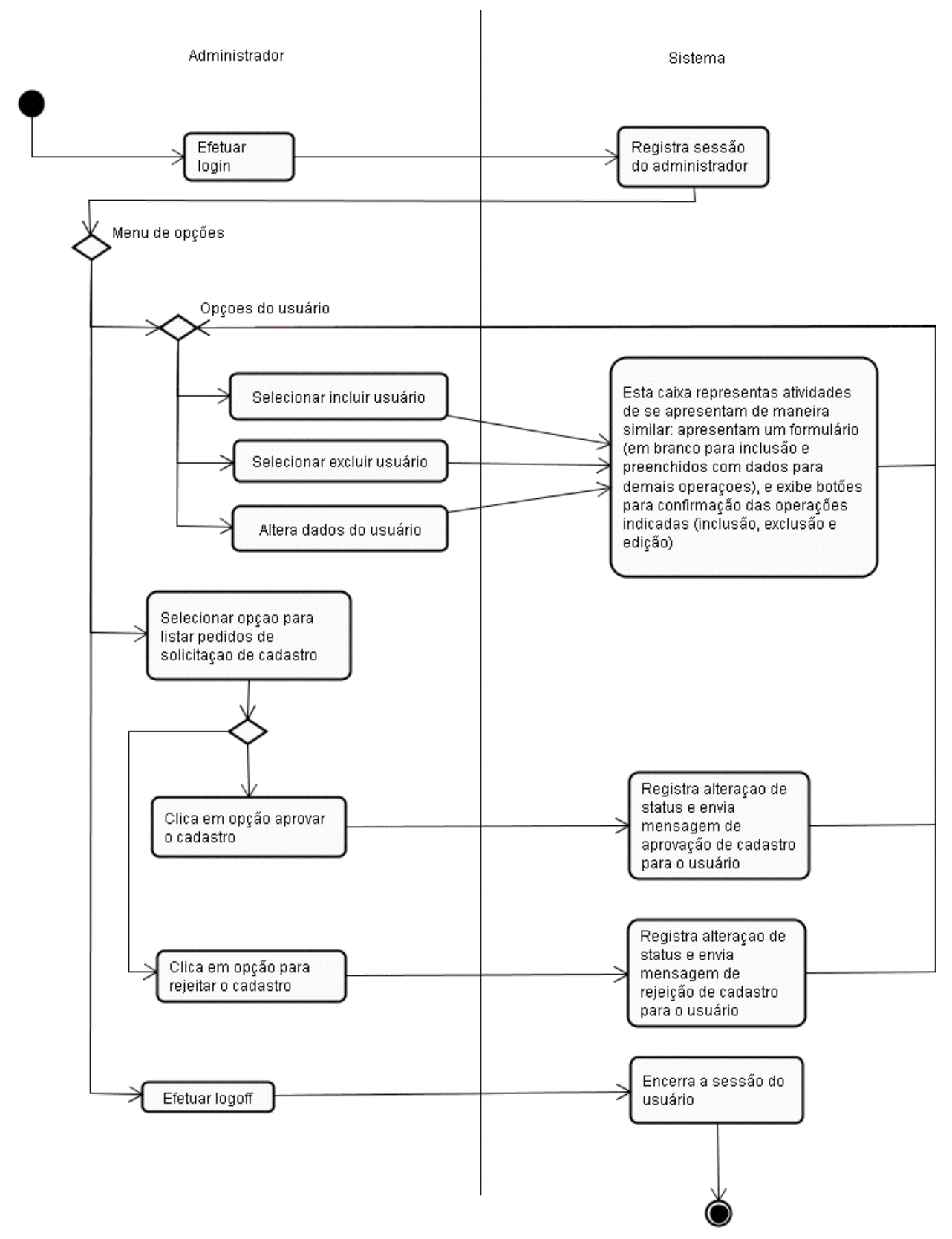

Figura A.3: Diagrama de atividades do administrador do Portal 


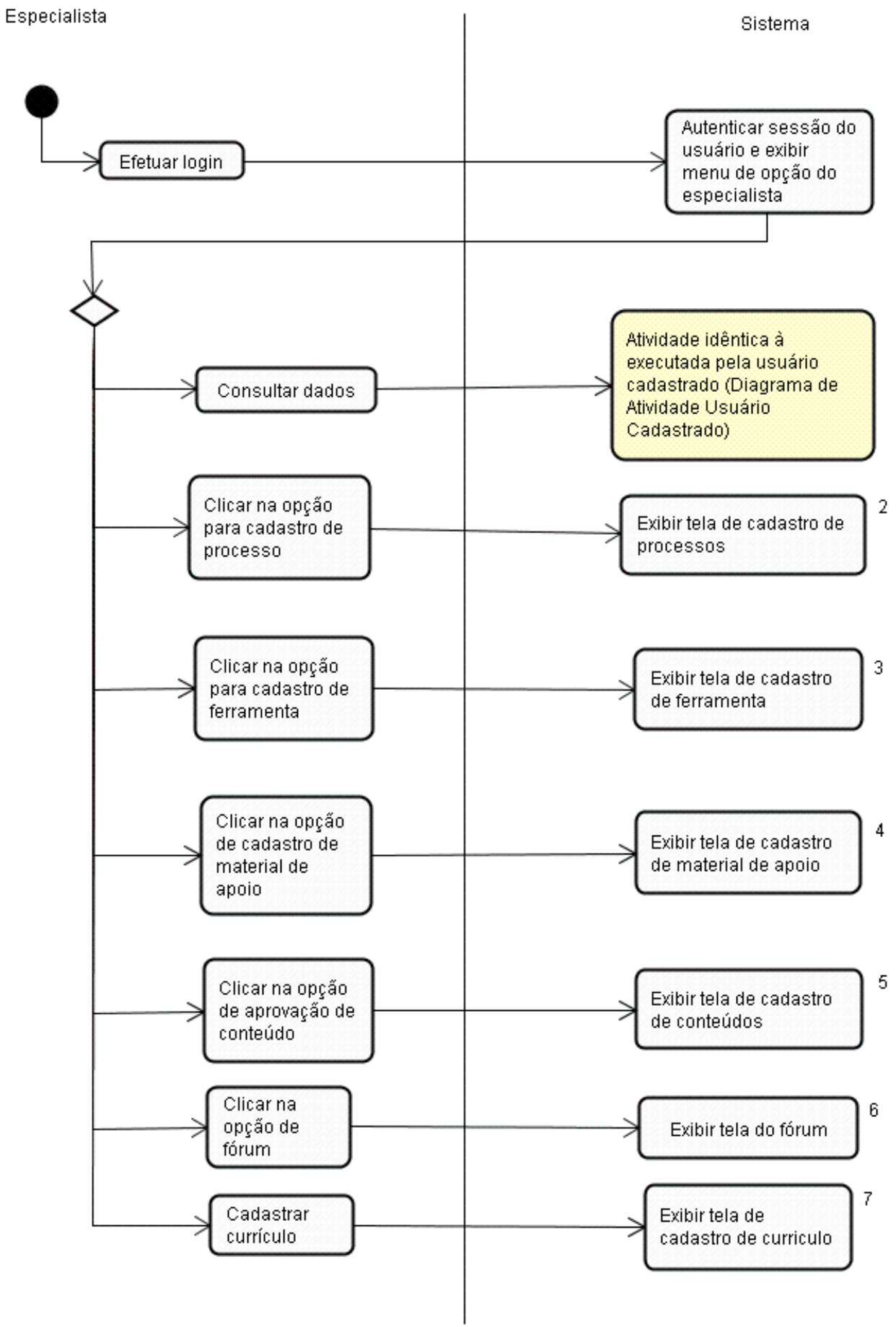

Figura A.4: Diagrama de atividades do especialista I. 


\section{Expansăo da atividade 2}

no diagrama de

atividade Especialista |

Especialista

Sistema

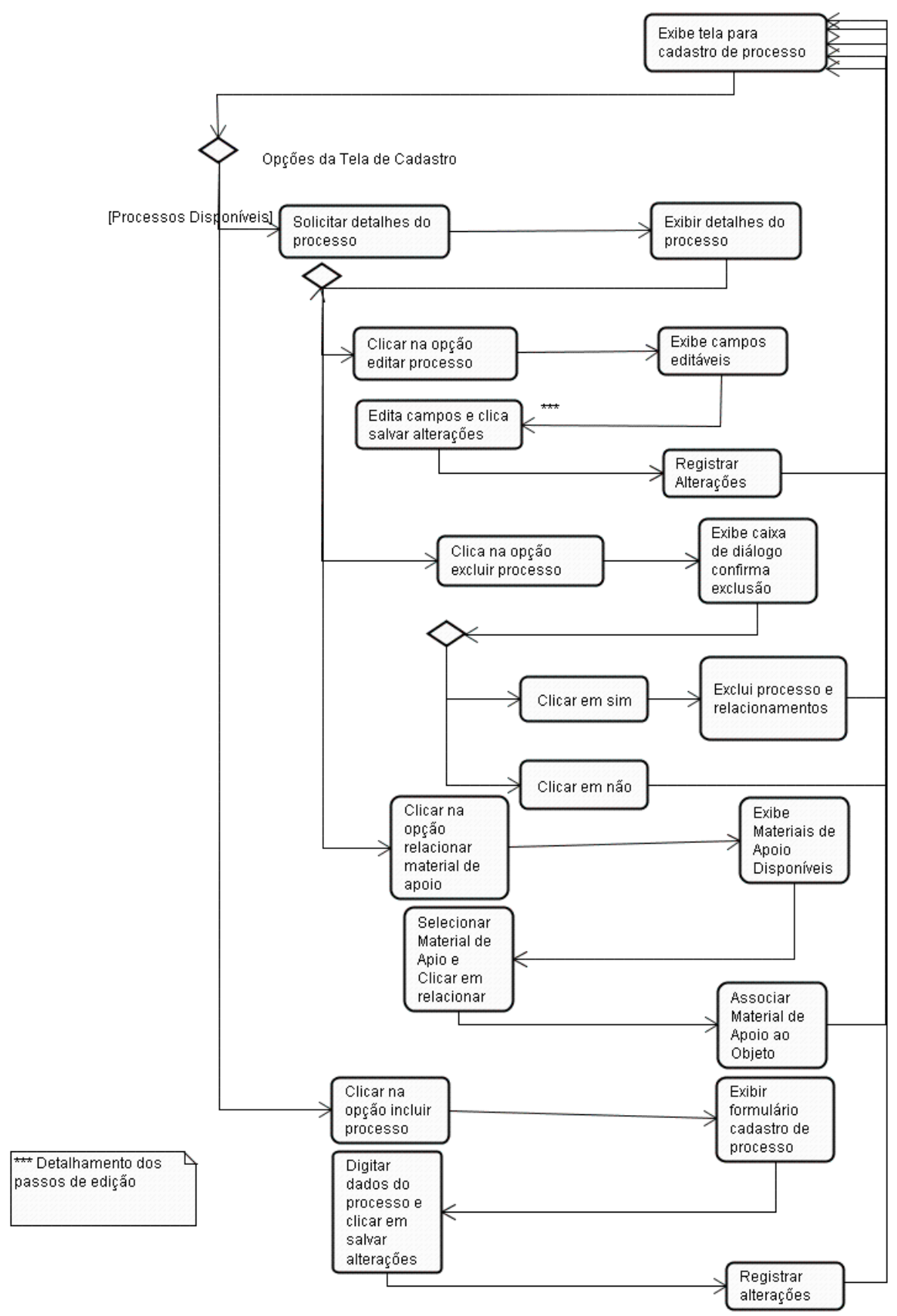

Figura A.5: Diagrama de atividade do especialista II. 
Expansẫo da atividade 34

no diagrama de

atividade Especialista I

Especialista

Sistema

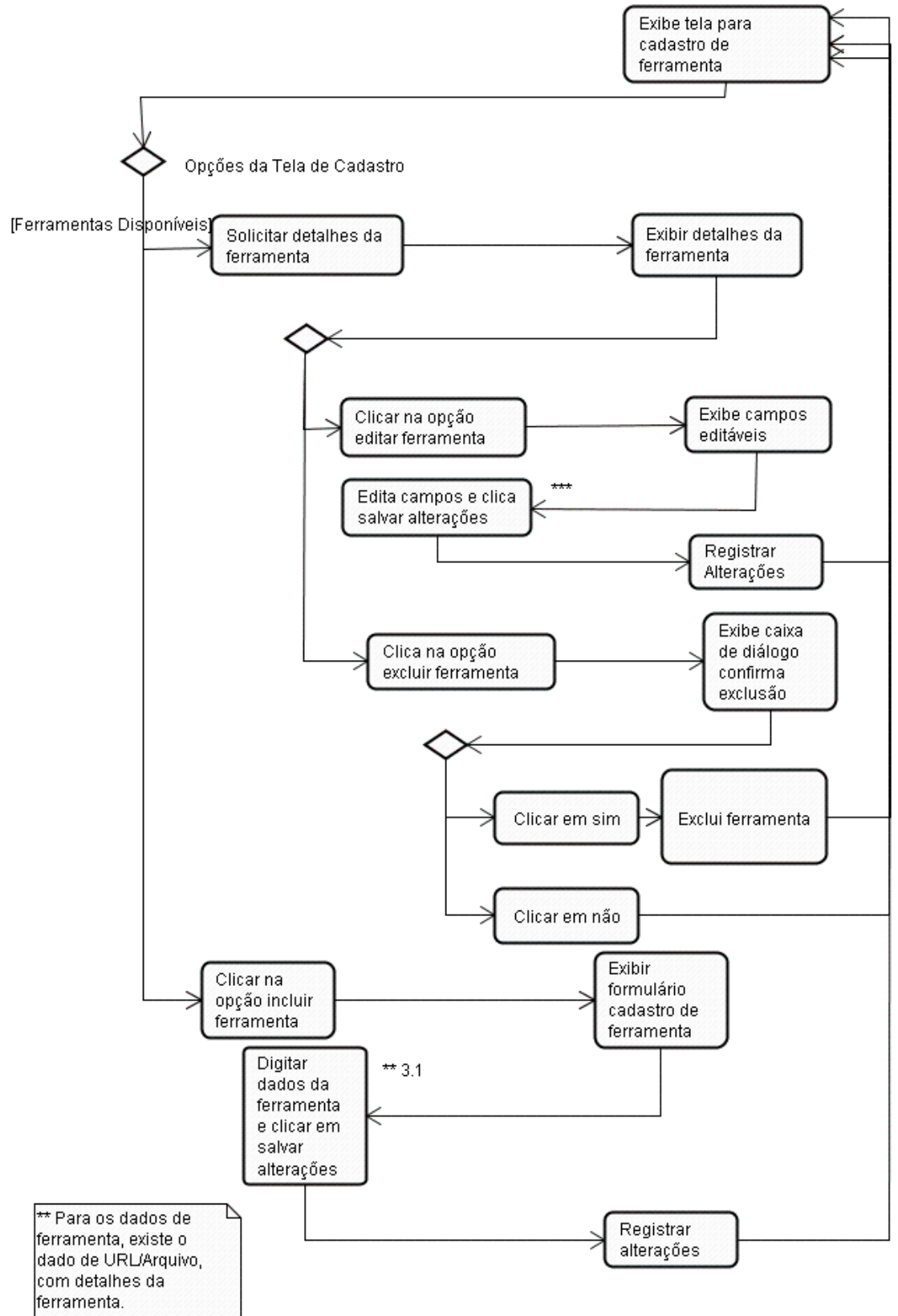

Figura A.6: Diagrama de atividade do especialista III. 

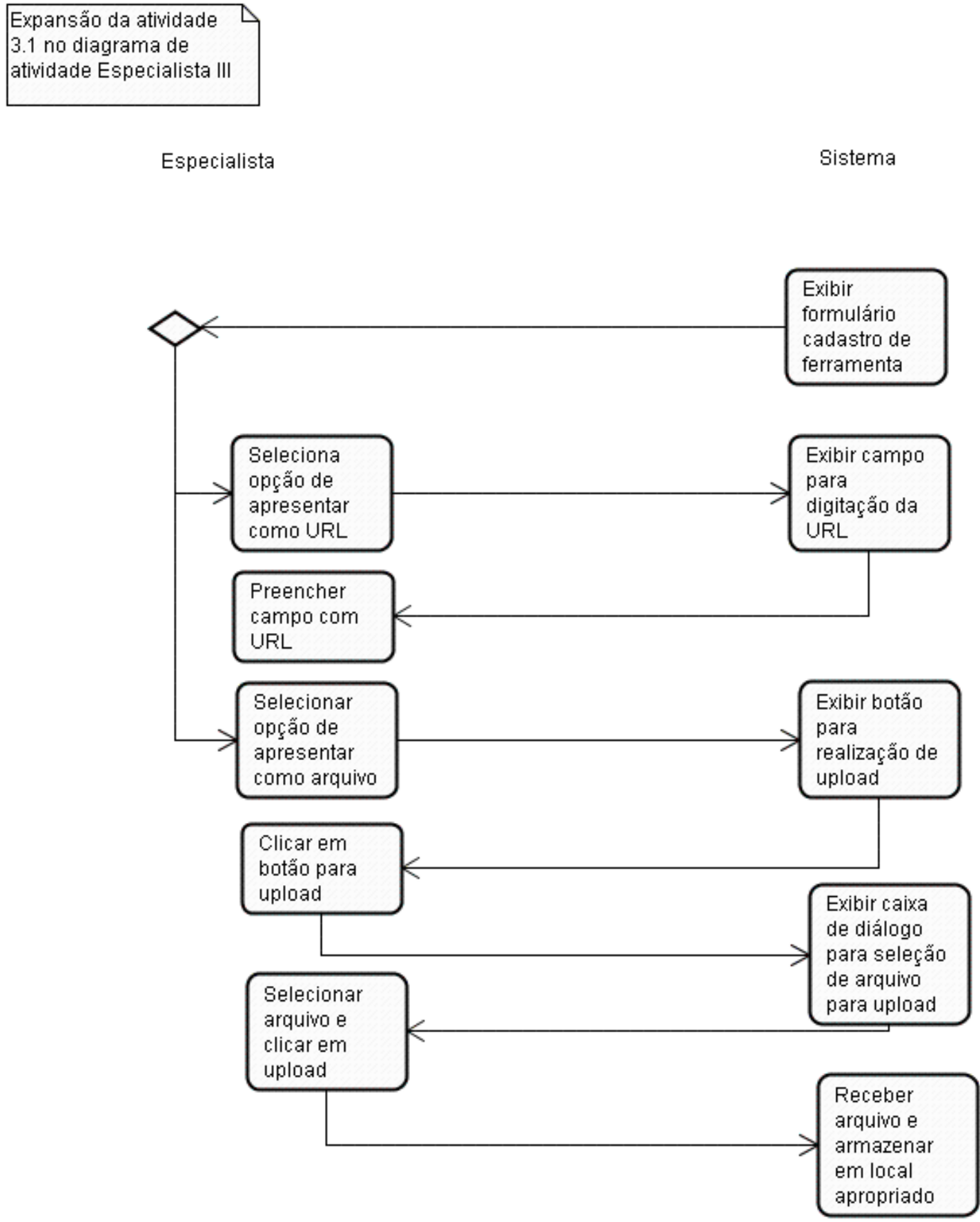

Figura A.7: Diagrama de atividade do especialista IV. 


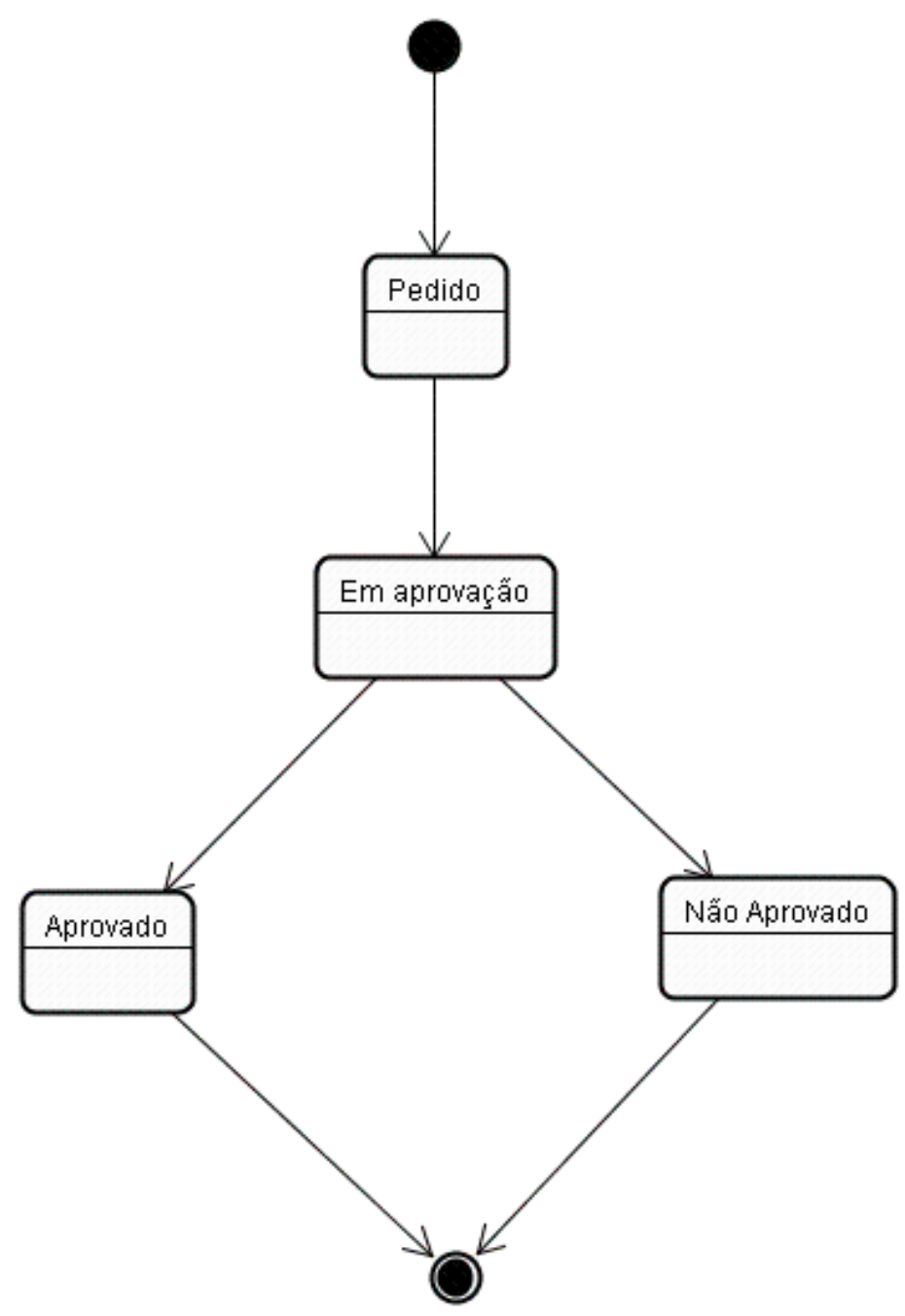

Figura A.8: Diagrama de evolução de estados para requisição de cadastro. 


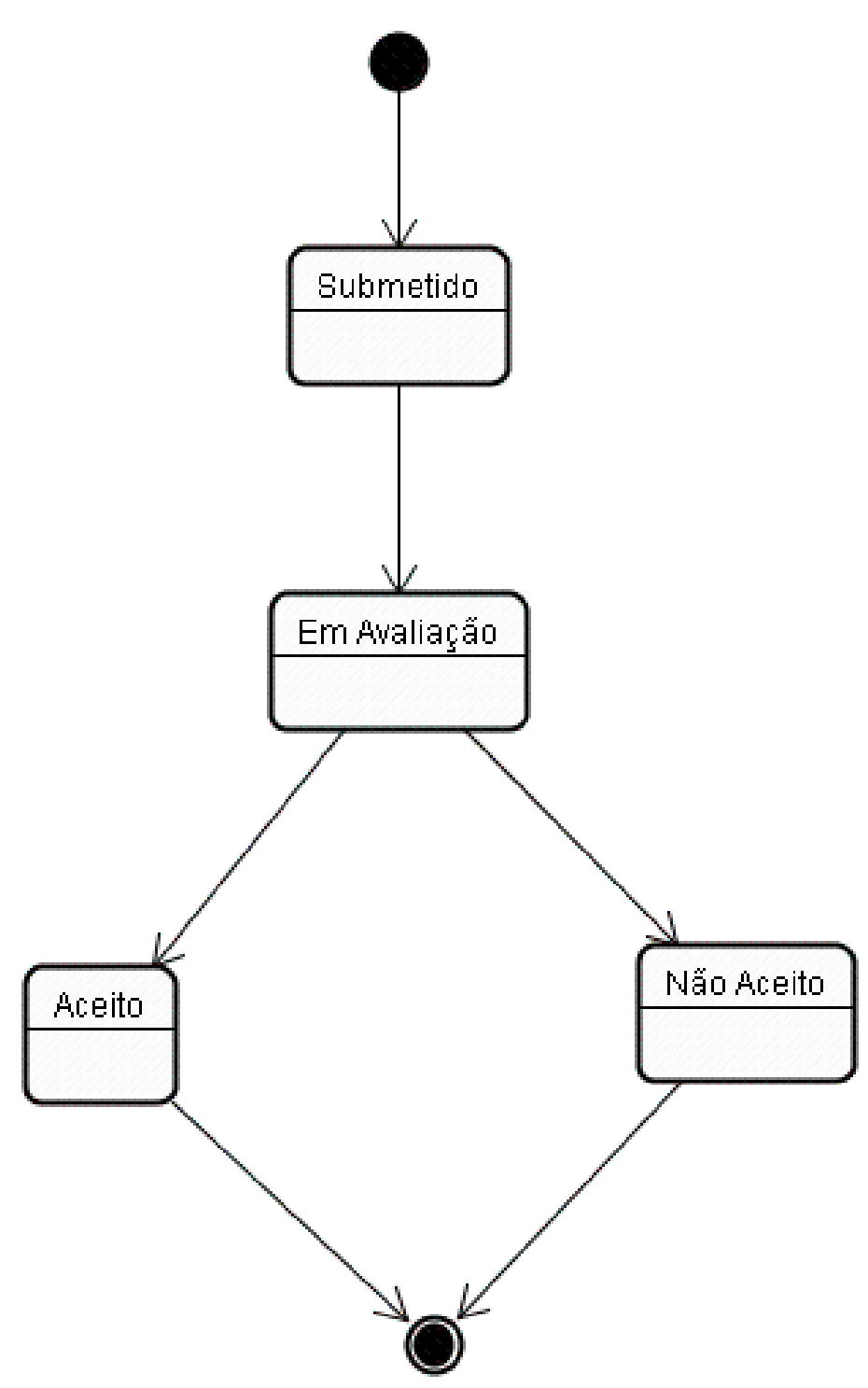

Figura A.9: Diagrama de evolução de estados para submissão de conteúdo. 


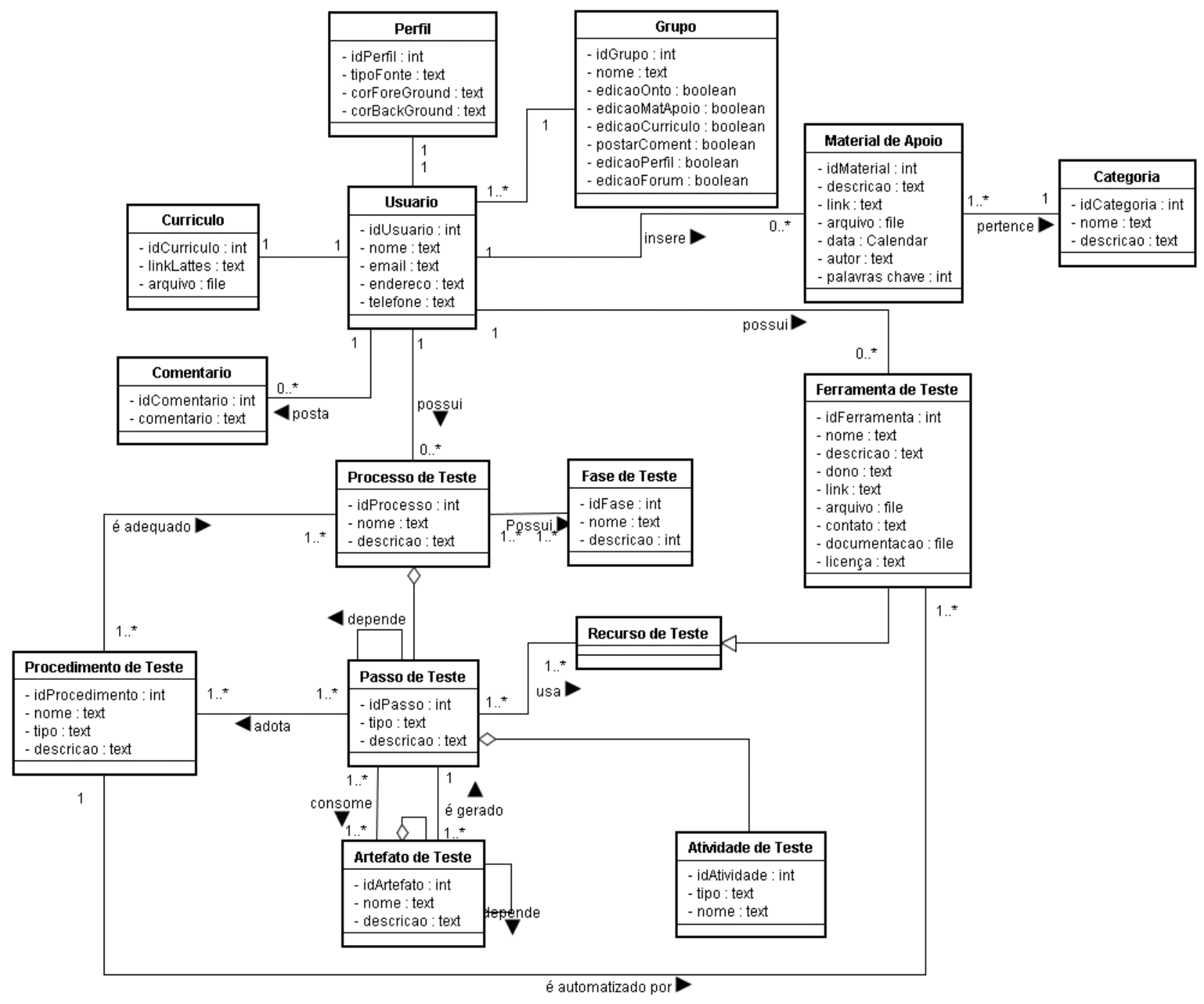

Figura A.10: Diagrama de classes do Portal de Conhecimento. 
Apêndice

$B$

Modelos de navegação

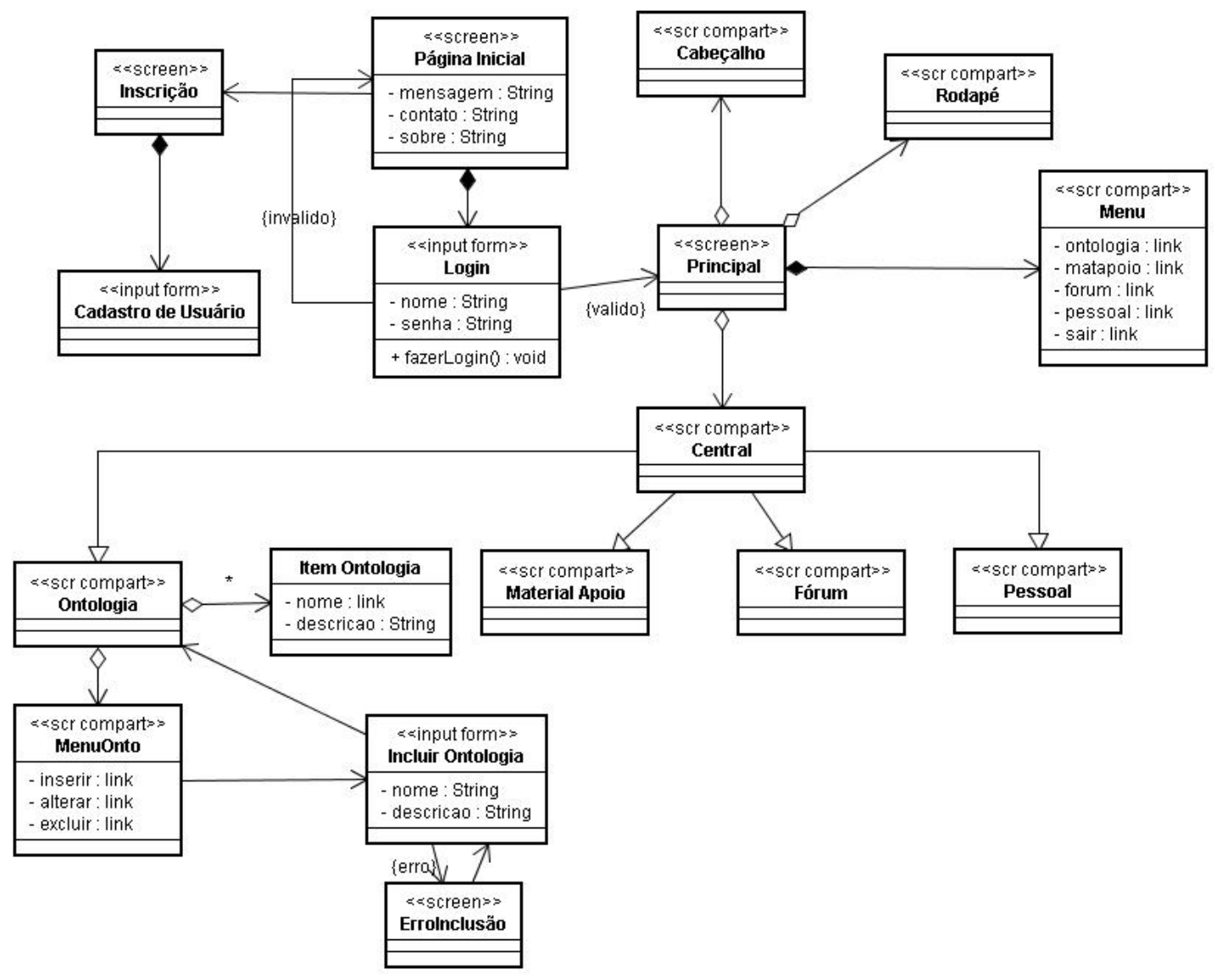

Figura B.1: Diagrama do modelo UX, do método WAE. 


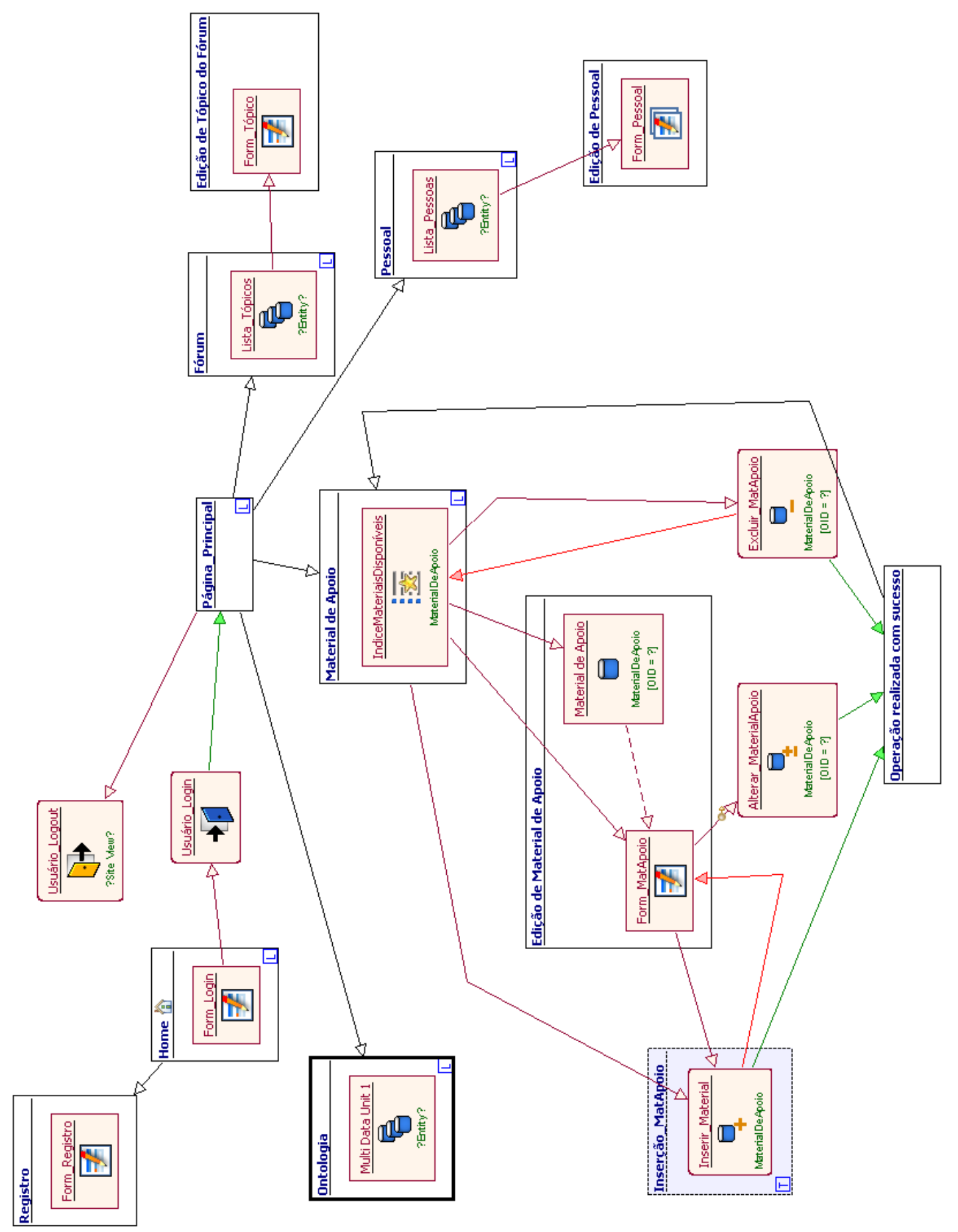

Figura B.2: Diagrama do modelo navegacional do método WebML. 


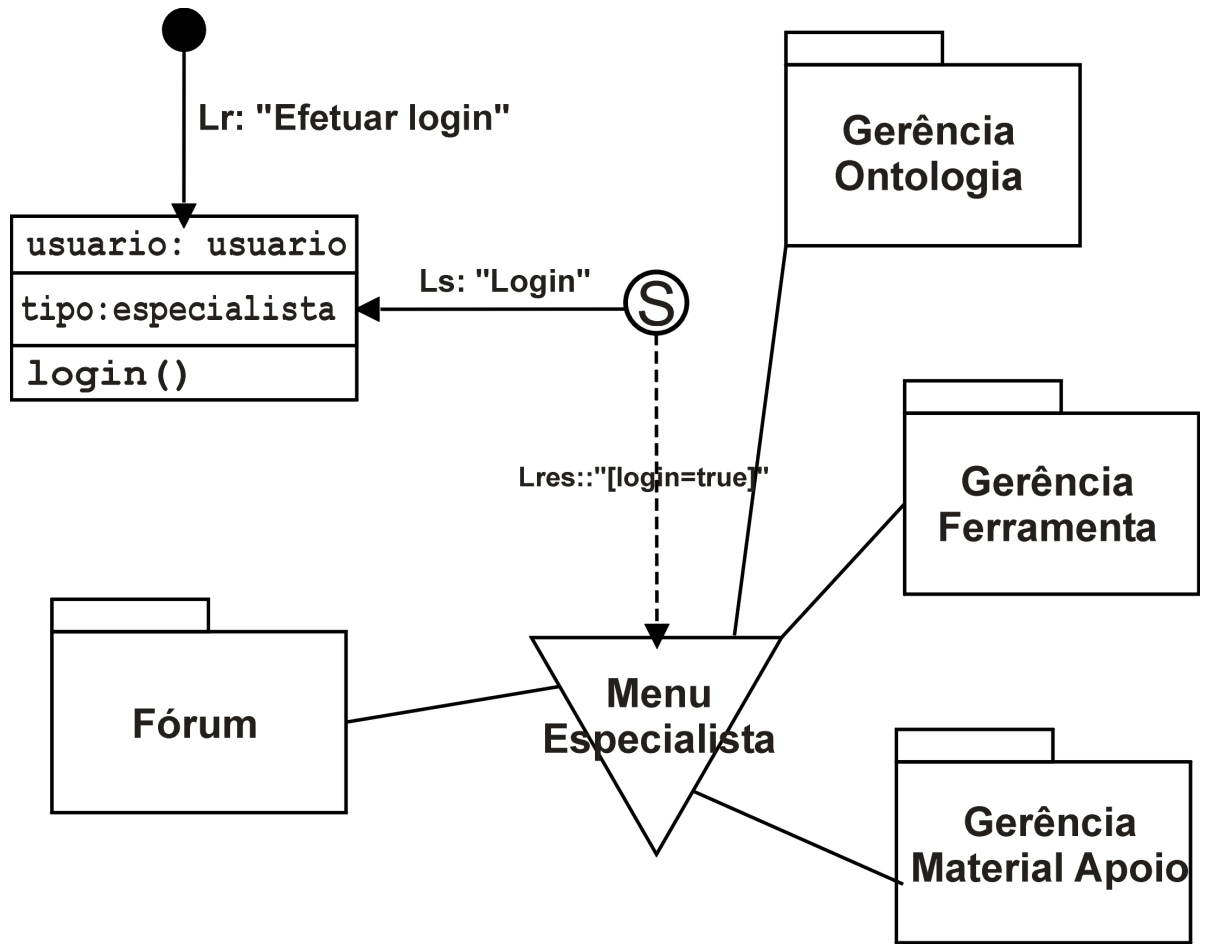

Figura B.3: Diagrama do modelo navegacional do método OO-H, um NAD (Navigational Access Diagram).

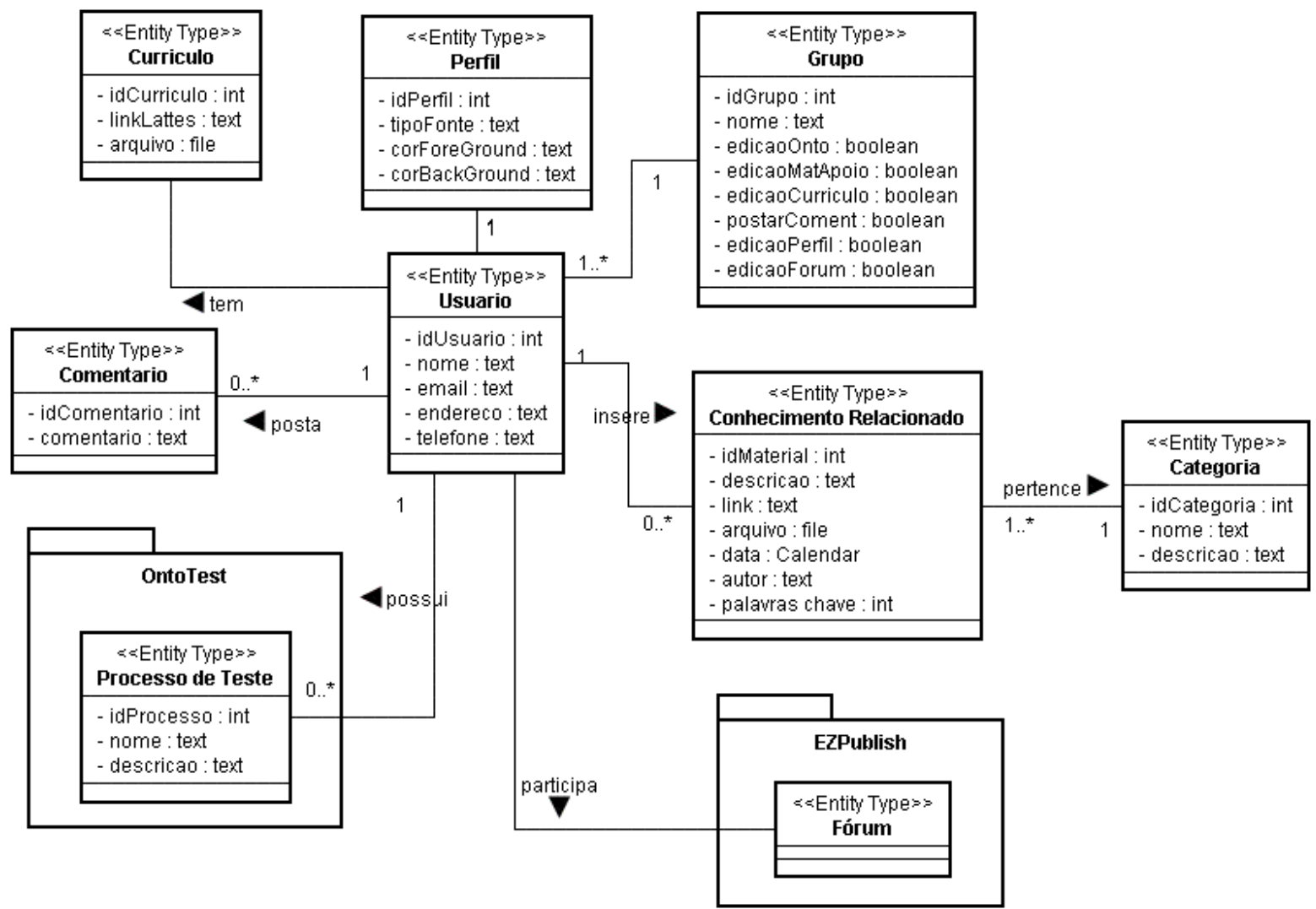

Figura B.4: Diagrama de informação da hyperbase, do W2000. 